\title{
WestVirginiaUniversity
}

THE RESEARCH REPOSITORY @ WVU

Graduate Theses, Dissertations, and Problem Reports

2011

\section{An analysis of strategic interaction between government jurisdictions}

George R. Crowley

West Virginia University

Follow this and additional works at: https://researchrepository.wvu.edu/etd

\section{Recommended Citation}

Crowley, George R., "An analysis of strategic interaction between government jurisdictions" (2011). Graduate Theses, Dissertations, and Problem Reports. 3357.

https://researchrepository.wvu.edu/etd/3357

This Dissertation is protected by copyright and/or related rights. It has been brought to you by the The Research Repository @ WVU with permission from the rights-holder(s). You are free to use this Dissertation in any way that is permitted by the copyright and related rights legislation that applies to your use. For other uses you must obtain permission from the rights-holder(s) directly, unless additional rights are indicated by a Creative Commons license in the record and/ or on the work itself. This Dissertation has been accepted for inclusion in WVU Graduate Theses, Dissertations, and Problem Reports collection by an authorized administrator of The Research Repository @ WVU.

For more information, please contact researchrepository@mail.wvu.edu. 


\title{
AN ANALYSIS OF STRATEGIC INTERACTION BETWEEN GOVERNMENT JURISDICTIONS
}

\author{
George R. Crowley
}

\author{
Dissertation submitted to the \\ College of Business and Economics \\ at West Virginia University \\ in partial fulfillment of the requirements \\ for the degree of
}
Doctor of Philosophy
in
Economics

\author{
Russell Sobel, Ph.D., Chair \\ Brian Cushing, Ph.D. \\ Tami Gurley-Calvez, Ph.D. \\ Donald Lacombe, Ph.D. \\ Santiago Pinto, Ph.D. \\ Department of Economics
}
Morgantown, West Virginia
2011

Keywords: Leviathan; Fiscal decentralization; Fiscal federalism; Intergovernmental competition; Constitutions; Diffusion

Copyright 2011 George R. Crowley 


\section{ABSTRACT \\ An Analysis of Strategic Interaction Between Government Jurisdictions}

George R. Crowley

This dissertation consists of three essays, each examining a type of strategic interaction between government jurisdictions. Specifically, I explore the effect of distributive politics in the legislature on intergovernmental competition, how fiscal decentralization serves as a constraint on Leviathan government, and how state constitutions are designed in response to neighboring institutions. In essay one, I combine the Brennan and Buchanan (1977, 1978, 1980) 'Leviathan' model with the seminal Weingast, Shepsle, and Johnsen (1981) 'Law of $1 / \mathrm{n}$ ' to show that the effect of increased decentralization on government size is limited by associated increases in legislature size. Essay two employs two distinct empirical strategies to test the 'Leviathan hypothesis' that fiscal decentralization decreases government size. While the theory holds at the municipal and county levels, school districts exhibit relatively high tax rates while simultaneously high levels of interdependence. This suggests collusive behavior at that level. In the final essay, I perform the first spatial econometric test of diffusion of constitutional rules. I find that provisions in neighboring constitutions are a key determinate of the types of provisions found in a given state's constitution. 


\section{ACKNOWLEDGEMENTS}

First and foremost I thank my parents, Pam and George Crowley, for always encouraging me to take on new intellectual challenges, and supporting me when those challenges took me to a high school 20 miles away, a college 500 miles away, and a graduate school 1,000 miles away.

Without your love and support I never would have achieved this level of success. I also thank my brother, Sean Crowley, whose strength and dedication have always inspired me.

It goes without saying that I owe a huge debt of gratitude to my wife, Andrea DeanCrowley. I cannot thank you enough for the love and support you have shown me during these often-stressful past few years, from surprising me with a good luck gift before my micro theory comp, to simply putting up with me while I worked all hours of the night on this dissertation. I literally could not have done it without you. I also thank my in-laws, Roberta and Russell Dean, for always making me feel at home, even 1,000 miles away from my own parents.

I will be forever grateful to Dr. Russell Sobel, my dissertation chair, mentor, and friend. The chance to work with you was the reason I came to WVU. From the first day I arrived on campus, you taught me how to succeed as an academic. Watching you teach, first as your TA and later as your student, has inspired my own teaching. Coauthoring research with you has always been an enjoyable and rewarding experience. I look forward to our future work together. It has truly been an honor and a privilege.

I would also like to thank the other members of my dissertation committee, Dr. Brian Cushing, Dr. Tami Gurley-Calvez, Dr. Donald Lacombe, and Dr. Santiago Pinto. Thank you for serving on my committee and providing helpful comments, suggestions, and advice.

I am also grateful to Dr. Andrew Young, Dr. William Reece, Dr. James LeSage, Sebastian Leguizamon, Adam Pellillo, and participants at the annual meetings of the Southern Economic Association, Public Choice Society, and Association of Private Enterprise Education for providing helpful comments on earlier drafts of these chapters.

Finally, I would also like to thank the other faculty, staff, and fellow graduate students (past and present) in the economics department at WVU for providing help, advice, friendship, and support over the past four years. 


\section{TABLE OF CONTENTS}

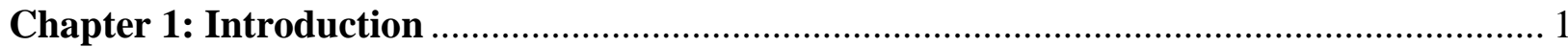

1.1 Strategic Interaction Between Government Jurisdictions ……................................ 1

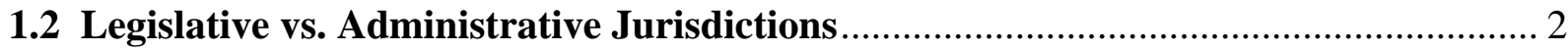

1.3 Fiscal Decentralization and the Constraint of Leviathan .......................................... 4

1.4 Spatial Dependence in Constitutional Constraints ……................................................. 6

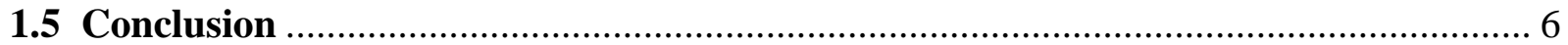

Chapter 2: Local Intergovernmental Competition and the Law of 1/n .............................. 7

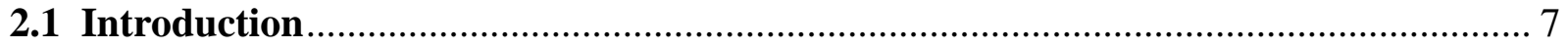

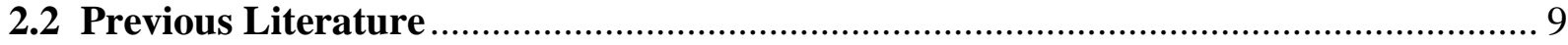

2.3 A Synthesis of the 'Law of 1/n' and 'Leviathan' Models .......................................... 12

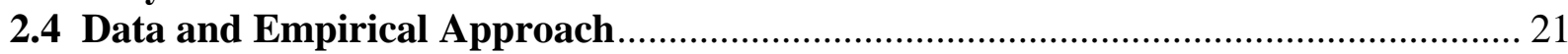

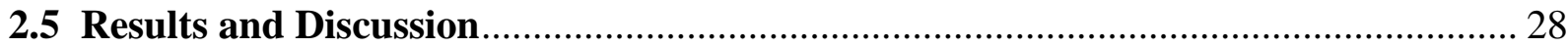

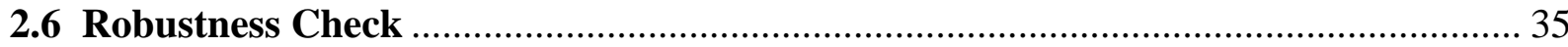

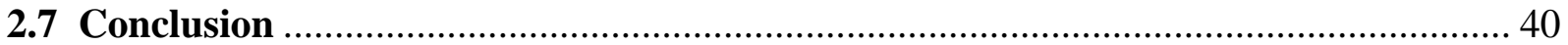

Chapter 3: Does Fiscal Decentralization Constrain Leviathan? New Evidence from Local Property Tax Competition ...................................................................................... 43

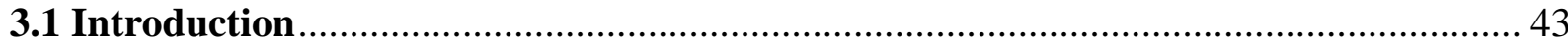

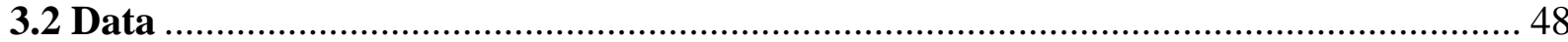

3.3 Laffer Curves and Leviathan: Theoretical Model .................................................... 49

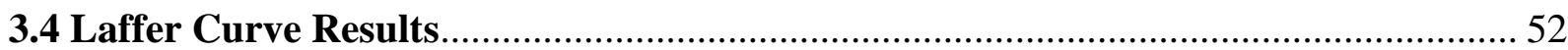

3.5 Spatial Competition and Interdependence: Theory …………………………........ 56

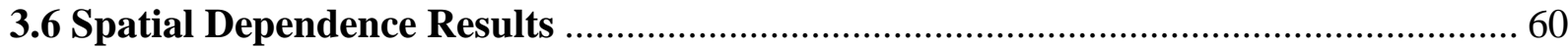

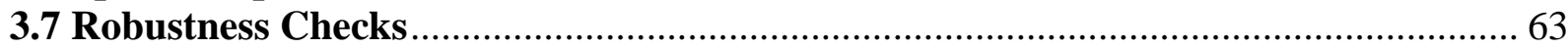

3.8 Revisiting School Districts: Collusion vs. Single-purpose Jurisdictions ..................... 72

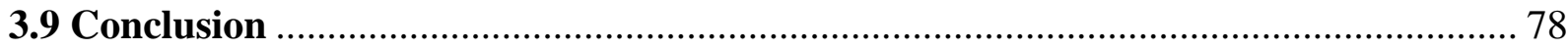

Chapter 4: Spatial Dependence in Constitutional Constraints: The Case of U.S. States..... 82

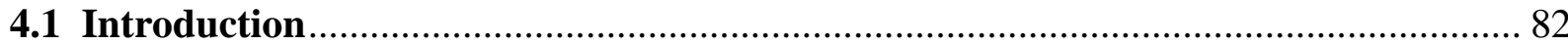

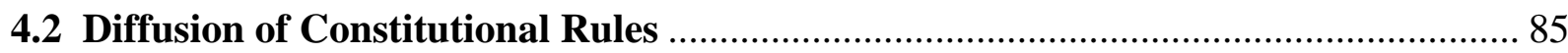

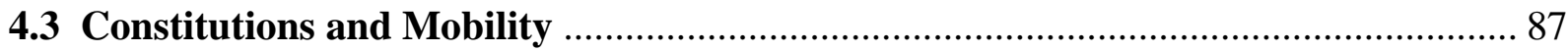

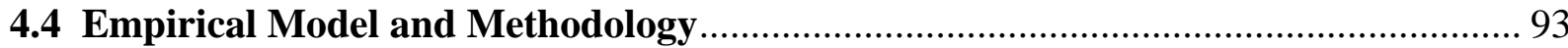

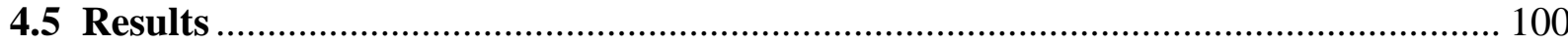

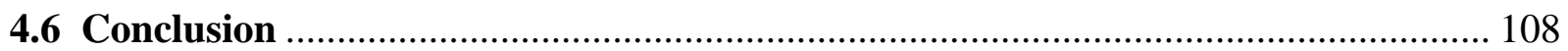

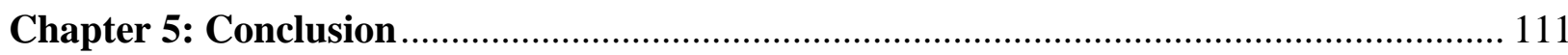

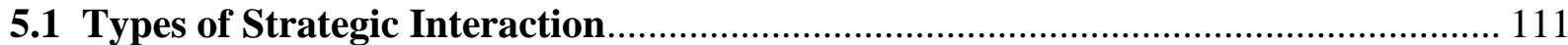

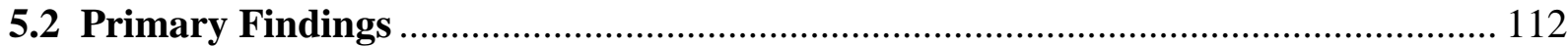

5.3 Policy Implications and Future Research ........................................................... 114

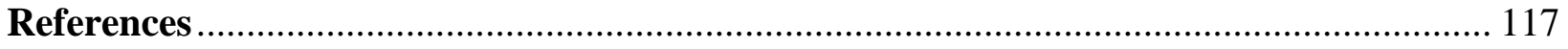

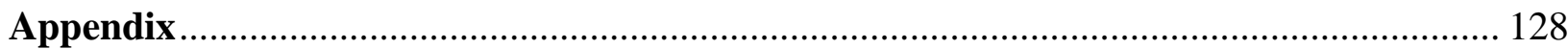




\section{LIST OF TABLES}

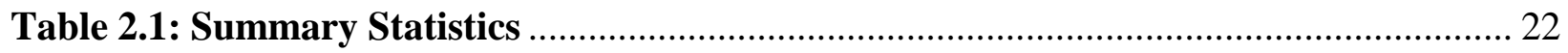

Table 2.2: Testing the Law of $1 / \mathbf{n}$ and Leviathan Theories ........................................... 29

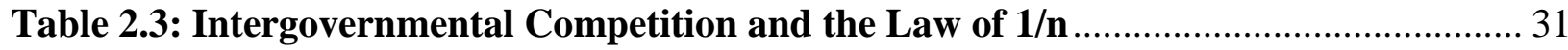

Table 2.4: Ranking of States by Upper Chamber $\lambda$, 2005 .............................................. 34

Table 2.5: Intergovernmental Competition and the Law of 1/n: Total State Expenditure . 36

Table 2.6: Intergovernmental Competition and the Law of 1/n: State General Expenditure

Table 2.7: Including the Chen and Malhotra (2007) ' $k$ ' Ratio ........................................... 39

Table 3.1: Laffer Curve Models ............................................................................... 52

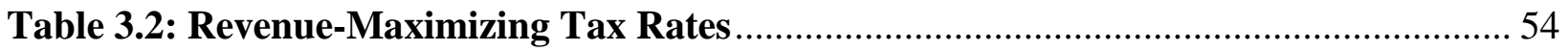

Table 3.3: Spatial Autoregressive Models ..................................................................... 61

Table 3.4: Laffer Curve Models: Balanced Panel Estimates ........................................ 64

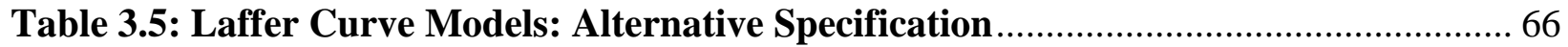

Table 3.6: Spatial Autoregressive Models: Alternative Specification ................................. 68

Table 3.7: Spatial Autoregressive Models: Alternative Weight Matrices ......................... 70

Table 3.8: Spatial Autoregressive Models: Alternative Weight Matrices ......................... 71

Table 4.1: Summary Statistics .................................................................................. 98

Table 4.2: Spatial Autoregressive Probit Models: Government Structure ....................... 101

Table 4.3: Spatial Autoregressive Probit Models: Fiscal and Social Constraints.............. 103

Table 4.4: Spatial Durbin Probit Models: Government Structure ............................... 105

Table 4.5: Spatial Durbin Models: Fiscal and Social Constraints ................................. 106

Appendix 2.1: Excluding States with Outlying $\lambda$ Values (TX, RI, NH) .......................... 128

Appendix 2.2: Excluding States without County Governments (CT, RI, MA)................. 129

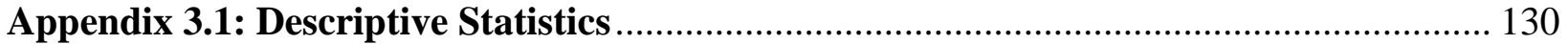




\section{LIST OF FIGURES}

Figure 2.1: Leviathan, 1/n, and Government Size ..................................................... 13

Figure 2.2: Number of Counties and Chamber Size (2005) ........................................... 15

Figure 2.3: Combined Model for a Hypothetical State with the Number of Legislators

Equal to the Number of Sub-State Governments $(\lambda=1)$

Figure 2.4: The Effect of $\lambda$ on the Relationship Between the Number of Districts and

Government Expenditure.

Figure 3.1: Relative Frequency Distribution: Leviathan Ratio ........................................ 55

Figure 3.2: Spatial Dependence vs. Leviathan Tax Rates ............................................ 76

Figure 4.1: Characteristics of State Constitutions, 2006 ........................................... 92 


\section{Chapter 1}

\section{Introduction}

\subsection{Strategic Interaction Between Government Jurisdictions}

Strategic interaction amongst governments has been identified as having major implications by scholars in both public finance and public choice. Traditionally, interaction has been explored in the context of intergovernmental competition in the vein of Tiebout (1956). Brennan and Buchanan $(1977,1978,1980)$ identify intergovernmental competition as a key to limiting Leviathan government while Mintz and Tulkens (1986) and others analyze it in the context of efficient public good provision. Numerous empirical studies following both of these theoretical approaches have appeared in the literature.

While the majority of the literature on strategic interaction between government jurisdictions has focused on competition, other types of interaction have been considered. The influential work of Weingast, Shepsle, and Johnsen (1981) focuses on interaction between legislators in the context of distributive politics. In the political science literature, the theory of diffusion explores the 'spread' of policy adoption across governments. The widespread adoption of the Missouri Plan for state supreme court justice selection is the classic example (Puro, Bergerson, and Puro 1985).

This dissertation contributes to each of these strands of the strategic interaction literature. First, I synthesize the Brennan and Buchanan $(1977,1978,1980)$ 'Leviathan' model with the Weingast, Shepsle and Johnsen (1981) 'Law of 1/n' to form a framework which explains how the effect of increases in legislature size may be partially offset by related increases in intergovernmental competition. Second, I reexamine the Leviathan hypothesis using a combination of Laffer curve estimation and spatial econometrics on a dataset comprised of three 
different levels of local government. Finally, I model the diffusion of constitutional rules across the U.S. states, again using spatial econometric techniques.

The following sections provide summaries of each chapter of this dissertation. Each summary provides a brief motivation and then discusses the major contribution of the essay. Finally, each summary briefly discusses the findings.

\subsection{Legislative vs. Administrative Jurisdictions}

Chapter 2 synthesizes the seminal 'Law of 1/n' model of Weingast, Shepsle and Johnsen (1981) with the similarly influential 'Leviathan' model of Brennan and Buchanan $(1977,1978,1980)$. Each of these models suggests a relationship between the overall size of government and the number of jurisdictions within the government's purview. ${ }^{1}$ Interestingly, the $1 / \mathrm{n}$ and Leviathan theories predict completely opposite effects of an increase in the number of jurisdictions. While the Leviathan hypothesis posits an increase in the number of competing jurisdictions will lead to a smaller overall size of government, the Law of $1 / \mathrm{n}$ predicts a positive relationship. The key distinction lies in the type of jurisdiction considered by each: Weingast, Shepsle, and Johnsen (1981) focus on legislative districts while Brennan and Buchanan (1971, 1978, 1980) are concerned with lower-level governments. For this reason, these theories have been heretofore considered separately in the empirical literature.

The Law of $1 / n$ is essentially a common pool problem. Legislators seek projects (funded by the legislature as a whole) for their districts so long as the costs borne by their constituency

\footnotetext{
${ }^{1}$ There has been considerable debate in both empirical literatures about the type of 'government spending' is appropriate for testing each theory's implications. While the $1 / \mathrm{n}$ literature has typically used the level of government associated with the legislature (state or national), the Leviathan literature has used local government spending, total spending of all governments, etc. in its empirical studies. I use total state and local government spending which will be positively correlated with whatever definition is preferred. Additionally, my robustness checks contain several other measures of spending.
} 
are exceeded at the margin by the benefits related to the projects. If one assumes that district tax shares for projects approved by the legislature are inversely related to the number of districts (for example, a regime where each district pays an equal share) the tax burden borne by each district falls as the number of districts increases. Thus, the number of inefficient projects will increase as a result of each legislator systematically underestimating projects' costs.

The Leviathan model is based on the notion that governments, when left unchecked, seek to maximize their size. The only possible constraints in the Brennan and Buchanan (1977, 1978, 1980) framework are a strict fiscal constitution or the presence of intergovernmental competition. The idea that competition between governments limits Leviathan-type behavior follows from a monopoly view of government. As the number of competing governments is increased, the monopoly power achieved by any one is weakened. In other words, the 'Leviathan hypothesis' suggests that as the number of competing governments increases, the overall size of government will fall.

The main contribution of the chapter is the linking of these models. Since the Law of 1/n predicts a positive relationship between the overall size of government and the number of legislators and the Leviathan theory predicts a negative relationship between the number of governments and government size, the strength of the relationship between the two types of jurisdictions has serious implications. For example, if an increase in the number of administrative districts (say, counties) also represents an increase in the number of legislative districts the effect on government size may be ambiguous as the Law of 1/n and Leviathan theories operate against each other.

I exploit the variation in this relationship across the U.S. states, and show that while both the Leviathan and Law of 1/n theories hold when tested separately, the marginal effect of an 
increase in the competing administrative jurisdictions is lessened by associated increases in distributive politics in the legislature. Further, the degree to which the Leviathan hypothesis is weakened is directly related to the degree to which the number of legislative districts is related to the number of sub-state governments. This helps explain the inconsistent results found in the empirical Leviathan literature - these previous studies do not account for associated increases in government spending due to larger legislatures.

\subsection{Fiscal Decentralization and the Constraint of Leviathan}

While the implications of the Brennan and Buchanan $(1977,1978,1980)$ Leviathan theory of government has been tested extensively, the empirical literature has yet to arrive at a clear consensus concerning its validity. Following Oates (1985) the majority of these studies seek to test the so-called 'Leviathan hypothesis' by analyzing the extent to which increases in fiscal decentralization (and thus, an increase in the level of intergovernmental competition) lead to decreases in the size of government. The methodologies vary, with several measures of decentralization being considered. Many studies have found the negative relationship predicted by Brennan and Buchanan, but nearly as many have found little to no evidence.

Chapter 3, coauthored with Russell Sobel, uses a new approach to reexamine this familiar question. Our methodology contributes in a variety of ways. Our analysis models true Leviathan 'behavior' by considering the property tax rate as the choice variable instead of simply looking at the level of revenue or expenditure. Our dataset is also quite extensive, covering three levels of local government (municipalities, school districts, and counties) in the state of Pennsylvania for a period of ten years. Our estimation strategy consists of two parts. First, we use a Laffer curve [see, for example Laffer (2004)] methodology to find each level of 
government's revenue-maximizing tax rate. We then compare the average rate of each level to this maximizing rate by using a 'Leviathan ratio' developed in the paper. The size of this ratio indicates the extent to which local governments are able to behave in a manner consistent with the Brennan and Buchanan $(1977,1978,1985)$ model. We follow this analysis with a spatial autoregressive model typically used to measure tax competition [see, for example, Brueckner and Saavedra (2001)].

Our Laffer curve findings indicate the expected effect of decentralization (as defined by the number of governments) as a constraint on Leviathan, with municipalities (of which there are many) setting tax rates on average much further below revenue-maximization than counties (of which there are relatively few). These results are also confirmed by the spatial autoregressive model, with each level of government exhibiting positive spatial dependence, and the magnitude of that dependence being higher for municipalities than counties.

Interestingly, school districts do not fit this mold. While there are more school districts than counties, there are more municipalities than school districts. School districts on average, however, set tax rates nearest to the revenue-maximizing level. Further, school districts exhibit the highest degree of spatial dependence as well. We propose a framework for interpreting these seemingly contradictory results which depends on the proper interpretation of the spatial autoregressive model as measuring 'interaction' rather than specifically 'competition.' With this in mind, the school district result of high interdependence and high tax rates is suggestive of collusion, which has been shown to be an effective way to circumvent intergovernmental competition (Shadbegian 1999). 


\subsection{Spatial Dependence in Constitutional Constraints}

As noted above, strategic interaction between governments is typically explored in the context of fiscal policy or distributive politics. However, other types of interaction have been discussed in the literature including the concept of policy diffusion. In general, the political science notion of diffusion is concerned with "the relative spend and the spatial patterns of adoption of new programs" (Walker 1969). While several studies have explored the adoption of policies and programs, little work has been done on spatial patterns of constitutional rule adoption.

Chapter 4 uses the theory of diffusion, along with the work of Holcombe (1991, 1992, 1994, 1998) on constitutions to motivate a spatial analysis of constitutional constraints in the U.S. states. To this point, analysis of diffusion has typically been restricted to case studies or non-spatial econometric models. In contrast to these approaches, I employ a spatial probit estimation of nineteen specific constitutional provisions. I analyze rules ranging from the extensively studied (such as balanced budget requirements) to the more obscure (such as a formally defined official language). My results find significant spatial dependence across a variety of constitutional constraints, providing evidence of diffusion of institutions across the states.

\subsection{Conclusion}

The final chapter summarizes the findings of the previous essays, reiterates the policy implications, and provides suggestions for future research. 


\section{Chapter 2}

\section{Local Intergovernmental Competition and the Law of $1 / n$}

\subsection{Introduction}

In their seminal paper on distributive politics, Weingast, Shepsle and Johnsen (1981) posit the 'Law of $1 / n$ ' which states that as the number of legislative districts (' $n$ ') increases, the tax share of public expenditures borne by each (' $1 / \mathrm{n}$ ') falls. This in turn leads to an increase in the number of inefficient projects passed by the legislature and, ceteris paribus, an increase in total government expenditure. In a similarly important contribution, Brennan and Buchanan (1977, 1978, 1980) present a 'Leviathan' model of government which assumes government's objective is to maximize its size. In the context of this model, government can only be constrained by either a strict fiscal constitution or intergovernmental competition resulting from fiscal decentralization. In other words, according the Law of $1 / \mathrm{n}$ the number of legislative districts is positively related to the size of government, while the Leviathan model proposes a negative relationship between the number of governments and government size.

This paper is the first to synthesize these theories. While a voluminous literature has concerned itself with the extension and empirical testing of these models separately, a unified model has thus far not been developed. This is most likely due to the fact that the work of Weingast, Shepsle, and Johnsen (1981) deals with legislative districts while the Brennan and Buchanan $(1977,1978,1980)$ model is based on administrative districts such as counties. While it may seem natural to assume a standard, relatively constant relationship between administrative and legislative districts exists across states, this is in fact an unsafe assumption. In fact, the degree of 'overlap' between legislative and administrative districts varies widely across the U.S. states. In this paper, I capitalize on this variation to empirically test the degree to which the 
intergovernmental competition inherent in the Leviathan model is partially offset by the Law of $1 / \mathrm{n}$.

I present a model where state and local government spending is dependent on both the number of lower level governments (as in the Leviathan literature) and the size of the legislature (as in the $1 / n$ literature). ${ }^{2}$ When analyzed separately, each of the above theories holds as predicted by their respective models. The main contribution of the unified model, however, is that the negative effect on government size associated with increases in intergovernmental competition is lessened by related increases in legislature size. The extent of this effect is determined by the degree to which legislature size is linked to the number of lower level governments. In states where the link is strongest, the marginal effect of an increase in the number of seats in the legislature is significantly less than it would be in an otherwise comparable state with a relatively weak linkage. In other words, if the increase in the number of lower level governments is also indicative of an increase in legislature size, the $1 / \mathrm{n}$ effect partially offsets the effect of increases in intergovernmental competition.

Far from being a purely theoretical issue, this unified analysis has serious implications for past empirical tests of the Law of $1 / n$ or Leviathan hypotheses. Studies of the Leviathan hypothesis which do not include the size of the legislature are failing to account for associated increases in spending attributable to distributive politics; this will lead to results which underestimate the effects of intergovernmental competition on spending. Similarly, studies of legislature size which do not account for the number of sub-state governments are likely overestimating the $1 / \mathrm{n}$ effect. The theoretical model presented below demonstrates that by

\footnotetext{
${ }^{2}$ The use of state and local government spending as the dependent variable is consistent with empirical studies in both the Leviathan [see Nelson (1987) and Wallis and Oates (1988) for examples ] and Law of 1/n [see Gilligan and Matsusaka $(1995,2001)$ and Primo (2006) for examples] literatures.
} 
focusing only on the partial effect, these studies are assuming away the relationship between legislative and administrative jurisdictions. The extent of the associated biases is a function of the strength of the link between the two types of districts.

This paper proceeds in the following manner. Section 2 provides a summary of the previous theoretical and empirical work following the Weingast, Shepsle, and Johnsen (1981) and Brennan and Buchanan $(1977,1978,1980)$ contributions. Section 3 presents a model which unifies these two approaches. Section 4 discusses the data and empirical approach used to test the model's implications. Section 5 presents the empirical results, while Section 6 offers a series of robustness checks. Finally, the last section offers concluding remarks and policy implications.

\subsection{Previous Literature}

The Weingast, Shepsle, and Johnsen (1981) Law of $1 / n$ is essentially a common pool model. Legislators seek projects for their districts so long as the costs associated with the projects are exceeded at the margin by the related benefits. If one assumes that district tax shares for projects approved by the legislature are inversely related to the number of districts (for example a regime where each pays an equal share) the tax burden borne by each district falls as the number of districts increases. Ceteris paribus, the number of inefficient projects will increase as a result of each legislator systematically underestimating the project's cost.

Numerous empirical studies have tested this straightforward implication. Studies using the U.S. states as the unit of analysis are most common [for example, Gilligan and Matsusaka (1995, 2001), Primo (2006), and Chen and Malhotra (2007)]. Other jurisdictions examined include U.S. cities (Baqir 2002), counties in the state of Georgia (Bradbury and Stephenson 2003), and an international sample of countries (Bradbury and Crain 2001). These studies 
generally find evidence of the Law of $1 / \mathrm{n}$ in unicameral legislatures and the upper chamber (senate) of bicameral legislatures. While Gilligan and Matsusaka $(1995,2001)$ find no such relationship for lower chambers (house), Primo (2006) and Chen and Malhotra (2007) find a negative relationship between lower chamber size and spending, indicating lower chambers may be uniquely immune to the Law of $1 / \mathrm{n}^{3}$

Chen and Malhotra (2007) use this discrepancy between upper and lower chamber results as the basis of their theoretical extension which explicitly models bicameral legislatures. Their model posits, and the results of their empirical specification support, a negative relationship between the ratio of lower to upper chamber size ('k') and spending. The authors refer to this as the 'Law of $\mathrm{k} / \mathrm{n}$ ' since the forces work on spending in opposite directions. Other theoretical extensions include Primo and Snyder Jr. (2008) (who show the Law of $1 / n$ is dependent on a number of factors including the cost-sharing regime in place and the project's size and type) and Crain (1999) (who shows that constituent diversity within and between districts affects the Law of $1 / \mathrm{n})$.

The Brennan and Buchanan $(1977,1978,1980)$ Leviathan model is based on the assumption that governments, left unchecked, seek to maximize their size. Within the model, the only possible constraints on the Leviathan government are a strict fiscal constitution or the presence of intergovernmental competition. While a great deal of the theoretical work by Brennan and Buchanan focuses on the strict fiscal constraints, empirical examination of the Leviathan model has relied almost exclusively on the proposed relationship between fiscal decentralization and government size.

\footnotetext{
${ }^{3}$ This lack of a ' $1 / \mathrm{n}$ effect' in the lower chamber has been a consistent finding in the empirical literature, and a discussion of why the theory does not to hold for lower chambers is beyond the scope of this paper. For a possible explanation, see Chen and Malhotra (2007) who model legislature chambers in a game-theoretic bargaining framework. Further examination of this issue is clearly an area ripe for future research.
} 
That competition between governments constrains Leviathan is based on a model of government as a monopoly. As the number of competing governments is increased, the monopoly power achieved by any one is weakened. In the words of Brennan and Buchanan (1980), "Total government intrusion into the economy should be smaller, ceteris paribus, the greater the extent to which taxes and expenditures are decentralized." In later work, Buchanan (1995) refers to fiscal decentralization as an "ideal political order." In the extreme, competition between governments may approximate market outcomes (Dowding, John, and Biggs 1994). This efficiency-enhancing competition between jurisdictions is clearly influenced by the work of Tiebout (1956).

A voluminous empirical literature has been devoted to testing the link between decentralization and spending, which is often dubbed the 'Leviathan hypothesis.' This previous literature has returned mixed results. Many studies find no relationship between decentralization and government size [see Oates (1985, 1989), Forbes and Zampelli (1989), Anderson and van den Berg (1998), and Heil (1991) for examples] while many others provide evidence of the Leviathan hypothesis's validity [examples include Zax (1989), Joulfaian and Marlow (1990), Nelson (1986, 1987), Eberts and Gronberg (1988), Grossman (1989), Marlow (1988), Shadbegian (1999), Rodden (2003) and Stansel (2006)]. This divergence in findings is striking given the variety of methodologies, units of analysis, and definitions of decentralization considered.

One explanation for the inconsistent findings not previously considered in the Leviathan literature is the role of the legislature. If increased competition (as measured by the number of governments) is accompanied by an increasingly large legislature, which in turn is characterized by a ' $1 / \mathrm{n}$ effect' of increased spending, total spending, on net, may increase. Given that the 
relationship between lower level governments and legislative districts varies across jurisdictions, it is perhaps unsurprising that the Leviathan hypothesis has not be convincingly confirmed or refuted in the empirical literature. Clearly, a model of the counterbalancing forces of the Leviathan hypothesis and the Law of $1 / \mathrm{n}$ is required to better address these questions. That is the task undertaken in the next section.

\subsection{A Synthesis of the 'Law of $1 / \mathbf{n}$ ' and 'Leviathan' Models}

A central implication of the Weingast, Shepsle, and Johnsen (1981) and Brennan and Buchanan $(1977,1978,1980)$ models is that total government spending is a function of the number of relevant jurisdictions (legislative districts in the case of the Law of $1 / \mathrm{n}$ and administrative districts in the case of the Leviathan model) within the government's purview. Thus, a basic model of government spending in state $i$ can be expressed as

$$
G_{i}=G\left(c_{i}, n_{i}, X_{i}\right)
$$

where $G_{i}$ is total government spending, $c_{i}$ is the number of sub-state governments (such as counties), $n_{i}$ is the number of seats in the state legislature, and $X_{i}$ is a collection of other political and demographic factors which influence spending but are not affected by legislature size or the number of counties.

As discussed above, the Brennan and Buchanan $(1977,1978,1980)$ model predicts that intergovernmental competition, a byproduct of fiscal decentralization, will help to constrain Leviathan government. Further, the degree of fiscal decentralization will increase as the number of sub-state governments increases, ceteris paribus (Tiebout 1956). In the context of Equation (2.1), the Leviathan model implies

$$
\partial G_{i} / \partial c_{i}<0
$$


indicating that total government spending in the state is inversely related to the number of substate governments in the state. Figure 2.1a shows a hypothetical example of this relationship.

Figure 2.1: Leviathan, 1/n, and Government Size

Figure 2.1a: Leviathan Model

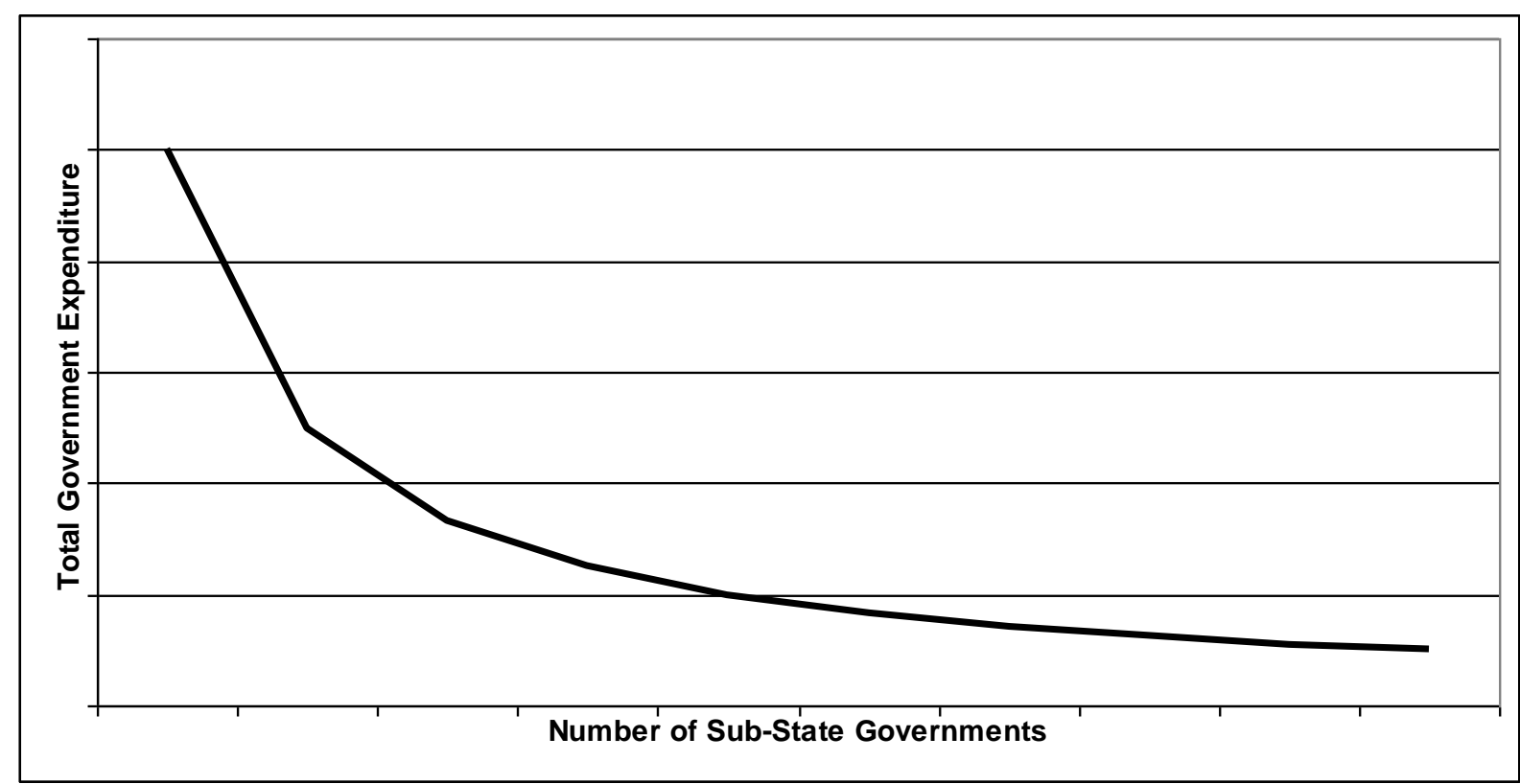

Figure 2.1b: Law of 1/n Model

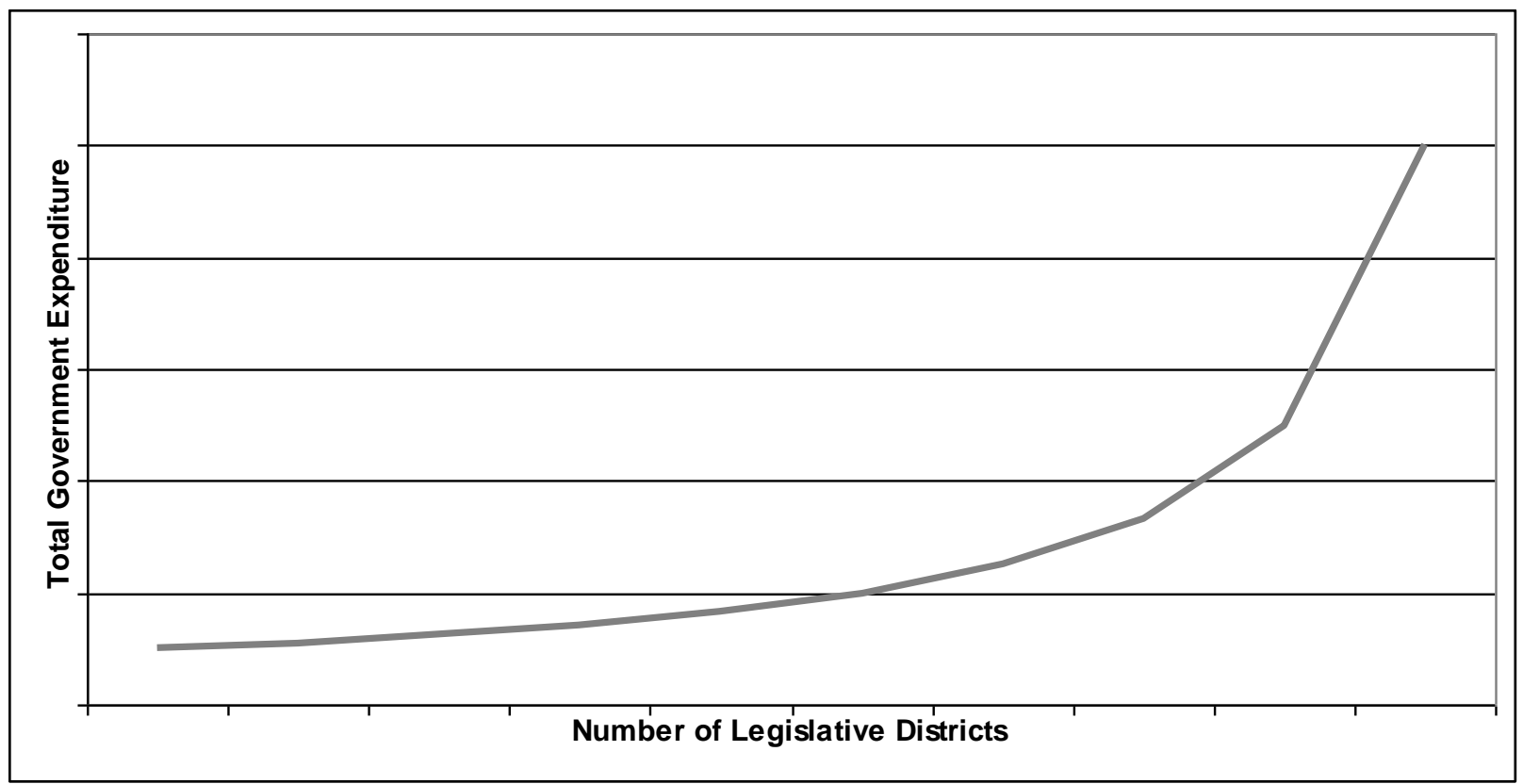


The most influential contribution of Weingast, Shepsle, and Johnsen (1981) paper is the Law of $1 / n$. The main idea can be summarized as follows. Legislators will endorse spending programs in their districts up to the point where the marginal benefit of such programs is just equal to the marginal cost. That is, the optimal (from the point of view of the legislator and his or her district) level of spending programs is characterized by

$$
b^{\prime}=t^{\prime}
$$

where $b$ is the benefit associated with the program and $t$ is the cost associated with it. Through the legislature, however, the costs of local projects can be partially passed off to other districts. In other words, the district in which the project is being undertaken bares only a share of the 'true' cost. Assuming taxes are evenly spread across districts, the optimal (again, from the point of view of the legislator and his or her district) level of spending in the district becomes

$$
b^{\prime}=(1 / n) t^{\prime}
$$

where $n$ is the number of legislative districts within the state.

Thus, the Law of $1 / \mathrm{n}$ implies that the optimal level of spending for each legislator is increasing in $n$. Assuming a traditional logrolling framework where legislators are able to bargain with one another for district-specific spending programs, total government spending is also positively related to the number of legislative districts. Specifically, in terms of Equation

$$
\partial G_{i} / \partial n_{i}>0
$$

Graphically, the relationship takes a form similar to Figure 2.1b.

In the unified model described by Equation (2.1), government spending is positively related to the number of legislative districts, but negatively related to the number of sub-state governments. While this result can be tested straightforwardly as a baseline, the more interesting 
relationship between these counteracting forces requires knowledge of how the two types of jurisdictions relate to one another. This relationship can be expressed as

$$
c_{i}=\lambda_{i} n_{i}
$$

where $\lambda_{i}$ is a positive value which represents the relationship between legislative districts and sub-state governments. It can be interpreted as the number of sub-state governments per legislative district. A value of $\lambda_{i}$ less than one implies counties are outnumbered by legislative districts, while a value greater than one implies the opposite. This $\lambda_{i}$ is exogenously determined as the number of and relationship between jurisdictions is typically codified in each state's constitution.

Figure 2.2: Number of Counties and Chamber Size (2005)

\section{2a: Upper Chamber (Senate)}

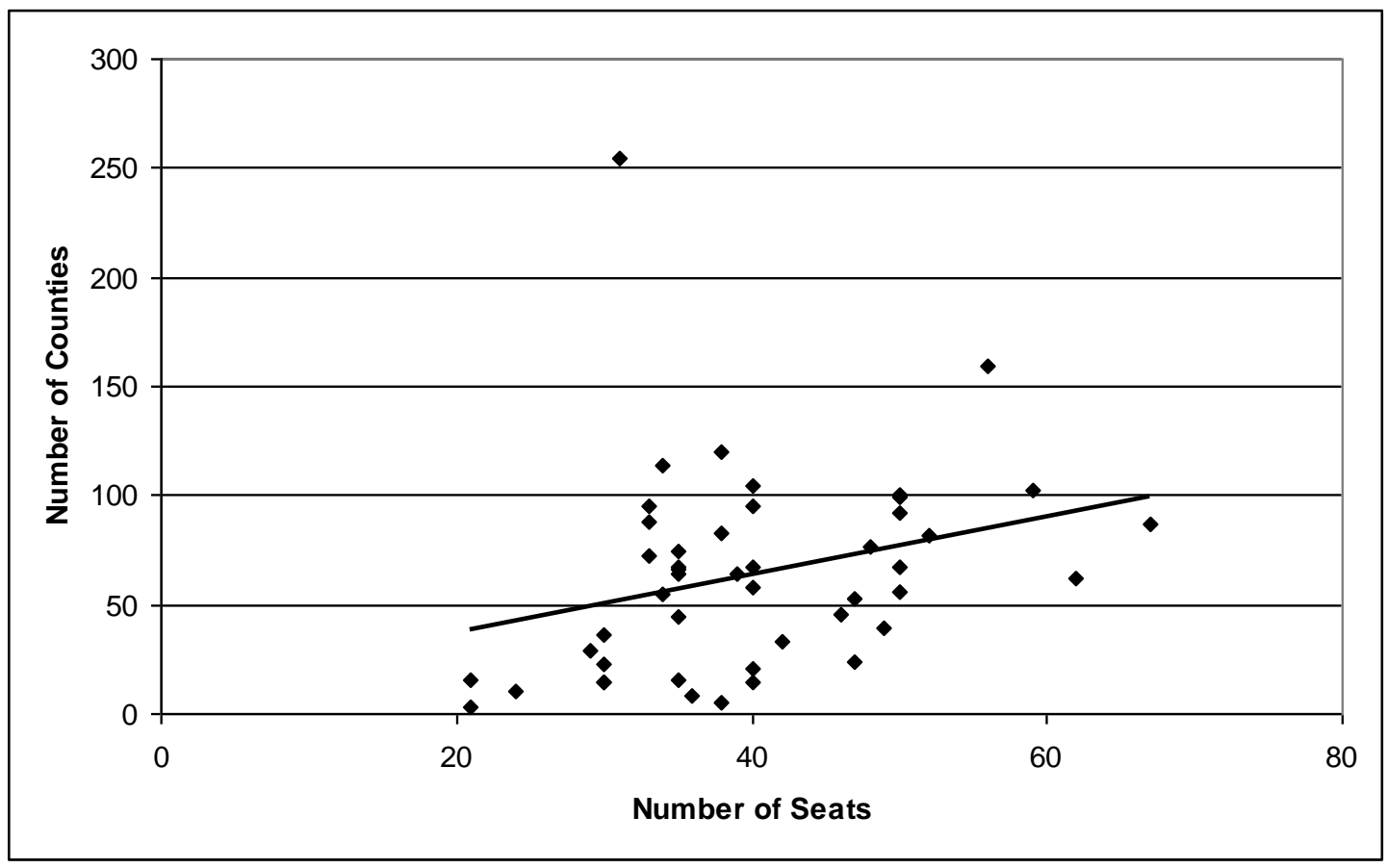




\section{2b: Lower Chamber (House)}

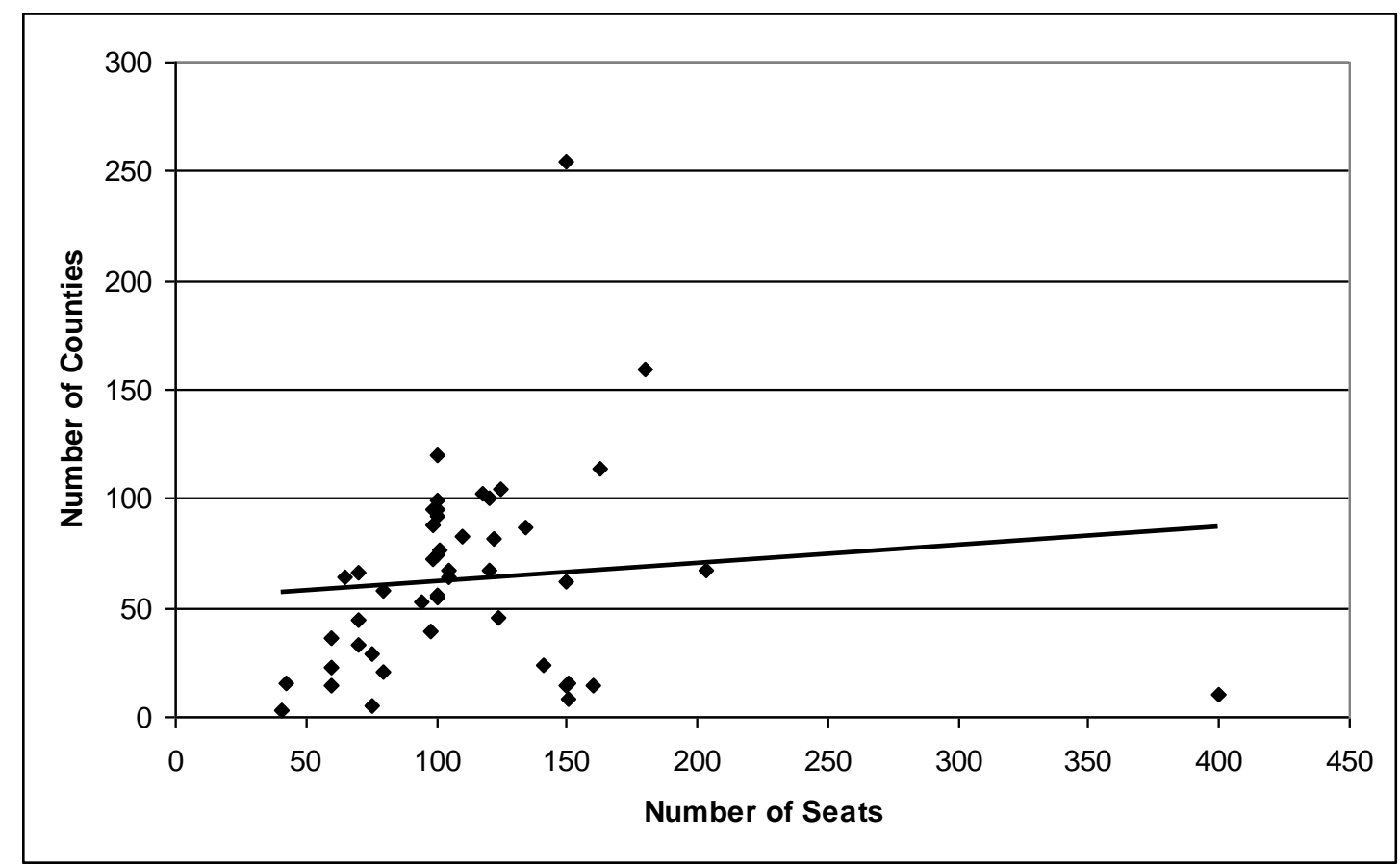

The value of $\lambda_{i}$ varies widely across states. Figure 2.2 plots the number of counties

against the number of seats in the legislator for the 47 contiguous U.S. states featuring bicameral legislatures. Panel a depicts the relationship for the upper chamber, while panel b shows the lower chamber. The correlation coefficient across the sample between counties and legislature size is 0.30 for the upper chamber and 0.10 for the lower chamber. Further, the R-squared value of the trends depicted in Figure 2.2 is 0.09 for the upper chamber and 0.01 for the lower chamber. Thus, while the relationship between counties and upper chamber seats is stronger than the relationship with lower chamber seats, it is still far from constant across states. For example, Texas is made up for 254 counties but has an upper chamber of only 31 seats $(\lambda=8.19)$ while Rhode Island has an upper chamber of 38 seats, and only 5 counties $(\lambda=0.13)$. It is important to note that dropping these outliers does not alter the sign or significance of any variables of interest in the coming empirical results (see Appendix 2.1). 
From a theoretical standpoint, the relationship defined in Equation (2.6) is important because it indicates the partial derivative in Equation (2.2) does not adequately reflect the total effect of an increase in the number of sub-state governments on total government spending. Instead, a total derivative of Equation (2.1) with respect to $c$ is required:

$$
d G_{i} / d c_{i}=G_{1}+G_{2}\left(\partial n_{i} / \partial c_{i}\right)
$$

with $G_{1}=\partial G_{i} / \partial c_{i}$ and $G_{2}=\partial G_{i} / \partial n_{i}$, and given $\partial X_{i} / \partial c_{i}=0$ by assumption. Differentiating Equation (2.6) and substituting into Equation (2.7) yields

$$
d G_{i} / d c_{i}=\partial G_{i} / \partial c_{i}+\partial G_{i} / \partial n_{i}\left(1 / \lambda_{i}\right) .
$$

Given the positive relationship between the number of seats in the legislature and total government spending described in Equation (2.5), the total effect of and increase in $c$ is less than the partial derivative $\partial G_{i} / \partial c_{i}$ would suggest. Specifically, the impact of an increase in intergovernmental competition is lessened by the interaction of the ' $1 / \mathrm{n}$ effect' $\left(\partial G_{i} / \partial n_{i}\right)$, and the relationship between legislative districts and sub-state governments $\left(\lambda_{i}\right)$. In other words, the effect of an increase in the level of intergovernmental competition (as measured by the number of sub-state governments) is partially offset by associated increases in legislature size (as the Law of $1 / n$ posits an opposite, positive relationship). The magnitude of this offsetting effect is determined by the 'link' between the number of sub-state governments and legislative districts. 
Figure 2.3: Combined Model for a Hypothetical State with the Number of Legislators Equal to the Number of Sub-State Governments $(\lambda=1)$

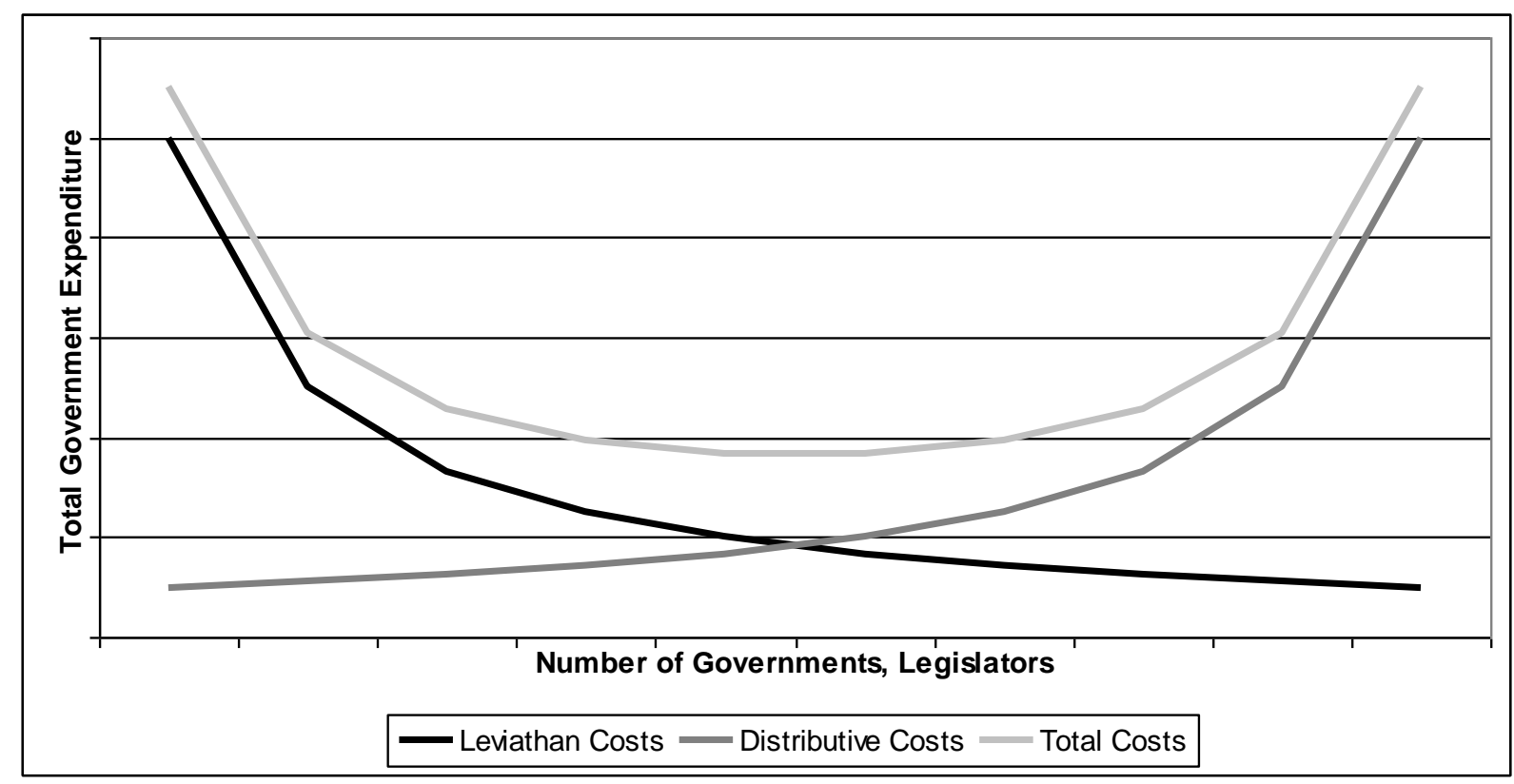

Note: For simplicity, the above figure assumes the rate at which an increase in the number of governments or legislators affects leviathan and distributive costs is the same. The major implication of this assumption is that total costs are minimized at the point where the two curves intersect. It is important to note that this need not, and will not, be the case unless this assumption holds.

To more clearly express this idea, Figure 2.3 presents a hypothetical case illustrative of a state where the number of sub-state governments is identical to the number of legislative jurisdictions $(\lambda=1)$. This diagram combines both panels of Figure 2.1, with the increases in government expenditure associated with increased legislature size referred to as 'Distributive Costs' and the increases in spending associated with decreased fiscal decentralization referred to as 'Leviathan Costs.' That is, Distributive Costs increase as the number of jurisdictions increase while Leviathan Costs fall as the number of districts increase. This representation is clearly inspired by Buchanan and Tullock's (1962) discussion of the costs associated with various voting rules. 
Following the approach of Buchanan and Tullock (1962), I define Total Costs as the sum of Distributive and Leviathan costs. Total Costs are highest at either extreme (zero or some maximum number of jurisdictions) and minimized at some point in between. At this point where Total Costs are minimized, the portion of government spending which is determined by the number of jurisdictions will also be minimized. In the simple case depicted in Figure 2.3, this happens to be at the intersection of the two costs. This need not be the case, and only occurs here because the rate at which the costs increase/decrease is identical, by construction.

In this example the Leviathan hypothesis holds for smaller numbers of jurisdictions, with increases in the number of jurisdictions leading to decreases in government spending. This is depicted in the figure as the area to the left of the minimum point, and it is here that the partial derivative $\partial G_{i} / \partial c_{i}$ is large enough (in absolute terms) to overcome the upward pressure of the $\partial G_{i} / \partial n_{i}\left(1 / \lambda_{i}\right)$ term. Given $\partial G_{i} / \partial n_{i}>0$, the smaller is $\lambda_{i}$ the larger is this offsetting effect of the Law of $1 / \mathrm{n}$. If $\lambda_{i}$ is sufficiently small, increases in the number of sub-state governments will actually lead to increases in total government size as the intergovernmental competition between administrative districts is more than offset by associated increases in the size of the legislature and a growing $1 / \mathrm{n}$ effect. Stated formally,

$$
\frac{\partial\left(d G_{i} / d c_{i}\right)}{\partial \lambda_{i}}<0
$$


Figure 2.4: The Effect of $\lambda$ on the Relationship Between the Number of Districts and Government Expenditure

\section{4a: Hypothetical State with $\lambda=0.5$}

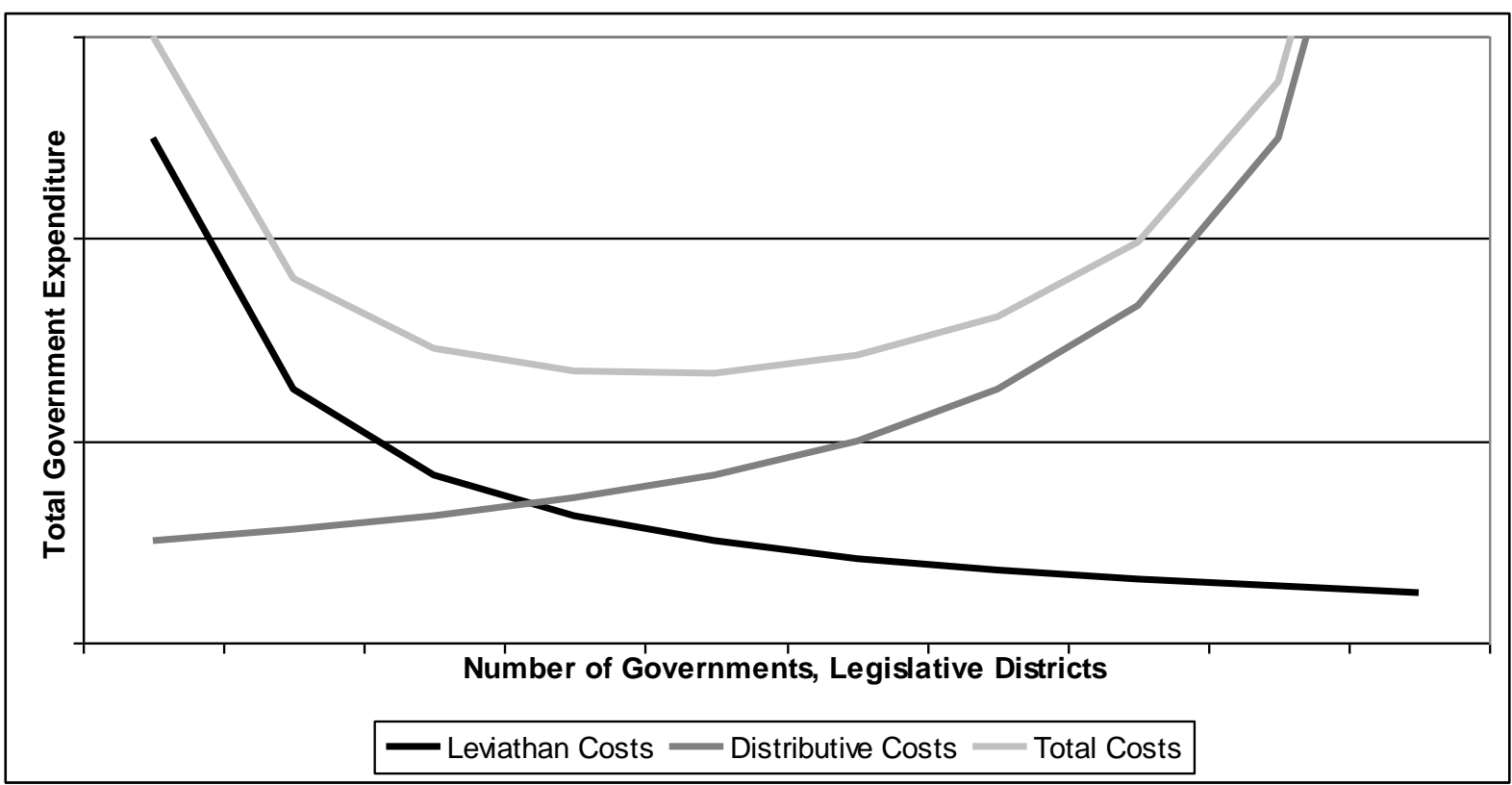

\section{4b: Hypothetical State with $\lambda=2$}

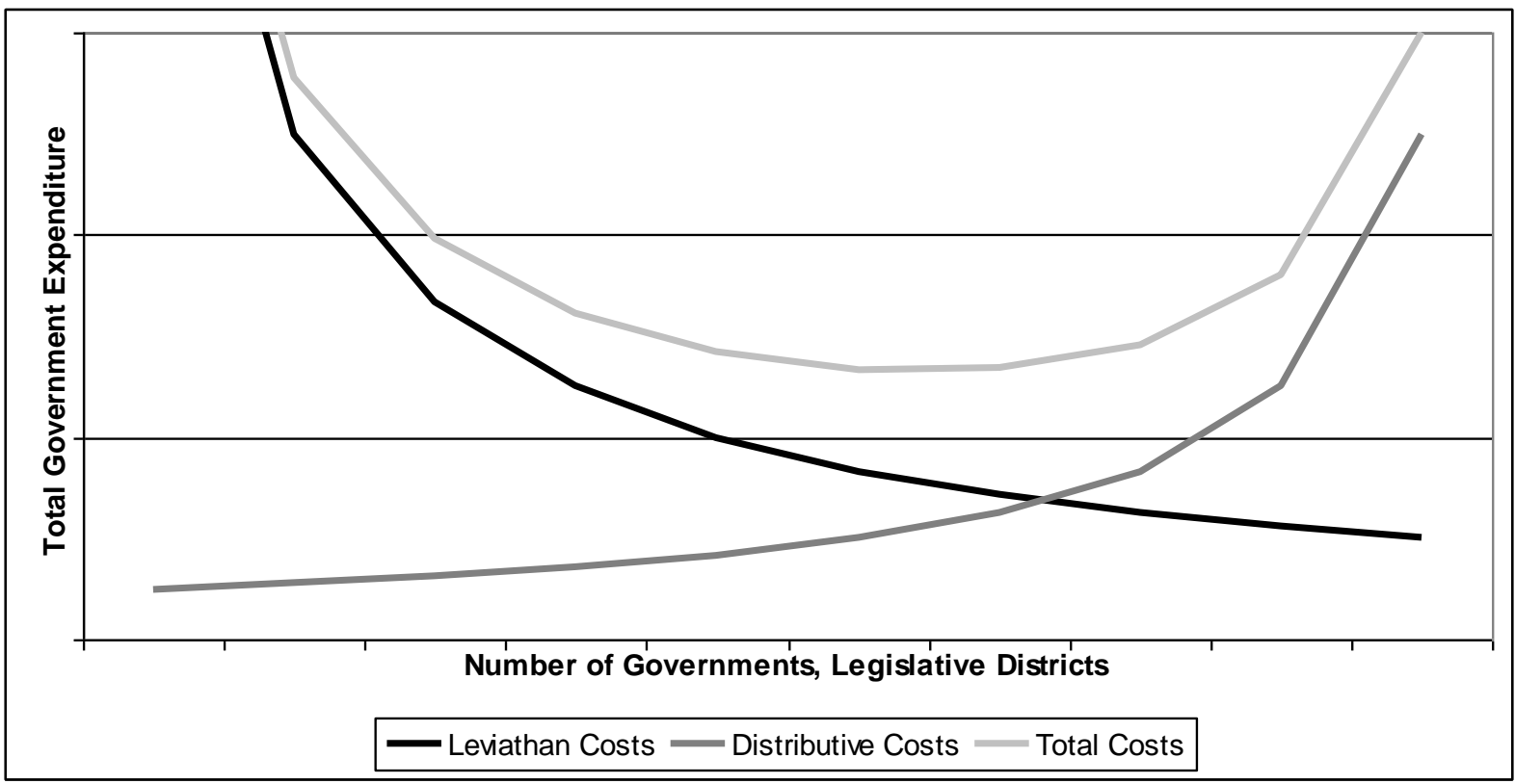

Note: For simplicity, the above figure assumes the rate at which an increase in the number of governments or legislators affects leviathan and distributive costs is the same. 
As the value of $\lambda$ changes, the curves depicted in Figure 2.3 shift. Figure 2.4 depicts an example of this. If $\lambda$ is small (Panel a), this indicates legislative districts outnumber sub-state governments, and the above model indicates the $1 / \mathrm{n}$ effect will start to dominate. This is depicted in the figure as a leftward shift of the Distributive Costs curve, as well as a leftward shift of the minimum point on the Total Cost curve, and indicates that the costs associated with the $1 / \mathrm{n}$ effect dominate the cost-savings associated by intergovernmental competition at a much lower number of jurisdictions than in the baseline case depicted in Figure 2.3. Panel b presents the opposite scenario, where a high value of $\lambda$ shifts the Leviathan cost curve to the right, and shows that total costs are minimized at a much higher number of jurisdictions than in the baseline case. In this high $\lambda$ case, intergovernmental competition overwhelms the $1 / \mathrm{n}$ effect, except at the highest number of jurisdictions.

\subsection{Data and Empirical Approach}

I test the synthesized model on a panel of U.S. state data. The data span the years 19922005 and cover 47 of the 48 contiguous states. As is standard in the empirical literature on state legislatures, Nebraska is excluded from the analysis due to its unique unicameral legislature. Table 2.1 reports summary statistics for all variables used in the analysis. 


\section{Table 2.1: Summary Statistics}

\begin{tabular}{|c|c|c|}
\hline \multicolumn{3}{|c|}{48 Contiguous U.S. States (Excluding Nebraska), Years: 1992-2005 } \\
\hline Variable Name & Mean & Standard Deviation \\
\hline Counties & 63.261 & 45.301 \\
\hline Upper Chamber Seats & 40.167 & 10.120 \\
\hline Lower Chamber Seats & 113.706 & 54.892 \\
\hline Real State and Local Government Expenditure Per Capita & 2909.397 & 487.066 \\
\hline Real State Total Expenditure Per Capita & 2191.507 & 453.397 \\
\hline Real State General Expenditure Per Capita & 1775.847 & 401.614 \\
\hline Democrat Governor & 0.415 & 0.493 \\
\hline Population Growth Rate (average percentage over 5 years) & 1.232 & 1.036 \\
\hline State Population (millions) & 5.768 & 6.091 \\
\hline Real Federal Aid Per Capita & 611.433 & 210.169 \\
\hline Real Personal Income Per Capita (thousands) & 15.430 & 2.496 \\
\hline Percent Young (Age 5-17) & 18.488 & 1.358 \\
\hline Percent (Age 18+) High School Graduates & 83.737 & 4.856 \\
\hline Percent Below Poverty Line & 12.511 & 3.613 \\
\hline Population Density (pop/sq mi) & 185.165 & 248.443 \\
\hline Percent White & 84.823 & 9.937 \\
\hline Calculated Variables & Mean & Standard Deviation \\
\hline Ratio of Counties/Upper Chamber Seats & 1.584 & 1.278 \\
\hline Ratio of Counties/Lower Chamber Seats & 0.589 & 0.344 \\
\hline Degree of Overlap: Counties and Upper Chamber Seats & -1.971 & 7.448 \\
\hline Degree of Overlap: Counties and Lower Chamber Seats & -0.287 & 0.297 \\
\hline Ratio Lower Chamber Seats/Upper Chamber Seats (k) & 2.995 & 2.193 \\
\hline
\end{tabular}

Note: All fiscal variables are adjusted for inflation using the Consumer Price Index with a base year of 1982-1984. 
The number of counties in a state refers to the number of counties or otherwise-named equivalent areas. For example, Louisiana is made up of parishes which are functionally equivalent to counties. This variable is constructed from data available from the National Association of Counties. I focus on county governments because they are the jurisdiction most similar to legislative districts in that they completely divide the state's area and encompass smaller local governments. Several northeastern states (Connecticut, Rhode Island, and parts of Massachusetts) have geographic areas called counties, but do not have county governments. Dropping these states does not substantially alter the results (see Appendix 2.2). The number of seats in the upper and lower legislative chambers is taken from various volumes of the Council of State Government's The Book of the States. The ratios of counties to chamber size and lower to upper chamber size are calculated using these variables.

State and local government expenditure is total state and local expenditure and is taken from the Census Bureau's State and Local Government Finance data. This variable is not available for the years 2003 or 2001 so these years are excluded from the initial analysis. To ensure that this exclusion is not driving the results, I also include two additional measures of state government expenditure which are available for all years 1992-2005. Total state expenditure is all spending at the state level while state general expenditure excludes utility, liquor store, and insurance expenditure. These variables are taken from the Census Bureau's Statistical Abstract. All of these variables are adjusted for inflation using the Consumer Price Index with a base year of 1982-84, and expressed in per capita terms using state population. Information on the governor's political party is taken from The Book of the States. State population is taken from the Statistical Abstract, and the population growth rate is the average annual percentage change over the previous five years. Experiments with the use of other 
growth rates, including difference in logs, total changes instead of average annual changes, and different time periods yielded nearly identical results. Personal income data comes from the Bureau of Economic Analysis and Federal aid comes from the Statistical Abstract. Both are adjusted for inflation and population in the same manner discussed above. Finally, the percentage of the population that is young (between ages 5-17), the percentage of the population that is white, and state population density all come from the Statistical Abstract while the percentage of individuals below the poverty line and the percentage of individuals over 18 with high school diplomas come from the Census Bureau's Current Population Survey data.

To test the effects of counties and legislative chamber size on government spending, I employ the following fixed effect panel model

$$
G_{i t}=\alpha+\beta_{1} n_{i t}^{U}+\beta_{2} n_{i t}^{L}+\beta_{3} c_{i t}+\delta X_{i t}+\mu_{t}+\varphi_{i}+\varepsilon_{i t}
$$

where $G_{i t}$ represents government expenditure, $n_{i t}^{U}$ represents the number of seats in the upper chamber, $n_{i t}^{L}$ represents the number of seats in the lower chamber, and $c_{i t}$ represents the number of counties in state $i$ during year $t$. $X_{i t}$ is a matrix of demographic and political factors which may affect government spending, and $\mu_{t}$ and $\varphi_{i}$ represent year and census region fixed effects. The variables which enter the $X_{i t}$ matrix include an indicator for the governor's political party, the state's population growth rate, the level of population, real per capita federal aid to the state, real per capita state personal income, population density, and variables representing the percentages of the population that is age $15-17$, age $18+$ with a high school education, living below the poverty line, and white. There is not enough variation in chamber sizes or the number of counties within states during this time frame to allow the use of state fixed effects, so census region effects are used. Finally, $\varepsilon_{i t}$ is an error term. As noted by Chen and Malhotra (2007), correlation of the error terms within cross-sections is a major concern in these types of studies. I 
follow their approach in using panel-corrected standard errors [see Beck and Katz (1995)] in my analysis.

Equation (2.10) can be estimated without the chamber size variables to test the traditional Leviathan hypothesis. Similarly, the county variable can be dropped to test a $1 / \mathrm{n}$ model. If the empirical results support the above theoretical model, the coefficient estimates on these variables of interest should not be affected by including both types of jurisdictions in the same regression. In other words, when Equation (2.10) is estimated with both the chamber size and county variables included, theory would predict a negative and significant coefficient on the number of counties with a positive and significant coefficient on the upper chamber size. Past empirical studies have typically found either an insignificant or negative coefficient on the lower chamber size variable.

The parabola-type relationship depicted in Figure 2.3 can also be tested for empirically by modifying Equation (2.10) to include squared terms. This specification will serve as a second-order linear approximation and has been used in a variety of empirical contexts such as tests of the Laffer curve [see for example, Sobel (1999), Garrett (2001) and Crowley and Sobel (2010)]. When the squared terms are included, the model becomes

$$
G_{i t}=\alpha+\beta_{1} n_{i t}^{U}+\beta_{2} n_{i t}^{L}+\beta_{3} c_{i t}+\beta_{4}\left(n_{i t}^{U}\right)^{2}+\beta_{5}\left(n_{i t}^{L}\right)^{2}+\beta_{6}\left(c_{i t}\right)^{2}+\delta X_{i t}+\mu_{t}+\varphi_{i}+\varepsilon_{i t}
$$

Results consistent with the parabola relationship will be characterized by negative first-order coefficients and positive coefficients on the squared term, indicating initial levels of decentralization reduce the size of government while the $1 / n$ effect increases spending at higher levels of decentralization.

While the previous empirical specifications are useful for testing the partial effects of chamber size and the number of counties, they do not adequately model the mechanism through 
which the counterbalancing forces occur. To test the effect of the relationship between the number of counties and legislature size on the size of government, I include several additional specifications. First, I include variables which interact the number of counties with the chamber sizes. These provide a test of the change of the marginal effect of an increase in counties or chamber sizes due to an increase in the other type of district. The empirical model then becomes

$$
G_{i t}=\alpha+\beta_{1} n_{i t}^{U}+\beta_{2} n_{i t}^{L}+\beta_{3}\left(n_{i t}^{U} \times c_{i t}\right)+\beta_{4}\left(n_{i t}^{L} \times c_{i t}\right)+\delta X_{i t}+\mu_{t}+\varepsilon_{i t}
$$

for chamber sizes and can be modified to look at the effects on counties as well. Either the chamber size variables or the counties variable must be dropped in order to get a meaningful interpretation of the marginal effect represented by the interaction term.

In the above model, $\lambda_{i}=\frac{c_{i}}{n_{i}}$, so $\lambda_{i}=1$ when $c_{i}=n_{i}$, a situation analogous to the one depicted in Figure 2.3. Thus, one possible measure of the degree of 'overlap' between counties and legislative districts is the squared 'distance' between $\lambda_{i t}$ and $1,\left(1-\lambda_{i t}\right)^{2}$. This measure treats positive and negative deviations from $c_{i}=n_{i}$ (that is, cases where $c_{i}>n_{i}$ and $c_{i}<n_{i}$ ) identically.

Empirically, I define this measure of the degree of overlap of chamber size and the number of counties for each as

$$
\theta_{i t}^{U}=-\left(1-\frac{c_{i t}}{n_{i t}^{U}}\right)^{2}
$$

for the upper chamber $U$ and

$$
\theta_{i t}^{L}=-\left(1-\frac{c_{i t}}{n_{i t}^{L}}\right)^{2}
$$


for the lower chamber $L$. This measure is the squared distance between $\lambda$ and 1 multiplied by -1 . Multiplying by -1 allows for ease in interpretation by changing the measure of distance from $\lambda=$ 1 to a measure of nearness. Thus, I interpret $\theta$ as a measure of the degree of overlap between legislative districts and counties, and use it as an interaction term in specifications analogous to the unified model described by Equation (2.10). If the linkage between counties and legislature size is truly important in determining the degree to which the Law of $1 / n$ impacts government size, these interaction variables should be statistically significant.

Finally, in the above theoretical model, the relationship between counties and legislative chamber size, $\lambda_{i}$, is responsible for determining the degree to which intergovernmental competition lessens the $1 / \mathrm{n}$ effect of an increase in chamber size. Including a $\lambda_{i t}$ for the upper and lower chambers in Equation (2.10) yields

$$
G_{i t}=\alpha+\beta_{1} n_{i t}^{U}+\beta_{2} n_{i t}^{L}+\beta_{3} c_{i t}+\beta_{4} \lambda_{i t}^{U}+\beta_{5} \lambda_{i t}^{L}+\delta X_{i t}+\mu_{t}+\varepsilon_{i t} .
$$

Empirically, I use a variety of measures of $\lambda_{i t}$. First, I test a specification which includes both values of $\lambda_{i t}$ without the county and legislature size variables. These variables' coefficients are expected to take negative signs indicating that larger $\lambda_{i t}$ values are associated with lower government spending as intergovernmental competition overwhelms the $1 / n$ effect. Next, I include indicator variables which take a value of 1 if the associated $\lambda_{i t}$ is greater than 1 . In other words, the number of counties exceeds the number of seats in the legislature. In this specification, the coefficient on the $\lambda_{i t}$ terms is expected to take a negative sign indicating lower spending in states where a high level of intergovernmental competition overpowers the $1 / \mathrm{n}$ effect. 
As a final test, I estimate a specification which examines Equation (2.8) directly by including interaction terms between the legislative chamber size variables with the variable $1 / \lambda_{\text {it }}$ such that

$$
G_{i t}=\alpha+\beta_{1} n_{i t}^{U}+\beta_{2} n_{i t}^{L}+\beta_{3} c_{i t}+\beta_{4}\left[n_{i t}^{U} \times\left(1 / \lambda_{i t}^{U}\right)\right]+\beta_{5}\left[n_{i t}^{L} \times\left(1 / \lambda_{i t}^{L}\right)\right]+\delta X_{i t}+\mu_{t}+\varepsilon_{i t}
$$

Here, the coefficients on the interaction terms are expected to take positive signs since the above model predicts that the $1 / \mathrm{n}$ effect is larger the smaller is the value of $\lambda$ (and thus the larger is the value of $1 / \lambda)$.

\subsection{Results and Discussion}

Before examining the effect of intergovernmental competition on the Law of $1 / \mathrm{n}$, I conduct an initial analysis to test both models separately. This serves two functions: first, it checks the robustness of previous empirical studies by using different data and second, it ensures that the primary findings are not an artifact of any characteristics of these data which are inconsistent with that used by others. Table 2.2 presents these baseline results.

Column 1 presents results from a test of the $1 / \mathrm{n}$ hypothesis. Consistent with the previous theoretical and empirical literature, the relationship between the number of seats in the upper chamber and government spending is positive and statistically significant. Also consistent with previous empirical work, the size of the lower chamber is negatively related to government spending. The specification presented in column 2 tests the Leviathan fiscal decentralization hypothesis. Specifically, the results show a negative relationship between government size and the number of counties in a state, again consistent with both theory and past empirical evidence. 
Table 2.2: Testing the Law of $1 / n$ and Leviathan Theories

\begin{tabular}{|c|c|c|c|c|}
\hline \multicolumn{5}{|c|}{ Dependent Variable: Real Per Capita State and Local Expenditure } \\
\hline Specification: & 1 & 2 & 3 & 4 \\
\hline Upper Chamber Seats & $\begin{array}{l}6.415^{\star * *} \\
(0.888)\end{array}$ & & $\begin{array}{l}7.689^{* * *} \\
(0.776)\end{array}$ & $\begin{array}{c}-68.286^{* * *} \\
(6.887)\end{array}$ \\
\hline Lower Chamber Seats & $\begin{array}{l}-2.170^{\star * *} \\
(0.192)\end{array}$ & & $\begin{array}{l}-2.077^{* * \star} \\
(0.178)\end{array}$ & $\begin{array}{l}-1.418^{* *} \\
(0.676)\end{array}$ \\
\hline Counties & & $\begin{array}{l}-1.296^{\star * *} \\
(0.286)\end{array}$ & $\begin{array}{l}-1.636^{* * *} \\
(0.197)\end{array}$ & $\begin{array}{l}-3.230^{* * *} \\
(0.738)\end{array}$ \\
\hline Upper Chamber Seats Squared & & & & $\begin{array}{l}0.876^{* * *} \\
(0.072)\end{array}$ \\
\hline Lower Chamber Seats Squared & & & & $\begin{array}{l}-0.002 \\
(0.002)\end{array}$ \\
\hline Counties Squared & & & & $\begin{array}{l}0.008^{\star * \star} \\
(0.003)\end{array}$ \\
\hline Democrat Governor & $\begin{array}{l}25.839^{*} \\
(14.796)\end{array}$ & $\begin{array}{c}22.316 \\
(15.847)\end{array}$ & $\begin{array}{l}33.030^{\star *} \\
(14.925)\end{array}$ & $\begin{array}{l}45.751^{\star * *} \\
(14.542)\end{array}$ \\
\hline Population Growth Rate & $\begin{array}{c}-44.914^{* * *} \\
(14.382)\end{array}$ & $\begin{array}{c}-44.596^{\star \star *} \\
(14.306)\end{array}$ & $\begin{array}{l}-34.120^{\star *} \\
(13.717)\end{array}$ & $\begin{array}{l}-122.799^{* * *} \\
(16.822)\end{array}$ \\
\hline Population (millions) & $\begin{array}{l}7.841^{\star * \star} \\
(1.580)\end{array}$ & $\begin{array}{c}12.294^{\star \star *} \\
(1.885)\end{array}$ & $\begin{array}{c}12.972^{\star * *} \\
(1.636)\end{array}$ & $\begin{array}{c}12.948^{\star * *} \\
(1.961)\end{array}$ \\
\hline Real Per Capita Federal Aid & $\begin{array}{l}0.885^{\star \star \star} \\
(0.136)\end{array}$ & $\begin{array}{l}0.961^{* \star *} \\
(0.139)\end{array}$ & $\begin{array}{c}0.857^{* * *} \\
(0.129)\end{array}$ & $\begin{array}{l}0.624^{\star * *} \\
(0.093)\end{array}$ \\
\hline Real Per Capita Personal Income & $\begin{array}{c}107.535^{\star * \star} \\
(8.244)\end{array}$ & $\begin{array}{l}92.184^{* * *} \\
(7.187)\end{array}$ & $\begin{array}{c}108.621^{* * *} \\
(8.663)\end{array}$ & $\begin{array}{l}81.846^{* \star *} \\
(7.580)\end{array}$ \\
\hline Percent Young (Age 5-17) & $\begin{array}{l}5.490 \\
(7.140)\end{array}$ & $\begin{array}{l}-3.766 \\
(7.626)\end{array}$ & $\begin{array}{c}16.426^{* *} \\
(8.013)\end{array}$ & $\begin{array}{l}-3.860 \\
(8.371)\end{array}$ \\
\hline Percent (Age 18+) High School Graduates & $\begin{array}{l}10.225^{\star \star *} \\
(3.445)\end{array}$ & $\begin{array}{c}13.461^{* * \star} \\
(3.594)\end{array}$ & $\begin{array}{l}9.424^{* * *} \\
(3.370)\end{array}$ & $\begin{array}{c}10.594^{* \star *} \\
(3.463)\end{array}$ \\
\hline Percent Below Poverty Line & $\begin{array}{l}-3.181 \\
(4.372)\end{array}$ & $\begin{array}{c}4.679 \\
(4.129)\end{array}$ & $\begin{array}{l}-0.838 \\
(4.137)\end{array}$ & $\begin{array}{l}3.026 \\
(4.044)\end{array}$ \\
\hline Population Density (pop/sq mi) & $\begin{array}{l}-0.360^{* * *} \\
(0.051)\end{array}$ & $\begin{array}{l}-0.082^{*} \\
(0.043)\end{array}$ & $\begin{array}{l}-0.414^{* * *} \\
(0.050)\end{array}$ & $\begin{array}{l}-0.240^{* * *} \\
(0.054)\end{array}$ \\
\hline Percent White & $\begin{array}{l}-2.021 \\
(1.259) \\
\end{array}$ & $\begin{array}{l}-3.030^{* * *} \\
(0.982) \\
\end{array}$ & $\begin{array}{r}-0.058 \\
(1.104) \\
\end{array}$ & $\begin{array}{l}-1.860^{*} \\
(1.126) \\
\end{array}$ \\
\hline $\begin{array}{l}\text { Number of Observations } \\
\text { R-Squared }\end{array}$ & $\begin{array}{c}564 \\
0.799\end{array}$ & $\begin{array}{c}564 \\
0.770\end{array}$ & $\begin{array}{c}564 \\
0.807\end{array}$ & $\begin{array}{c}564 \\
0.844\end{array}$ \\
\hline
\end{tabular}

Note: All models include year and census region fixed effects. Constant and fixed effect coefficient estimates not shown. Panel-corrected standard errors in parentheses: * indicates statistical significance at the $10 \%$ level, ** at the $5 \%$ level, and $* * *$ at the $1 \%$ level.

Column 3 presents results for a specification which includes both upper and lower legislative chamber size and the number of county governments. As discussed above, the correlation between chamber sizes and the number of counties is low, indicating models which include only chamber size or the number of governments largely ignore the effects of the 
excluded variable. The sign and significance of both chamber size variables as well as the number of counties variable are consistent with the previous, separated specifications. The magnitudes for each coefficient are also very similar to the previous specifications. This result lends credence to the joint analysis of the counteracting forces of the Law of $1 / \mathrm{n}$ and 'Leviathan' models: the size of the upper legislative chamber is positively related to the size of government while the number of county governments is negatively related to government size.

Column 4 presents results for a specification which analyzes the second-order effects of increases in chamber size and the number of counties. Specifically, this specification is identical to column 3 but for the addition of squared upper and lower chamber sizes and a squared county variable. This model tests for the relationship modeled in Figure 2.3. While the results for the lower chamber are vague, upper chamber size and the number of counties clearly exhibit the expected parabola shape. The number of both types of jurisdiction is negatively related to government spending, but the second-order effect is positive. These results are consistent with the relationship shown in Figure 2.3, and also provide evidence that decentralization constrains government up to some point, after which it may lead to increases in expenditure. ${ }^{4}$

While the previous results are noteworthy in that they empirically identify the concurrent and counterbalancing effects of chamber size and the number of governments, they do not adequately measure the interplay of the effects. In other words, the previous specifications treat the effects as behaving independently while the true power of the above theoretical analysis lies in the interaction of the two effects. Specifically, the theory outlined above describes

\footnotetext{
${ }^{4}$ The estimates from Column 4 of Table 2.2 can be used to calculate the level of decentralization which minimizes government spending. By substituting $n=(1 / \lambda) c$ into Equation (2.11) and differentiating with respect to $c$, the expenditure-minimizing level of decentralization (as a function of $\lambda$ ) can be found. $38 \%$ of states have a number of counties above this 'optimal' number, while $62 \%$ of states have a number of counties below this expenditureminimizing number. Thus, while the majority of states in the sample could expect decreases in spending by engaging in further decentralization, many may actually experience increases in expenditure. The average (across all states) expenditure-minimizing number of counties is 64 .
} 
intergovernmental competition as having a limiting effect on the Law of $1 / \mathrm{n}$ which is magnified

by the relationship between the number of legislators and the number of sub-state governments, referred to above as $\lambda$. Table 2.3 presents results from specifications designed to test this

interaction of effects.

Table 2.3: Intergovernmental Competition and the Law of $1 / \mathbf{n}$

\begin{tabular}{|c|c|c|c|c|c|c|}
\hline \multicolumn{7}{|c|}{ Dependent Variable: Real Per Capita State and Local Expenditure } \\
\hline Specification: & 1 & 2 & 3 & 4 & 5 & 6 \\
\hline Upper Chamber Seats & $\begin{array}{c}10.846^{\star \star \star} \\
(1.244)\end{array}$ & & $\begin{array}{c}9.590^{\star \star *} \\
(0.802)\end{array}$ & & $\begin{array}{c}8.708^{\star \star *} \\
(0.738)\end{array}$ & $\begin{array}{c}7.738^{\star * \star} \\
(0.983)\end{array}$ \\
\hline Lower Chamber Seats & $\begin{array}{c}-2.177^{\star \star \star} \\
(0.205)\end{array}$ & & $\begin{array}{c}1.307^{\star \star \star} \\
(0.502)\end{array}$ & & $\begin{array}{c}-2.234^{\star \star *} \\
(0.172)\end{array}$ & $\begin{array}{c}-2.652^{\star \star \star} \\
(0.334)\end{array}$ \\
\hline Counties & & $\begin{array}{c}-4.629^{\star \star \star} \\
(0.762)\end{array}$ & $\begin{array}{c}-7.238^{\star \star \star} \\
(0.644)\end{array}$ & & $\begin{array}{c}-1.280^{\star \star \star *} \\
(0.265)\end{array}$ & $\begin{array}{c}-1.355^{\star \star \star} \\
(0.209)\end{array}$ \\
\hline Upper Chamber Seats x Counties & $\begin{array}{c}-0.049^{* * *} \\
(0.010)\end{array}$ & $\begin{array}{c}0.083^{* * *} \\
(0.006)\end{array}$ & & & & \\
\hline Lower Chamber Seats $\times$ Counties & $\begin{array}{l}0.004^{\star *} \\
(0.002)\end{array}$ & $\begin{array}{l}-0.000 \\
(0.004)\end{array}$ & & & & \\
\hline Upper Chamber Seats x Degree of Overlap & & & $\begin{array}{c}-0.786^{\star * \star} \\
(0.078)\end{array}$ & & & \\
\hline Lower Chamber Seats x Degree of Overlap & & & $\begin{array}{c}3.689^{\star \star \star} \\
(0.570)\end{array}$ & & & \\
\hline Upper Chamber $\lambda$ & & & & $\begin{array}{c}-55.171^{\star \star \star} \\
(6.534)\end{array}$ & & \\
\hline Lower Chamber $\lambda$ & & & & $\begin{array}{c}-49.995 \\
(50.000)\end{array}$ & & \\
\hline Upper Chamber $\lambda>1\left(c>n^{U}\right)$ & & & & & $\begin{array}{c}-155.117^{\star \star \star} \\
(27.435)\end{array}$ & \\
\hline Lower Chamber $\lambda>1\left(c>n^{L}\right)$ & & & & & $\begin{array}{l}74.135^{\star *} \\
(29.713)\end{array}$ & \\
\hline Upper Chamber Seats $\times 1 / \lambda$ & & & & & & $\begin{array}{l}0.439^{* *} \\
(0.195)\end{array}$ \\
\hline Lower Chamber Seats $\times 1 / \lambda$ & & & & & & $\begin{array}{l}0.0126 \\
(0.008)\end{array}$ \\
\hline Democrat Governor & $\begin{array}{l}32.529^{\star *} \\
(15.131)\end{array}$ & $\begin{array}{c}16.204 \\
(16.990)\end{array}$ & $\begin{array}{l}36.998^{\star \star} \\
(15.346)\end{array}$ & $\begin{array}{c}20.311 \\
(16.471)\end{array}$ & $\begin{array}{l}31.448^{\star \star} \\
(14.397)\end{array}$ & $\begin{array}{l}35.739^{\star *} \\
(15.098)\end{array}$ \\
\hline Population Growth Rate & $\begin{array}{c}-32.799^{* *} \\
(14.184)\end{array}$ & $\begin{array}{c}-40.237^{\star \star \star} \\
(15.287)\end{array}$ & $\begin{array}{c}-45.074^{\star \star *} \\
(13.357)\end{array}$ & $\begin{array}{c}-39.764^{\star \star \star} \\
(14.982)\end{array}$ & $\begin{array}{c}-56.985^{\star \star \star} \\
(14.366)\end{array}$ & $\begin{array}{c}-40.075^{\star \star \star} \\
(13.218)\end{array}$ \\
\hline Population (millions) & $\begin{array}{c}10.623^{\star \star \star} \\
(1.591)\end{array}$ & $\begin{array}{c}13.485^{\star \star \star} \\
(1.777)\end{array}$ & $\begin{array}{c}11.800^{\star \star \star} \\
(1.704)\end{array}$ & $\begin{array}{c}14.313^{\star \star \star} \\
(1.656)\end{array}$ & $\begin{array}{c}14.951^{\star \star \star} \\
(1.776)\end{array}$ & $\begin{array}{c}14.248^{\star * *} \\
(1.873)\end{array}$ \\
\hline Real Per Capita Federal Aid & $\begin{array}{c}0.861^{* * *} \\
(0.136)\end{array}$ & $\begin{array}{c}0.958^{\star \star \star} \\
(0.141)\end{array}$ & $\begin{array}{c}0.779^{\star * *} \\
(0.124)\end{array}$ & $\begin{array}{c}0.952^{\star \star *} \\
(0.138)\end{array}$ & $\begin{array}{c}0.782^{* \star *} \\
(0.121)\end{array}$ & $\begin{array}{c}0.829^{\star \star \star} \\
(0.124)\end{array}$ \\
\hline Real Per Capita Personal Income & $\begin{array}{c}110.833^{\star \star \star} \\
(8.889)\end{array}$ & $\begin{array}{c}90.853^{\star \star *} \\
(7.250)\end{array}$ & $\begin{array}{c}113.225^{\star \star *} \\
(9.029)\end{array}$ & $\begin{array}{c}93.288^{\star * *} \\
(7.415)\end{array}$ & $\begin{array}{c}104.973^{\star \star \star} \\
(8.707)\end{array}$ & $\begin{array}{c}110.599^{\star \star * *} \\
(8.786)\end{array}$ \\
\hline Percent Young (Age 5-17) & $\begin{array}{l}12.622 \\
(7.887)\end{array}$ & $\begin{array}{l}2.094 \\
(7.563)\end{array}$ & $\begin{array}{l}12.053 \\
(8.808)\end{array}$ & $\begin{array}{c}1.897 \\
(7.885)\end{array}$ & $\begin{array}{c}4.012 \\
(8.963)\end{array}$ & $\begin{array}{l}15.886^{*} \\
(8.261)\end{array}$ \\
\hline Percent (Age 18+) High School Graduates & $\begin{array}{c}9.308^{* \star *} \\
(3.506)\end{array}$ & $\begin{array}{c}11.768^{\star \star \star} \\
(3.366)\end{array}$ & $\begin{array}{l}7.345^{\star \star} \\
(3.547)\end{array}$ & $\begin{array}{c}12.430^{* * *} \\
(3.458)\end{array}$ & $\begin{array}{c}9.481^{\star \star *} \\
(3.310)\end{array}$ & $\begin{array}{c}11.502^{* * *} \\
(3.716)\end{array}$ \\
\hline Percent Below Poverty Line & $\begin{array}{l}-2.619 \\
(4.210)\end{array}$ & $\begin{array}{c}4.691 \\
(4.177)\end{array}$ & $\begin{array}{l}-2.227 \\
(3.982)\end{array}$ & $\begin{array}{l}5.657 \\
(4.060)\end{array}$ & $\begin{array}{c}0.300 \\
(4.183)\end{array}$ & $\begin{array}{c}0.307 \\
(4.090)\end{array}$ \\
\hline Population Density (pop/sq mi) & $\begin{array}{c}-0.444^{\star \star \star} \\
(0.060)\end{array}$ & $\begin{array}{l}-0.034 \\
(0.042)\end{array}$ & $\begin{array}{c}-0.500^{\star \star \star} \\
(0.055)\end{array}$ & $\begin{array}{c}-0.087^{\star *} \\
(0.043)\end{array}$ & $\begin{array}{c}-0.508^{\star * \star} \\
(0.050)\end{array}$ & $\begin{array}{c}-0.531^{\star \star *} \\
(0.065)\end{array}$ \\
\hline Percent White & $\begin{array}{c}-0.821 \\
(1.217) \\
\end{array}$ & $\begin{array}{c}0.312 \\
(1.097 \\
\end{array}$ & $\begin{array}{c}0.732 \\
(1.308) \\
\end{array}$ & $\begin{array}{l}-1.100 \\
(0.966) \\
\end{array}$ & $\begin{array}{c}-0.423 \\
(1.070) \\
\end{array}$ & $\begin{array}{c}-0.982 \\
(1.135) \\
\end{array}$ \\
\hline $\begin{array}{l}\text { Number of Observations } \\
\text { R-Squared }\end{array}$ & $\begin{array}{c}564 \\
0.803 \\
\end{array}$ & $\begin{array}{c}564 \\
0.785 \\
\end{array}$ & $\begin{array}{c}564 \\
0.815 \\
\end{array}$ & $\begin{array}{c}564 \\
0.777 \\
\end{array}$ & $\begin{array}{c}564 \\
0.815 \\
\end{array}$ & $\begin{array}{c}564 \\
0.809 \\
\end{array}$ \\
\hline
\end{tabular}

Note: All models include year and census region fixed effects. Constant and fixed effect coefficient estimates not shown. Panel-corrected standard errors in parentheses: * indicates statistical significance at the $10 \%$ level, ** at the $5 \%$ level, and $* * *$ at the $1 \%$ level. 
The first two columns of Table 2.3 are analogous to columns 1 and 2 in Table 2.2 with two additional interaction terms included. These terms interact the number of counties with upper and lower chamber sizes. The results in column 1 indicate that while the size of the upper chamber is positively related to government spending, this effect is lessened at the margin by increases in the number of county governments since the interaction term is negative and statistically significant. Similarly, column 2 shows that while the number of counties in a state is negatively related to the size of total government, the effect is lessened by an increase in the size of the upper chamber, since the interaction term is positive and statistically significant. These results provide evidence of the counterbalancing effects of the Law of $1 / n$ and Leviathan theories.

Column 3 incorporates the overlap measure described above. Again, this measure increases as the ratio $\lambda_{i t}=\frac{c_{i t}}{n_{i t}}$ approaches 1 . First and foremost, the chamber size and county variables retain their previous signs and statistical significance, but the lower chamber is now positive as well, providing the first evidence of a ' $1 / \mathrm{n}$ effect' in that chamber. The effect of an increase in upper chamber size on government spending decreases, however, as the degree of overlap increases. As before, this is evidenced by the negative and significant interaction term. In other words, while the Law of 1/n holds for the upper chamber in these data, the effect is lessened by the degree to which an increase in the number of legislators corresponds to an increase in the number of counties and thus the level of intergovernmental competition. The interaction between overlap and lower chamber size is positive and significant, suggesting that as lower chamber size approaches the number of counties spending increases further. This result is 
puzzling, but again unsurprising given the similarly unexpected lower chamber results in previous studies.

The fourth column of Table 2.3 presents the results of the specification which includes the $\lambda$ values for the upper and lower chambers. The upper chamber variable has a coefficient that is negative and statistically significant, indicating that government spending is negatively related to the size of $\lambda$. The lower chamber $\lambda$ variable is negative but insignificant. This result is consistent with the model outlined above: the higher is the value of $\lambda$, the fewer legislativedistricts-per-county in a state, which likely means the downward pressure on spending associated with intergovernmental competition is overwhelming the $1 / \mathrm{n}$ effect. Column 5 shows the results of a specification which includes variables indicating whether the value of $\lambda$ is greater than one for the upper and lower chambers. As shown above, this occurs whenever the number of counties in the state exceeds the number of seats in the legislative chamber. First, the chamber size and county variables retain their sign and significance. The Upper Chamber $\lambda>1$ variable is negative and statistically significant, which implies that states with more counties than upper chamber districts are characterized by lower spending. Likewise, as the number of legislative districts relative to counties rises so too will spending.

The final column of Table 2.3 tests Equation (2.8) directly by including interaction terms of legislative chamber size with $1 / \lambda$. These results (for the upper chamber) are again consistent with the model, as the chamber size and county variables retain their sign and significance, and the marginal effect of an increase in upper chamber size increases as the value of $1 / \lambda$ increases (in other words, $\lambda$ decreases). The smaller is $\lambda$, the stronger is the $1 / \mathrm{n}$ effect. 
Table 2.4: Ranking of States by Upper Chamber $\lambda, 2005$

\begin{tabular}{|c|c|}
\hline \multicolumn{2}{|c|}{ Largest Upper Chamber $\lambda$ Values } \\
\hline State & $\lambda$ \\
\hline Texas & 8.194 \\
\hline Missouri & 3.353 \\
\hline Kentucky & 3.158 \\
\hline Tennessee & 2.879 \\
\hline Georgia & 2.839 \\
\hline Ohio & 2.667 \\
\hline Kansas & 2.625 \\
\hline Virginia & 2.375 \\
\hline Michigan & 2.184 \\
\hline Wisconsin & 2.182 \\
\hline \multicolumn{2}{|c|}{ Smallest Upper Chamber $\lambda$ Values } \\
\hline State & $\lambda$ \\
\hline New Jersey & 0.525 \\
\hline Maryland & 0.511 \\
\hline Arizona & 0.500 \\
\hline Vermont & 0.467 \\
\hline Maine & 0.457 \\
\hline New Hampshire & 0.417 \\
\hline Massachusetts & 0.350 \\
\hline Connecticut & 0.222 \\
\hline Delaware & 0.143 \\
\hline Rhode Island & 0.132 \\
\hline
\end{tabular}

Table 2.4 presents the ten states with the largest and smallest values of $\lambda$ for the upper legislative chamber. The above model predicts, and the empirical analysis supports, that the larger is $\lambda$ the more likely the Leviathan hypothesis is to hold, as the $1 / \mathrm{n}$ effect is overwhelmed by increases in intergovernmental competition. Thus, the states with relatively high $\lambda$ values can be expected to see decreases in government size as a result of intergovernmental competition, assuming the relationship between counties and legislative districts remains constant. Conversely, the states with the smallest $\lambda$ values can be expected to see increases in government spending following increased decentralization as the associated growth of the legislature (and related $1 / \mathrm{n}$ effect) more than offsets the increased intergovernmental competition (again, assuming the ratio of sub-state governments to legislative districts remains unchanged). 
The logic here follows from the idea that the effect of intergovernmental competition is lessened by the Law of $1 / \mathrm{n}$, and the extent to which it is lessened depends on how closely legislative districts are linked to administrative districts. If the link is relatively strong, a state can have a relatively centralized government and still feature less government spending than a state with comparatively little overlap between the types of jurisdictions. The mechanism which affects this phenomenon is the Law of $1 / \mathrm{n}$ within the legislature-if increases in the number of sub-state governments correspond to increases in legislature size, government spending may not decline as predicted by the Leviathan hypothesis.

\subsection{Robustness Check}

The analysis discussed above was conducted on selected years in the period 1992-2005 using total state and local expenditure. Numerous other dependent variables have been used in both the $1 / \mathrm{n}$ and Leviathan literatures. I estimate my primary results again using two of these alternative measures of government size, namely total state expenditure and total state general expenditure. Both of these measures do not contain local spending, and the chief difference between general and total state expenditure is that total expenditure includes spending on utilities, liquor stores, and insurance while general expenditure does not. Further, these data are available for all years, 1992-2005, allowing for an expansion in the number of observations.

Table 2.5 presents results of the primary specifications described above now estimated on total state expenditure. Column 1 is analogous to column 3 in Table 2.2. This specification includes both the sizes of the upper and lower chambers as well as the number of county governments in the state. The coefficients retain their sign and significance, as well as similar 
magnitudes. The same is true for the upper chamber and county variables of interest in column

2, which includes the squared chamber size and county variables.

Table 2.5: Intergovernmental Competition and the Law of 1/n: Total State Expenditure

\begin{tabular}{|c|c|c|c|c|c|c|}
\hline \multicolumn{7}{|c|}{ Dependent Variable: Real Per Capita Total State Expenditure } \\
\hline Specification: & 1 & 2 & 3 & 4 & 5 & 6 \\
\hline Upper Chamber Seats & $\begin{array}{c}4.958^{\star \star \star *} \\
(0.466)\end{array}$ & $\begin{array}{c}-76.191^{* * *} \\
(8.517)\end{array}$ & $\begin{array}{c}9.402^{\star \star \star} \\
(1.049)\end{array}$ & & $\begin{array}{c}8.047^{\star \star \star} \\
(0.512)\end{array}$ & \\
\hline Lower Chamber Seats & $\begin{array}{c}-1.854^{\star \star \star} \\
(0.157)\end{array}$ & $\begin{array}{l}1.093^{\star \star} \\
(0.548)\end{array}$ & $\begin{array}{c}-1.902^{\star \star \star} \\
(0.180)\end{array}$ & & $\begin{array}{c}0.540 \\
(0.427)\end{array}$ & \\
\hline Counties & $\begin{array}{c}-2.724^{\star \star \star} \\
(0.267)\end{array}$ & $\begin{array}{c}-5.973^{\star \star \star} \\
(0.636)\end{array}$ & & $\begin{array}{c}-5.954^{\star \star \star} \\
(0.662)\end{array}$ & $\begin{array}{c}-7.947^{\star \star \star} \\
(0.551)\end{array}$ & \\
\hline Upper Chamber Seats Squared & & $\begin{array}{c}0.929^{\star * \star} \\
(0.093)\end{array}$ & & & & \\
\hline Lower Chamber Seats Squared & & $\begin{array}{c}-0.007^{\star \star \star} \\
(0.001)\end{array}$ & & & & \\
\hline Counites Squared & & $\begin{array}{c}0.014^{\star * *} \\
(0.002)\end{array}$ & & & & \\
\hline Upper Chamber Seats x Counties & & & $\begin{array}{c}-0.068^{\star \star \star} \\
(0.010)\end{array}$ & $\begin{array}{c}0.056^{\star * *} \\
(0.004)\end{array}$ & & \\
\hline Lower Chamber Seats $\times$ Counties & & & $\begin{array}{c}0.002 \\
(0.002)\end{array}$ & $\begin{array}{l}0.007^{\star *} \\
(0.003)\end{array}$ & & \\
\hline Upper Chamber Seats x Degree of Overlap & & & & & $\begin{array}{c}-0.784^{\star * \star} \\
(0.068)\end{array}$ & \\
\hline Lower Chamber Seats x Degree of Overlap & & & & & $\begin{array}{c}2.639^{* * *} \\
(0.466)\end{array}$ & \\
\hline Upper Chamber $\lambda$ & & & & & & $\begin{array}{c}-35.830^{\star \star *} \\
(6.908)\end{array}$ \\
\hline Lower Chamber $\lambda$ & & & & & & $\begin{array}{c}-298.214^{\star \star \star} \\
(37.548)\end{array}$ \\
\hline Democrat Governor & $\begin{array}{c}56.344^{\star * *} \\
(20.978)\end{array}$ & $\begin{array}{c}71.777^{\star \star * *} \\
(19.727)\end{array}$ & $\begin{array}{l}58.761^{* *} \\
(23.040)\end{array}$ & $\begin{array}{l}38.716^{* *} \\
(16.753)\end{array}$ & $\begin{array}{c}65.598^{\star * *} \\
(21.983)\end{array}$ & $\begin{array}{l}38.386^{\star *} \\
(16.181)\end{array}$ \\
\hline Population Growth Rate & $\begin{array}{c}-103.643^{\star \star \star} \\
(14.813)\end{array}$ & $\begin{array}{c}-199.507^{\star \star *} \\
(23.582)\end{array}$ & $\begin{array}{c}-97.794^{\star \star \star} \\
(15.334)\end{array}$ & $\begin{array}{c}-108.798^{\star \star *} \\
(15.712)\end{array}$ & $\begin{array}{c}-117.754^{\star \star \star} \\
(14.835)\end{array}$ & $\begin{array}{c}-112.290^{\star \star \star} \\
(15.347)\end{array}$ \\
\hline Population (millions) & $\begin{array}{c}6.477^{\star \star \star} \\
(1.746)\end{array}$ & $\begin{array}{c}6.422^{* * *} \\
(2.090)\end{array}$ & $\begin{array}{l}3.561^{* *} \\
(6.534)\end{array}$ & $\begin{array}{c}6.887^{\star \star * \star} \\
(1.860)\end{array}$ & $\begin{array}{c}5.704^{\star \star \star} \\
(1.847)\end{array}$ & $\begin{array}{c}6.813^{\star \star \star} \\
(1.785)\end{array}$ \\
\hline Real Per Capita Federal Aid & $\begin{array}{c}0.813^{\star \star \star} \\
(0.106)\end{array}$ & $\begin{array}{c}0.549^{\star \star \star} \\
(0.072)\end{array}$ & $\begin{array}{c}0.827^{\star \star \star} \\
(0.116)\end{array}$ & $\begin{array}{c}0.897^{\star \star *} \\
(0.112)\end{array}$ & $\begin{array}{c}0.711^{\star \star *} \\
(0.100)\end{array}$ & $\begin{array}{c}0.881^{\star \star *} \\
(0.108)\end{array}$ \\
\hline Real Per Capita Personal Income & $\begin{array}{c}51.588^{\star * *} \\
(6.262)\end{array}$ & $\begin{array}{c}24.225^{\star \star \star} \\
(5.868)\end{array}$ & $\begin{array}{c}53.573^{* \star *} \\
(6.534)\end{array}$ & $\begin{array}{c}38.255^{\star \star *} \\
(5.425)\end{array}$ & $\begin{array}{c}52.725^{\star \star \star} \\
(7.012)\end{array}$ & $\begin{array}{c}41.043^{\star \star *} \\
(5.550)\end{array}$ \\
\hline Percent Young (Age 5-17) & $\begin{array}{l}12.975 \\
(8.175)\end{array}$ & $\begin{array}{l}-9.953 \\
(7.980)\end{array}$ & $\begin{array}{c}8.485 \\
(7.589)\end{array}$ & $\begin{array}{c}0.132 \\
(7.187)\end{array}$ & $\begin{array}{c}4.517 \\
(8.511)\end{array}$ & $\begin{array}{l}-2.654 \\
(7.184)\end{array}$ \\
\hline Percent (Age 18+) High School Graduates & $\begin{array}{c}0.102 \\
(3.414)\end{array}$ & $\begin{array}{l}-0.071 \\
(3.503)\end{array}$ & $\begin{array}{c}0.160 \\
(3.616)\end{array}$ & $\begin{array}{c}0.789 \\
(3.306)\end{array}$ & $\begin{array}{l}-1.505 \\
(3.660)\end{array}$ & $\begin{array}{c}0.232 \\
(3.370)\end{array}$ \\
\hline Percent Below Poverty Line & $\begin{array}{l}-2.343 \\
(3.914)\end{array}$ & $\begin{array}{c}1.584 \\
(3.759)\end{array}$ & $\begin{array}{l}-5.128 \\
(4.161)\end{array}$ & $\begin{array}{c}2.376 \\
(3.927)\end{array}$ & $\begin{array}{l}-3.788 \\
(3.777)\end{array}$ & $\begin{array}{c}2.929 \\
(3.808)\end{array}$ \\
\hline Population Density (pop/sq mi) & $\begin{array}{c}-0.118^{* *} \\
(0.057)\end{array}$ & $\begin{array}{c}0.056 \\
(0.044)\end{array}$ & $\begin{array}{l}-0.154^{\star \star} \\
(0.060)\end{array}$ & $\begin{array}{c}0.203^{\star \star \star} \\
(0.047)\end{array}$ & $\begin{array}{c}-0.230^{\star \star *} \\
(0.057)\end{array}$ & $\begin{array}{c}0.166^{\star \star *} \\
(0.047)\end{array}$ \\
\hline Percent White & $\begin{array}{c}2.608^{\star * *} \\
(0.869)\end{array}$ & $\begin{array}{c}0.770 \\
(0.801)\end{array}$ & $\begin{array}{c}1.360 \\
(0.847)\end{array}$ & $\begin{array}{c}3.627^{\star \star *} \\
(0.978)\end{array}$ & $\begin{array}{l}2.528^{* *} \\
(1.021)\end{array}$ & $\begin{array}{c}3.106^{\star \star \star} \\
(0.901)\end{array}$ \\
\hline $\begin{array}{l}\text { Number of Observations } \\
\text { R-Squared }\end{array}$ & $\begin{array}{c}658 \\
0.744\end{array}$ & $\begin{array}{c}658 \\
0.795\end{array}$ & $\begin{array}{c}658 \\
0.735\end{array}$ & $\begin{array}{c}658 \\
0.727\end{array}$ & $\begin{array}{c}658 \\
0.756\end{array}$ & $\begin{array}{c}658 \\
0.729\end{array}$ \\
\hline
\end{tabular}

Note: All models include year and census region fixed effects. Constant and fixed effect coefficient estimates not shown. Panel-corrected standard errors in parentheses: * indicates statistical significance at the $10 \%$ level, ** at the $5 \%$ level, and $* * *$ at the $1 \%$ level.

Columns 3 and 4 are analogous to columns 1 and 2 of Table 2.3. These specifications contain interaction terms of the chamber size variables with the number of counties. As before, 
all variables of interest retain sign and significance, as well as similar magnitudes. Regardless of the expenditure measure used, increases in the number of counties, ceteris paribus, decrease the positive effect of increases in upper chamber size. Likewise, an increase in upper chamber size partially counteracts the negative effect of increased intergovernmental competition.

Column 5 presents the results of a specification which includes an interaction between chamber sizes and the degree of overlap variable. Once again, most variables retain sign, statistical significance, and similar magnitudes. The clear relationship between upper chamber size's impact on expenditure and the degree of overlap with county governments remains with the alternative expenditure measure. Finally, column 6 includes the $\lambda$ values for the upper and lower chamber. As before, higher values of $\lambda$ correspond to lower government spending, consistent with the model. Interestingly, the lower chamber $\lambda$ variable is now negative and statistically significant as well.

Table 2.6 presents the same primary specifications using the general expenditure dependent variable. Again, all variables of interest retain their sign and significance as well as similar magnitudes. The results presented in the previous section are robust to alternative measures of government size. Specifically, regardless of the definition of 'government spending' considered, the size of the upper legislative chamber is positively correlated with government size while the number of counties is negatively related. Further, the parabola relationship depicted in Figure 2.3 can be found for all measures of spending and an increase in the number of jurisdictions of the other type decreases the marginal effect predicted by the Leviathan hypothesis and Law of $1 / \mathrm{n}$. Finally, the effect of an increase in legislature size is diminished when the degree of overlap between districts and counties is high, and the larger is the value of $\lambda$ the smaller is the level of government spending. 
Table 2.6: Intergovernmental Competition and the Law of 1/n: State General Expenditure

\begin{tabular}{|c|c|c|c|c|c|c|}
\hline \multicolumn{7}{|c|}{ Dependent Variable: Real Per Capita Total State General Expenditure } \\
\hline Specification: & 1 & 2 & 3 & 4 & 5 & 6 \\
\hline Upper Chamber Seats & $\begin{array}{c}3.944^{\star * *} \\
(0.515)\end{array}$ & $\begin{array}{c}-44.004^{\star \star \star} \\
(6.757)\end{array}$ & $\begin{array}{c}8.062^{\star \star \star} \\
(0.975)\end{array}$ & & $\begin{array}{c}6.888^{\star \star \star} \\
(0.458)\end{array}$ & \\
\hline Lower Chamber Seats & $\begin{array}{c}-1.492^{\star \star \star} \\
(0.138)\end{array}$ & $\begin{array}{c}1.078^{\star} \\
(0.604)\end{array}$ & $\begin{array}{c}-1.605^{\star \star \star} \\
(0.169)\end{array}$ & & $\begin{array}{l}-0.525 \\
(0.423)\end{array}$ & \\
\hline Counties & $\begin{array}{c}-1.969^{* * *} \\
(0.221)\end{array}$ & $\begin{array}{c}-5.856^{\star \star \star} \\
(0.563)\end{array}$ & & $\begin{array}{c}-5.039^{* * *} \\
(0.589)\end{array}$ & $\begin{array}{c}-5.322^{* \star *} \\
(0.590)\end{array}$ & \\
\hline Upper Chamber Seats Squared & & $\begin{array}{l}0.555^{\star \star *} \\
(0.075)\end{array}$ & & & & \\
\hline Lower Chamber Seats Squared & & $\begin{array}{l}-0.006^{* * *} \\
(0.001)\end{array}$ & & & & \\
\hline Counties Squared & & $\begin{array}{l}0.016^{\star * *} \\
(0.002)\end{array}$ & & & & \\
\hline Upper Chamber Seats x Counties & & & $\begin{array}{c}-0.062^{\star \star \star} \\
(0.111)\end{array}$ & $\begin{array}{c}0.043^{* * *} \\
(0.006)\end{array}$ & & \\
\hline Lower Chamber Seats $\times$ Counties & & & $\begin{array}{l}0.005^{\star} \\
(0.003)\end{array}$ & $\begin{array}{l}0.009^{* * *} \\
(0.003)\end{array}$ & & \\
\hline Upper Chamber Seats x Degree of Overlap & & & & & $\begin{array}{c}-0.542^{\star \star \star} \\
(0.071)\end{array}$ & \\
\hline Lower Chamber Seats $x$ Degree of Overlap & & & & & $\begin{array}{l}1.093^{\star \star} \\
(0.495)\end{array}$ & \\
\hline Upper Chamber $\lambda$ & & & & & & $\begin{array}{c}-23.973^{\star \star \star} \\
(8.549)\end{array}$ \\
\hline Lower Chamber $\lambda$ & & & & & & $\begin{array}{c}-241.434^{\star \star \star} \\
(36.833)\end{array}$ \\
\hline Democrat Governor & $\begin{array}{l}34.021^{*} \\
(18.753)\end{array}$ & $\begin{array}{c}46.445^{\star \star *} \\
(17.030)\end{array}$ & $\begin{array}{l}35.731^{*} \\
(20.554)\end{array}$ & $\begin{array}{c}18.749 \\
(14.393)\end{array}$ & $\begin{array}{l}43.097^{\star *} \\
(18.952)\end{array}$ & $\begin{array}{c}20.261 \\
(14.008)\end{array}$ \\
\hline Population Growth Rate & $\begin{array}{c}-68.054^{\star \star \star} \\
(12.360)\end{array}$ & $\begin{array}{c}-133.016^{\star \star *} \\
(17.519)\end{array}$ & $\begin{array}{c}-64.869^{\star \star *} \\
(13.048)\end{array}$ & $\begin{array}{c}-74.409^{\star \star \star} \\
(13.428)\end{array}$ & $\begin{array}{c}-80.189^{\star \star \star} \\
(12.756)\end{array}$ & $\begin{array}{c}-74.895^{\star \star \star} \\
(12.985)\end{array}$ \\
\hline Population (millions) & $\begin{array}{l}-0.296 \\
(2.799)\end{array}$ & $\begin{array}{l}-0.058 \\
(2.914)\end{array}$ & $\begin{array}{l}-2.720 \\
(2.721)\end{array}$ & $\begin{array}{c}0.084 \\
(2.832)\end{array}$ & $\begin{array}{l}-0.596 \\
(2.791)\end{array}$ & $\begin{array}{c}0.259 \\
(2.818)\end{array}$ \\
\hline Real Per Capita Federal Aid & $\begin{array}{c}0.718^{\star \star \star} \\
(0.107)\end{array}$ & $\begin{array}{c}0.519^{\star \star \star} \\
(0.087)\end{array}$ & $\begin{array}{c}0.720^{* * *} \\
(0.116)\end{array}$ & $\begin{array}{c}0.780^{\star * *} \\
(0.113)\end{array}$ & $\begin{array}{c}0.632^{\star \star \star} \\
(0.105)\end{array}$ & $\begin{array}{c}0.770^{\star \star \star} \\
(0.110)\end{array}$ \\
\hline Real Per Capita Personal Income & $\begin{array}{c}43.470^{\star \star \star} \\
(6.608)\end{array}$ & $\begin{array}{c}25.331^{\star \star \star} \\
(6.270)\end{array}$ & $\begin{array}{c}45.850^{\star \star \star} \\
(6.596)\end{array}$ & $\begin{array}{c}32.857^{\star \star \star} \\
(5.848)\end{array}$ & $\begin{array}{c}42.001^{\star \star \star} \\
(7.235)\end{array}$ & $\begin{array}{c}35.049^{\star \star \star} \\
(5.932)\end{array}$ \\
\hline Percent Young (Age 5-17) & $\begin{array}{c}26.122^{\star \star \star} \\
(9.159)\end{array}$ & $\begin{array}{c}7.442 \\
(9.193)\end{array}$ & $\begin{array}{c}22.308^{\star \star} \\
(8.976)\end{array}$ & $\begin{array}{l}15.201^{*} \\
(8.454)\end{array}$ & $\begin{array}{l}17.229^{*} \\
(9.527)\end{array}$ & $\begin{array}{l}13.941 \\
(8.529)\end{array}$ \\
\hline Percent (Age 18+) High School Graduates & $\begin{array}{c}1.585 \\
(3.702)\end{array}$ & $\begin{array}{c}1.099 \\
(3.809)\end{array}$ & $\begin{array}{c}1.478 \\
(3.814)\end{array}$ & $\begin{array}{c}2.036 \\
(4.394)\end{array}$ & $\begin{array}{c}0.875 \\
(3.837)\end{array}$ & $\begin{array}{c}1.710 \\
(3.640)\end{array}$ \\
\hline Percent Below Poverty Line & $\begin{array}{l}-2.051 \\
(4.324)\end{array}$ & $\begin{array}{c}0.409 \\
(4.228)\end{array}$ & $\begin{array}{l}-4.292 \\
(4.493)\end{array}$ & $\begin{array}{c}2.067 \\
(4.394)\end{array}$ & $\begin{array}{l}-2.930 \\
(4.274)\end{array}$ & $\begin{array}{c}2.370 \\
(4.297)\end{array}$ \\
\hline Population Density (pop/sq mi) & $\begin{array}{c}-0.097^{\star *} \\
(0.043)\end{array}$ & $\begin{array}{l}-0.030 \\
(0.034)\end{array}$ & $\begin{array}{c}-0.138^{\star \star \star} \\
(0.048)\end{array}$ & $\begin{array}{l}0.164^{\star * \star} \\
(0.035)\end{array}$ & $\begin{array}{c}-0.193^{* * *} \\
(0.043)\end{array}$ & $\begin{array}{c}0.126^{\star \star *} \\
(0.034)\end{array}$ \\
\hline Percent White & $\begin{array}{c}4.153^{\star * \star} \\
(1.068)\end{array}$ & $\begin{array}{c}2.707^{\star \star \star} \\
(1.054) \\
\end{array}$ & $\begin{array}{c}3.275^{\star \star \star} \\
(1.088) \\
\end{array}$ & $\begin{array}{c}5.165^{\star * \star} \\
(1.141) \\
\end{array}$ & $\begin{array}{c}3.481^{* * *} \\
(1.056) \\
\end{array}$ & $\begin{array}{c}4.556^{\star * *} \\
(1.048) \\
\end{array}$ \\
\hline $\begin{array}{l}\text { Number of Observations } \\
\text { R-Squared }\end{array}$ & $\begin{array}{c}658 \\
0.879\end{array}$ & $\begin{array}{c}658 \\
0.896\end{array}$ & $\begin{array}{c}658 \\
0.866\end{array}$ & $\begin{array}{c}658 \\
0.872\end{array}$ & $\begin{array}{c}658 \\
0.884\end{array}$ & $\begin{array}{c}658 \\
0.873\end{array}$ \\
\hline
\end{tabular}

Note: All models include year and census region fixed effects. Constant and fixed effect coefficient estimates not shown. Panel-corrected standard errors in parentheses: * indicates statistical significance at the $10 \%$ level, ** at the $5 \%$ level, and *** at the $1 \%$ level.

In a recent contribution, Chen and Malhotra (2007) provide a theoretical extension of the original Weingast, Shepsle, and Johnsen (1981) model which specifically models bicameral legislatures. The major implication of the model is that the ratio of lower to upper chamber size, which the authors refer to as ' $\mathrm{k}$,' has a negative effect on expenditure while upper chamber size, 
' $\mathrm{n}$,' retains its traditional positive effect. In empirical practice, the ' $\mathrm{k}$ ' ratio is used in place of the lower chamber size variable used in previous studies. To control for this effect, I again estimate my primary results, here using ' $\mathrm{k}$ ' instead of lower chamber size.

Table 2.7: Including the Chen and Malhotra (2007) ' $k$ ' Ratio

\begin{tabular}{|c|c|c|c|c|}
\hline \multicolumn{5}{|c|}{ Dependent Variable: Real Per Capita State and Local Expenditure } \\
\hline Specification: & 1 & 2 & 3 & 4 \\
\hline Upper Chamber Seats & $\begin{array}{c}4.044^{* * *} \\
(0.960)\end{array}$ & $\begin{array}{c}-73.662^{* * *} \\
(6.715)\end{array}$ & $\begin{array}{c}6.431 \\
(0.998)\end{array}$ & $\begin{array}{c}6.393^{\star * *} \\
(0.901)\end{array}$ \\
\hline Ratio Lower/Upper Chamber Seats 'k' & $\begin{array}{c}-44.974^{* \star *} \\
(4.360)\end{array}$ & $\begin{array}{c}-54.336^{* * *} \\
(3.968)\end{array}$ & $\begin{array}{c}-44.282^{\star * *} \\
(4.431)\end{array}$ & $\begin{array}{c}-46.504^{* * *} \\
(4.382)\end{array}$ \\
\hline Counties & $\begin{array}{c}-1.853^{\star * *} \\
(0.213)\end{array}$ & $\begin{array}{c}-3.484^{* * *} \\
(0.734)\end{array}$ & & $\begin{array}{c}-3.613^{\star * *} \\
(0.489)\end{array}$ \\
\hline Upper Chamber Seats Squared & & $\begin{array}{c}0.896^{* * *} \\
(0.072)\end{array}$ & & \\
\hline Counties Squared & & $\begin{array}{c}0.009^{\star * *} \\
(0.002)\end{array}$ & & \\
\hline Upper Chamber Seats x Counties & & & $\begin{array}{c}-0.037^{\star \star *} \\
(0.004)\end{array}$ & \\
\hline Upper Chamber Seats x Degree of Overlap & & & & $\begin{array}{c}-0.320^{* * *} \\
(0.064)\end{array}$ \\
\hline Democrat Governor & $\begin{array}{l}31.222^{* \star} \\
(14.885)\end{array}$ & $\begin{array}{c}45.181^{* * *} \\
(14.614)\end{array}$ & $\begin{array}{l}31.149^{\star \star} \\
(14.964)\end{array}$ & $\begin{array}{c}39.010^{\star \star \star} \\
(15.025)\end{array}$ \\
\hline Population Growth Rate & $\begin{array}{c}-31.200^{* *} \\
(13.999)\end{array}$ & $\begin{array}{c}-125.321^{* * *} \\
(17.071)\end{array}$ & $\begin{array}{l}-27.952^{*} \\
(14.340)\end{array}$ & $\begin{array}{c}-40.632^{* * *} \\
(13.608)\end{array}$ \\
\hline Population (millions) & $\begin{array}{c}12.900^{* * *} \\
(1.635)\end{array}$ & $\begin{array}{c}13.044^{\star \star *} \\
(1.967)\end{array}$ & $\begin{array}{c}10.733^{\star * *} \\
(1.514)\end{array}$ & $\begin{array}{c}12.889^{\star * *} \\
(1.656)\end{array}$ \\
\hline Real Per Capita Federal Aid & $\begin{array}{c}0.875^{\star * *} \\
(0.132)\end{array}$ & $\begin{array}{c}0.620^{\star \star *} \\
(0.921)\end{array}$ & $\begin{array}{c}0.891^{* * *} \\
(0.137)\end{array}$ & $\begin{array}{c}0.811^{\star * *} \\
(0.128)\end{array}$ \\
\hline Real Per Capita Personal Income & $\begin{array}{c}107.689^{\star * \star} \\
(8.704)\end{array}$ & $\begin{array}{c}81.276^{\star \star \star} \\
(7.469)\end{array}$ & $\begin{array}{c}108.578^{\star * \star} \\
(8.695)\end{array}$ & $\begin{array}{c}105.269^{\star \star *} \\
(8.473)\end{array}$ \\
\hline Percent Young (Age 5-17) & $\begin{array}{c}17.322^{* *} \\
(8.178)\end{array}$ & $\begin{array}{l}-2.646 \\
(8.426)\end{array}$ & $\begin{array}{l}13.709^{*} \\
(8.000)\end{array}$ & $\begin{array}{c}9.857 \\
(8.644)\end{array}$ \\
\hline Percent (Age 18+) High School Graduates & $\begin{array}{c}8.894^{\star \star \star} \\
(3.366)\end{array}$ & $\begin{array}{c}10.321^{\star \star \star} \\
(3.308)\end{array}$ & $\begin{array}{c}9.008^{\star \star \star} \\
(3.462)\end{array}$ & $\begin{array}{c}8.677^{\star * *} \\
(3.322)\end{array}$ \\
\hline Percent Below Poverty Line & $\begin{array}{c}-0.202 \\
(4.104)\end{array}$ & $\begin{array}{c}3.760 \\
(4.018)\end{array}$ & $\begin{array}{l}-1.876 \\
(4.193)\end{array}$ & $\begin{array}{l}-0.563 \\
(4.014)\end{array}$ \\
\hline Population Density (pop/sq mi) & $\begin{array}{c}-0.364^{\star \star *} \\
(0.050)\end{array}$ & $\begin{array}{c}-0.221^{\star * *} \\
(0.053)\end{array}$ & $\begin{array}{c}-0.372^{\star * *} \\
(0.054)\end{array}$ & $\begin{array}{c}-0.441^{* * *} \\
(0.054)\end{array}$ \\
\hline Percent White & $\begin{array}{c}0.719 \\
(1.206) \\
\end{array}$ & $\begin{array}{l}-1.163 \\
(1.208) \\
\end{array}$ & $\begin{array}{c}-0.187 \\
(1.264) \\
\end{array}$ & $\begin{array}{c}-0.134 \\
(1.179) \\
\end{array}$ \\
\hline $\begin{array}{l}\text { Number of Observations } \\
\text { R-Squared }\end{array}$ & $\begin{array}{c}564 \\
0.803\end{array}$ & $\begin{array}{c}564 \\
0.844 \\
\end{array}$ & $\begin{array}{c}564 \\
0.798 \\
\end{array}$ & $\begin{array}{c}564 \\
0.808 \\
\end{array}$ \\
\hline
\end{tabular}

Note: All models include year and census region fixed effects. Constant and fixed effect coefficient estimates not shown. Panel-corrected standard errors in parentheses: * indicates statistical significance at the $10 \%$ level, ** at the $5 \%$ level, and $* * *$ at the $1 \%$ level. 
Table 2.7 presents these results. Column 1 shows that the variables of interest in the combined chamber size and counties model retain their sign and significance, as well as similar magnitudes. Further, the ' $k$ ' ratio is negative and statistically significant as is found by Chen and Malhotra (2007). The magnitudes in column 1 are also similar to the findings in their study. Column 2 indicates the second-order relationships from previous specifications are robust to this alternative specification as well. The same can be said for the specification which includes the interaction of counties with upper chamber seats, shown in column 3. Again, the ' $\mathrm{k}$ ' ratio is negative and significant in these specifications as well. Finally, the last column, which shows the results of the specification including the degree of overlap variable, also indicates that the inclusion of the ' $\mathrm{k}$ ' ratio does not significantly alter the results.

The results presented in Tables 2.5, 2.6, and 2.7 speak to the robustness of the empirical investigation's findings. Specifically, upper chamber size is positively related to several measures of state government spending. Likewise, the number of county governments is negatively related to spending, regardless of how it is measured. The more complex relationships detailed above also hold under a variety of dependent variables. Finally, the inclusion of the ' $k$ ' ratio in lieu of lower chamber size does not alter the results.

\subsection{Conclusion}

The influential work of Weingast, Shepsle and Johnsen (1981) predicts a positive relationship between legislative chamber size and government spending due to decreasing district tax shares and the associated increase in inefficient projects. At the same time, the work of Brennan and Buchanan (1977, 1978, 1980) posits a negative relationship between the number of sub-state governments and total spending due to increases in intergovernmental competition. While 
extensive work has been devoted to testing these theories independently, a model unifying these effects has not yet been developed. This paper presents and empirically tests such a model.

The extent to which an increase in the level of intergovernmental competition affects government spending is a function of the relationship between legislature size and the number of sub-state governments. If an increase in the number of sub-state governments (and associated increase in the level of competition) implies an increase in the number of legislative districts as well (in other words, the link between legislature size and the number of counties is strong) the effect predicted by the Leviathan hypothesis is lessened. This lessening effect is caused by the positive relationship between legislature size and total spending. In the extreme case where the link is very strong, increases in the number of sub-state governments may actually lead to increases in spending as the associated increase in legislature size more than offsets the effects of intergovernmental competition.

The empirical findings support the unified model. While the effect of an increase in intergovernmental competition is negative when tested separately, once the relationship between legislature size and the number of county governments is included the effect is weakened. Specifically, I employ a variety of additional empirical definitions for the relationship, ranging from an interaction between seats in the upper chamber with the number of counties to a degree of overlap measure. In each case, the predicted weakening of the Leviathan hypothesis is clearly evident. The results are also robust to several different measures of spending and the inclusion of the Chen and Malhotra (2007) 'k' ratio.

These results have serious implications for the study the effects of legislature size and fiscal decentralization on government size. By ignoring the interplay between the Law of $1 / n$ and intergovernmental competition effects, previous studies have likely overestimated the 
positive relationship between legislature size and spending as well as underestimated the negative relationship between the number of sub-state governments and total expenditure. At the very least, the present paper provides a plausible explanation for the rather inconsistent results of previous tests of the Leviathan hypothesis. Further, the above results and discussion confirm the uniqueness of the lower legislative chamber found by previous studies indicating the need for further research on bicameralism in the vein of Chen and Malhotra (2007).

Finally, this paper has important policy implications. Any attempts to reform government which target total expenditure need to consider the effects of the structure of both the lower level governments as well as the legislature. While fiscal decentralization may be an “objective for constitutional reform," as in Buchanan (1995), it may not necessarily lead to smaller government in cases where it corresponds to a larger upper chamber in the legislature. At the same time, the increased distributive politics which characterize larger legislatures may not be as problematic in states exhibiting a high degree of intergovernmental competition. Future work on 'optimal' government structure will do well to consider the counterbalancing effects of the Law of $1 / \mathrm{n}$ and Leviathan theories. 


\section{Chapter 3}

\section{Does Fiscal Decentralization Constrain Leviathan? New Evidence from Local Property Tax Competition}

\subsection{Introduction}

The Brennan and Buchanan $(1977,1978,1980)$ Leviathan model of government has become a mainstay of the public economics literature. In this framework, the Leviathan government's objective is to maximize its size. In the absence of any constraints, a Leviathan government will set tax rates that maximize tax revenue, and end up operating at the peak of the Laffer curve. According to the model, there are only two possible constraints on the Leviathan behavior of governments - constitutional constraints and the presence of intergovernmental competition from competing jurisdictions. $^{5}$

The related fiscal federalism/fiscal decentralization literature spins out of the Tiebout (1956) theory of intergovernmental competition. Oates (1999) describes fiscal federalism as a framework assigning different functions to the different levels of government, usually on the basis of the extent of external (or spillover) costs and benefits. While federalism describes a hierarchy of governments, its byproduct is a large number of competitive jurisdictions at lower levels. It is this 'horizontal' competition on which studies of decentralization and government size are based. As the level of competition between governmental units increases the constraint on Leviathan-type behavior grows stronger. In the extreme, competition between governments may approximate market outcomes (Dowding, John, and Biggs 1994).

\footnotetext{
${ }^{5}$ It is worth explicitly noting that Brennan and Buchanan (1980) use their model to derive the precise constitutional constraints that best limit the Leviathan power of government. Also, see Holcombe (1994) for an explanation of how constitutions serve as a substitute for mobility in constraining the Leviathan behavior of governments.
} 
A large body of literature exists that attempts to empirically examine whether the presence of intergovernmental competition constrains the Leviathan behavior of governments. This literature has used the number of local governments as a measure of fiscal decentralization, and the level of taxes or spending per capita, or as a percent of economic activity, as a measure of government size. This previous literature has examined local, state, and international data and has found mixed results. For example, Oates (1972, 1985, 1989), Forbes and Zampelli (1989), Anderson and van den Berg (1998), and Heil (1991) all find little or no impact of a larger number of governments on government size, while Zax (1989), Joulfaian and Marlow (1990), Nelson (1986, 1987), Eberts and Gronberg (1988), Grossman (1989), Marlow (1988), Shadbegian (1999), and Stansel (2006) all support the conclusion that fiscal decentralization constrains Leviathan. ${ }^{6}$ Finally, Cassette and Paty (forthcoming) show that decentralization decreases spending at the federal level while increasing expenditure at the sub-national level using data from the European Union.

In this literature, several recurrent problems have been identified that may explain the mixed nature of the findings across studies. First, both constitutional constraints and competition tend to constrain the Leviathan behavior of governments and none of these studies attempt to explicitly control for the different constitutional constraints faced by the governments in their samples. This is a significant problem for studies done using international, cross-country data as constitutions differ significantly across countries, and is also a problem (although of a lesser extent) for studies using cross-sections of U.S. states or Canadian provinces who also face

\footnotetext{
${ }^{6}$ In related studies using international data, Arikan (2004) finds that a larger number of governmental units lowers government corruption and Faguet (2004) finds that decentralization increases responsiveness to local demand for public services. Akai and Sakata (2002) find that decentralization increases the rate of economic growth, and Brueckner (2006) presents a theoretical model in which fiscal federalism leads to increased investment in human capital. Thus, these studies all implicitly support the Leviathan model in which decentralization constrains government. Dye and McGuire (1997) provide further indirect evidence in support of the Leviathan model by analyzing changes in fiscal behavior under property tax limits.
} 
different constitutional constraints. A second problem faced in previous studies is the use of measures of total government size to measure the level of competition or constraints on the government rather than data on specific tax rates and how they compare across jurisdictions or levels of government.

The third and final problem identified in this literature, the largest of the three, is that the results for single-purpose governmental units (like school districts or special governmental units offering only fire or water service) seem to be fundamentally different than the results found using traditional (multi-purpose) jurisdictions such as city, county, or national governments. For single-purpose jurisdictions the theory and evidence seem to suggest that fragmenting them into more units tends to either have no impact or a positive impact on their size [see Nelson (1987), Boyne (1992), Eberts and Gronberg (1988), Baird and Landon (1972), Chicoine and Walzer (1985), Dowding, John, and Biggs (1994), and Zax (1988)]. Once single-purpose districts are thrown out of the analysis, Nelson (1987) and others show that more decentralization clearly leads to more competitive, and smaller, governments.

In this paper we contribute to this literature using panel data on property tax rates for municipalities, counties, and school districts in Pennsylvania. By focusing on one state we are able to avoid problems with differing state or national constitutional constraints (e.g., even local property tax limit laws in the U.S. are generally imposed on a state-wide basis). While tax limits are imposed on jurisdictions in Pennsylvania, they are typically not strictly binding. ${ }^{7}$ In addition, by narrowing our focus we are able to specifically examine tax rates rather than more vague measures of overall government size, which can be misleading due to intergovernmental grants or other factors [see Grossman (1989), Marlow (1988), and Shadbegian (1999) for an argument

\footnotetext{
${ }^{7}$ For school districts, for example, additional levies above the limit are allowed to pay teachers, rent, and interest on debt. These exceptions effectively eliminate (or at least significantly reduce) the 'constitutional constraint' on taxing power (Hartman and Nelson 2000).
} 
about intergovernmental grants and collusion among governments interfering with the previous Leviathan tests]. Finally, and perhaps most importantly, we use two more recently introduced measures of the competitiveness of governmental units that are becoming widely used, but are not fully understood in terms of how they compare or what they exactly measure. In particular, our measures are: (1) a Laffer-curve based estimate of the extent to which the current tax rate compares to the rate that would maximize tax revenue, and (2) an estimate of spatial dependence across jurisdictions $(\rho)$ that measures the correlations across geographic space in the setting of tax rates.

Our study differs from the previous federalism/Leviathan literature in that we model and empirically test the mechanism through which federalism limits Leviathan. Likewise, we extend the intergovernmental competition literature by providing empirical evidence on its implications for the size of government. In sum, this paper combines the Leviathan, federalism, and government competition literatures into one concise framework based on two models.

Using the Laffer-curve framework, we find that local Pennsylvania jurisdictions do indeed set tax rates below the Leviathan revenue-maximizing levels, and that the more prevalent (and thus more competitive) municipal governments operate further below their revenuemaximizing rates than do less prevalent (and thus less competitive) county governments. In addition, using spatial econometric methods we find that the level of spatial dependence among tax rates is higher (and thus more competitive) among municipal governments than among county governments. Therefore, both measures point to the conclusion that more fiscal decentralization, as measured by a larger number of governments in a given geographic area, leads to a weakened ability for governments to achieve Leviathan outcomes. 
Our results for Pennsylvania school districts, which differ in that they are single-purpose jurisdictions, are even more interesting. Our results confirm the idea from the previous literature that single-purpose governments differ. We find that school districts, which are more prevalent than county governments, but less prevalent than municipal governments, do not fall in the middle in our measures of Leviathan tax rate setting and spatial dependence as expected. Instead, school districts seem to be the closest to achieving Leviathan, revenue-maximizing, tax rates (suggesting they are the least competitive) while they have the highest degree of spatial dependence among their tax rates (suggesting, oppositely, that they are the most competitive). This result highlights the fact that the more modern measure of spatial dependence as an estimate of intergovernmental competition that is becoming widely used in the literature may fail to truly measure the level of intergovernmental competitiveness. In fact, a high level of spatial dependence in tax rates could be either a sign of competition or its opposite, collusion, as collusive behavior also results in high interdependence in the setting of tax rates. We further delve into this result for school districts by attempting to uncover whether it is their singlepurpose nature that causes this odd result, along the lines of Nelson (1987) and Eberts and Gronberg (1988), or instead whether this result is due to collusive behavior among school districts similar to that described by Grossman (1989), Marlow (1988), and Shadbegian (1999). Based on these findings, we propose a new taxonomy that classifies governmental behavior in one of four possible types, and shows the necessity of relying on more than the single measure of spatial dependence to determine the competitiveness of governments.

Taken together, our results provide compelling evidence that fiscal decentralization does constrain Leviathan behavior, and that measures of spatial dependence in tax rates are likely imperfect measures of intergovernmental competition in the face of collusive behavior and/or 
single-purpose jurisdictions, relative to measures based on Laffer-curve estimates of how close governments are to achieving revenue maximization.

\subsection{Data}

We use a panel of annual data on property tax rates and tax revenue for all levels of local governments in Pennsylvania from 1995 through 2005 to empirically estimate our models. Our unique data set includes three distinct levels of government: municipalities, school districts, and counties. In total there are 2,522 municipalities, 501 school districts, and 66 counties in our sample. Based on the fiscal decentralization literature one would expect that municipalities would be the most competitive (as they are the most numerous), while counties would be the least (as they are the least numerous), with school districts somewhere in the middle. ${ }^{8}$

While we are able to use the full sample for our Laffer-curve type estimates of how close each government's tax rate is to the revenue-maximizing level, our spatial dependence measures require the estimation of a balanced panel. Our balanced panel consists of 1,730 municipalities, 58 counties, and 500 school districts for the ten-year period 1995-2004. To ensure that the differences in the estimates from the two different approaches were not driven by the different samples, we estimate our Laffer-curve type model on both the balanced and unbalanced panels. Descriptive statistics for all variables used in our paper are found in Appendix 3.1.

For county and municipal governments we obtain property tax rates from the Pennsylvania Department of Community and Economic Development's Municipal Statistics data. The tax rates used in this study are millage rates, expressed as taxes paid on each $\$ 1,000$ of assessed value. The rate at which property is assessed relative to its market value varies by

\footnotetext{
${ }^{8}$ While this is the view taken in the majority of the literature, Epple and Zelenitz (1981) present a theoretical model which shows that increasing the number of jurisdictions does not necessarily completely eliminate governmental inefficiency.
} 
county and year. We use the 'common-level ratio' (CLR) computed by the Pennsylvania State Tax Equalization Board to adjust for this. Our definition of the effective tax rate is thus the product of the statutory tax rate and its corresponding CLR (the rate at which property is assessed relative to its market value). Per-capita property tax revenue is also obtained from the Municipal Statistics data and we adjust it for inflation using the Consumer Price Index (CPI).

School district property tax rates and revenues are from the Pennsylvania Department of Education. Differences in assessment rates are again corrected for using data from the State Tax Equalization Board. The computation of annual revenue on a per capita basis for school districts, however, is not possible because unlike municipal and county populations, which are available annually, school district population is only available once per decade in census data. We therefore employ two measures. First, the number of students in each school district is available annually, so we can compute property tax revenue per student. Second, as a check for robustness, we also estimate annual school district population to compute property tax revenue per capita (rather than per student) by assuming the ratio of school district-to-county population remains unchanged and then using annual county level population changes to extrapolate annual changes in population within school districts starting from the true 2000 census school district population.

\subsection{Laffer Curves and Leviathan: Theoretical Model}

The Laffer curve shows the inverted U-shaped relationship that exists for a government between the tax rate it sets and the tax revenue it receives [see, for example, Laffer (2004)]. Tax revenues are the smallest at either very low or very high tax rates, and are at their maximum somewhere in between. This tax rate that maximizes tax revenue is the rate a Leviathan government would set 
in the absence of constitutional constraints or intergovernmental competition. Mathematical models of this relationship, used by Brennan and Buchanan (1980), Garrett (2001), Sobel (1999), and others, allow the empirical estimation of the tax rate that maximizes tax revenue for a government. This revenue-maximizing rate can then be compared to the actual tax rates to derive a measure of the extent to which a government is able to achieve its Leviathan goals. The further the current tax rate is below the revenue-maximizing tax rate, the more the government is being constrained by either formal constitutional constraints or by intergovernmental competition.

This methodology has been used extensively in the literature, and we specifically follow Garrett (2001) and Sobel (1999) in developing a Leviathan model that can be subsequently estimated on our data. For government $i$ at time $t$, total tax revenue, $R_{i t}$ is given by the product of the tax rate $\left(\tau_{i t}\right)$ and the level of the tax base, $B_{i t}$. The tax base is a function of the tax rate in that higher rates lower the quantity of the tax base, thus necessitating a functional form of $B_{i t}\left(\tau_{i t}\right)$ for the tax base to show that it is a function of the tax rate. ${ }^{9}$

$$
R_{i t}=\tau_{i t} B_{i t}\left(\tau_{i t}\right)
$$

A first-order linear approximation of the impact of the tax rate on the tax base can be given by:

$$
B_{i t}=\alpha+\beta \tau_{i t}
$$

where $\alpha>0$ and $\beta<0$. Substituting (2) into (1) yields:

$$
R_{i t}=\alpha \tau_{i t}+\beta \tau_{i t}^{2}
$$

The Leviathan revenue-maximizing tax rate is then found by differentiating (3) with respect to $\tau_{i t}$ and solving the first-order condition:

\footnotetext{
${ }^{9}$ Consistent with other models of taxation in a federal system, see for example Sobel (1997), we model each level of government as setting tax rates holding constant the rates of the other levels of government.
} 


$$
\partial R_{i t} / \partial \tau_{i t}=\alpha+2 \beta \tau_{i t}=0
$$

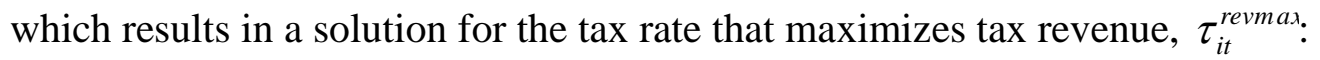

$$
\tau_{i t}^{\text {revmax }}=-\frac{\alpha}{2 \beta}
$$

An unconstrained Leviathan government seeking to maximize revenue will set its tax rate equal to the one shown in Equation (3.5). ${ }^{10}$ Thus, an approximation for the degree to which a government is able to achieve this Leviathan outcome can be measured as the ratio of their current tax rate, $\tau_{i t}$, to the revenue-maximizing rate, $\tau_{i t}^{\text {revmas. }}$. This relationship, which we dub the 'Leviathan ratio,' is thus given by:

$$
\text { LeviathanRatio }=\frac{\tau_{i t}}{\tau_{i t}^{\text {revmax }}}
$$

In theory this Leviathan ratio should take on values between zero and one with higher values indicating less competitive behavior. ${ }^{11}$ The Leviathan ratio will take the value of one if the government is currently achieving revenue maximization, while it will be less than one (but greater than zero) if it is not. The lower is this ratio, the more the government is being constrained from reaching its Leviathan goals.

Empirically, this revenue-maximizing tax rate to which the actual tax rate is to be compared can be found by first estimating the revenue equation given in (3.3) to obtain the values of $\alpha$ and $\beta$ necessary to compute the revenue-maximizing rate using Equation (3.5). Including cross-section $\left(Z_{i}\right)$ and time-period $\left(Y_{t}\right)$ fixed effects as well as an error term yields the equation to be estimated:

\footnotetext{
${ }^{10}$ Our empirical model focuses only on property tax rates and revenue and does not consider other types of optional taxes or usage fees.

${ }^{11}$ A value greater than one is mathematically possible, but would suggest the government is setting a rate above the revenue-maximizing rate, in the 'prohibitive range' of the Laffer curve.
} 


$$
R_{i t}=\alpha \tau_{i t}+\beta \tau_{i t}^{2}+\mu_{1} Z_{i}+\mu_{2} Y_{t}+\varepsilon_{i t}
$$

where $R_{i t}$ is empirically measured as real per capita tax revenue to adjust for inflation and jurisdiction size.

\subsection{Laffer Curve Results}

We estimate Laffer-curve models for each level of local government independently. Our Laffercurve estimates are summarized in Table 3.1. The coefficients for both effective tax rate and effective tax rate squared are statistically significant in all three specifications and have signs consistent with our model, with $\alpha>0$ and $\beta<0$.

\section{Table 3.1: Laffer Curve Models}

\begin{tabular}{|c|c|c|c|}
\hline \multicolumn{4}{|c|}{ Dependent Variable: Real Per Capita Property Tax Revenue } \\
\hline & Municipality & County & School District \\
\hline Years & $1995-2005$ & $1995-2004$ & $1995-2005$ \\
\hline Effective Property Tax Rate $(\alpha)$ & $\begin{array}{c}6.576 * * * \\
(6.723)\end{array}$ & $\begin{array}{c}32.293 * * * \\
(6.138)\end{array}$ & $\begin{array}{c}276.143 * * * \\
(28.515)\end{array}$ \\
\hline Effective Property Tax Rate Squared ( $\beta$ ) & $\begin{array}{c}-0.094 * * * \\
(-4.794)\end{array}$ & $\begin{array}{c}-1.280^{* *} \\
(-2.094)\end{array}$ & $\begin{array}{c}-3.458 * * * \\
(-17.417)\end{array}$ \\
\hline Calculated Revenue-Maximizing Rate $(\alpha /-2 \beta)$ & 35.12 & 12.62 & 39.93 \\
\hline Number of Observations $(\mathrm{N}, \mathrm{T})$ & $26391(2522,11)$ & $649(66,10)$ & $5511(501,11)$ \\
\hline R-squared & 0.90 & 0.92 & 0.98 \\
\hline
\end{tabular}

Note: All models include cross-section and time period fixed effects. t-statistics in parentheses: $*$ indicates statistical significance at the $10 \%$ level, $* *$ at $5 \%, * * *$ at $1 \%$.

The third row of Table 3.1 includes the estimated revenue-maximizing rate, calculated in accordance with Equation (3.5). The estimated revenue-maximizing effective property tax rate is 35.12 mills for municipalities, 12.62 mills for counties, and 39.93 mills for school districts.

As detailed in Sobel (1999) and Garrett (2001), these point estimates of the revenuemaximizing rates found by taking the ratio of the two coefficient estimates are not actually the 
true 'best' estimates as they ignore the covariance between the estimates of $\alpha$ and $\beta$. That is, the expected value of the ratio of two coefficients is not identical to the ratio of the expected values of each individual coefficient. To account for this, we follow the procedure used in Sobel (1999) and originally described by Jeong and Maddala (1993) of using Monte Carlo simulations based on the point estimates and covariance matrices of each jurisdiction to compute empirical distributions of the estimated revenue-maximizing tax rates. The means of these distributions, along with the associated $90 \%$ and $95 \%$ confidence intervals are summarized in Table 3.2. These rates provide a more accurate approximation of the revenue-maximizing rates for each jurisdiction. The municipality and school district simulation estimates are nearly identical to the original regression estimate, while the county rate taken from the empirical distribution is higher.

To analyze how close jurisdictions are coming to behaving like revenue-maximizing Leviathans, we compare actual tax rates to our simulation estimates by computing the Leviathan ratio given in Equation (3.6). Simply comparing these estimated revenue-maximizing rates with the average rates set by each level of government suggests that, on average, all levels set tax rates well below revenue-maximization. The average municipality in our sample has an effective tax rate set at only $5 \%$ of the revenue-maximizing rate. Similarly, the average county sets a rate equal to $24 \%$ of revenue maximization. Interestingly, school districts set rates nearest to revenue-maximization, with the average district tax rate $53 \%$ of the Leviathan rate. Thus, using these ratios to infer about the relative Leviathan abilities of the different levels of government would imply that municipalities are the most competitive and least able to achieve Leviathan goals, followed by counties, with school districts as the least competitive and closest to achieving the Leviathan outcome of unconstrained revenue maximization. 
Table 3.2: Revenue-Maximizing Tax Rates

\begin{tabular}{|c|c|c|c|}
\hline & Municipality & County & School District \\
\hline $\begin{array}{l}\text { Revenue-Maximizing Tax Rate: Regression } \\
\text { Point Estimate }(\alpha /-2 \beta)\end{array}$ & 35.12 & 12.62 & 39.93 \\
\hline $\begin{array}{l}\text { Revenue-Maximizing Tax Rate: Monte Carlo } \\
\text { Simulation Estimate of Mean of the Empirical } \\
\text { Distribution }\end{array}$ & 35.71 & 14.41 & 39.99 \\
\hline Lower $90 \%$ Confidence Interval & 29.95 & 8.61 & 38.43 \\
\hline Upper $90 \%$ Confidence Interval & 43.75 & 34.52 & 41.72 \\
\hline Lower 95\% Confidence Interval & 29.03 & 8.04 & 38.19 \\
\hline Upper 95\% Confidence Interval & 46.18 & 51.74 & 42.11 \\
\hline \multicolumn{4}{|c|}{ Number of Observations } \\
\hline Number $<90 \%$ CI & 26388 & 649 & 5486 \\
\hline Number within $90 \%$ CI & 4 & 0 & 20 \\
\hline Number $>90 \%$ CI & 3 & 0 & 5 \\
\hline Number $<95 \%$ CI & 26388 & 649 & 5482 \\
\hline Number within $95 \%$ CI & 4 & 0 & 24 \\
\hline Number $>95 \%$ CI & 3 & 0 & 5 \\
\hline \multicolumn{4}{|c|}{ Percentage of Observations } \\
\hline$\%<90 \% \mathrm{CI}$ & $99.97 \%$ & $100.00 \%$ & $99.55 \%$ \\
\hline$\%$ within $90 \% \mathrm{CI}$ & $0.02 \%$ & $0.00 \%$ & $0.36 \%$ \\
\hline$\%>90 \% \mathrm{CI}$ & $0.01 \%$ & $0.00 \%$ & $0.09 \%$ \\
\hline$\%<95 \% \mathrm{CI}$ & $99.97 \%$ & $100.00 \%$ & $99.47 \%$ \\
\hline$\%$ within $95 \% \mathrm{CI}$ & $0.02 \%$ & $0.00 \%$ & $0.44 \%$ \\
\hline$\%>95 \% \mathrm{CI}$ & $0.01 \%$ & $0.00 \%$ & $0.09 \%$ \\
\hline \multicolumn{4}{|c|}{ Leviathan Ratio: Ratio of Actual to Revenue-Maximizing Tax Rate } \\
\hline Mean Actual Tax Rate & 0.05443 & 0.24152 & 0.53291 \\
\hline Mode Actual Tax Rate & 0.03193 & 0.21867 & 0.47263 \\
\hline
\end{tabular}

Note: The regression point estimate is based on a calculation using the coefficient estimates from the model, a nonlinear combination of expected values; the mean of the empirical distribution is the expected value of the nonlinear combination, which differs because of the covariance between the coefficient estimates. Estimates are derived from 3,000 Monte Carlo simulations. Because of the skewness of the distributions, the upper and lower confidence ranges were switched appropriately (see Hall (1992); Jeong and Maddala (1993)).

These averages, however, can mask differences across jurisdictions. Thus, it is necessary to compare each jurisdiction's tax rate individually against the estimated revenue-maximizing 
rate. In addition, with our estimated Monte Carlo distributions we can ask whether the rates set by any given jurisdiction are significantly below the revenue-maximizing rate. All 649 county observations lie below the revenue-maximizing rate, and outside of the associated confidence interval. Overall, $99.97 \%$ of municipalities have tax rates below those that would maximize revenue with only 7 of the 26,388 observations lying either within or above the confidence interval. School districts have the highest percentage of jurisdictions within or above the confidence interval of revenue maximization, but still have $99.55 \%$ of observations falling below the Leviathan rate.

Figure 3.1: Relative Frequency Distribution: Leviathan Ratio

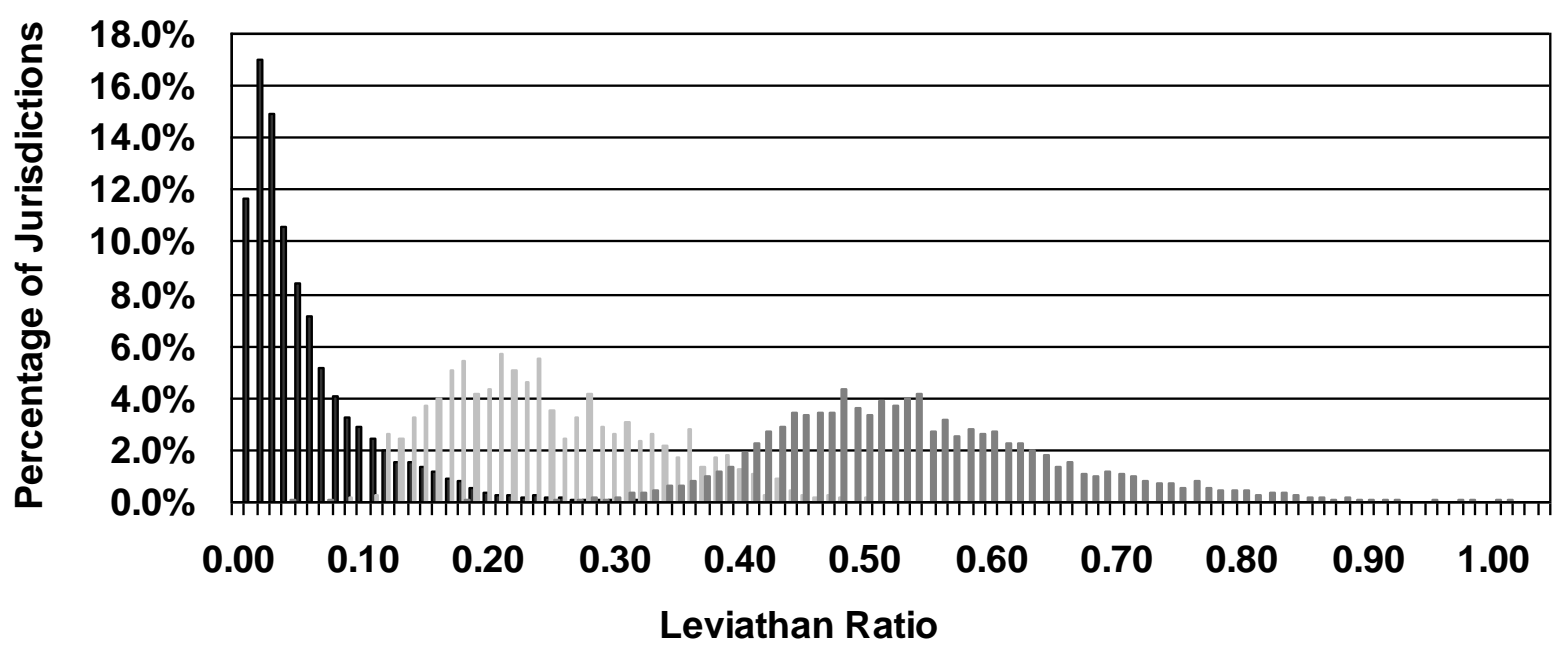

Municipality

County School District

Figure 3.1 shows the relative frequency distribution of the Leviathan ratio for each individual local government for all three levels of government. The distribution for municipalities shows that they are clearly the furthest from achieving revenue maximization, followed by counties, with school districts being the closest to maximizing revenues. As is visible in Figure 3.1, some school districts actually approach a Leviathan ratio of 1, implying that they are coming close to true Leviathan revenue maximization. 
The results from this Laffer-curve based estimation suggest that municipalities are indeed more competitive than counties, or alternatively, that counties are closer to achieving Leviathan outcomes than municipalities. With municipalities numbering much greater than counties, this is consistent with the idea that greater decentralization, measured by a greater number of local governments, leads to more intergovernmental competition, and a lessened ability of governments to achieve Leviathan goals. School districts, on the other hand, do not fit this model, as they seem to be more able to achieve Leviathan goals than counties even though they are more numerous. Simply based on the number of governments, one would have expected the Leviathan ratios for school districts to fall somewhere between those for municipalities and counties. We revisit this issue after presenting our results of competitiveness based on spatial dependence in tax rates.

\subsection{Spatial Competition and Interdependence: Theory}

Following the tradition of Tiebout (1956), a number of studies have attempted to model and empirically test strategic interaction across competing jurisdictions. Inter-jurisdictional tax competition has theoretical foundations in Mintz and Tulkens (1986), Oates and Schwab (1988), Kanbur and Keen (1993), and Brueckner (2000). Brueckner (2003) provides a survey of the empirical methodologies employed in these types of studies. Typically, the empirical specifications are based on policy best response functions derived from models assuming a mobile factor. One such paper by Brueckner and Saavedra (2001) finds evidence of strategic property-tax competition in a sample of Boston metropolitan jurisdictions. Other tax competition studies based on this reaction function approach include Hayashi and Boadway (2001), Buettner (2001), and Brett and Pinkse (2000). 
These models generally assume a mobile factor for which governments compete through setting of tax or expenditure policy. ${ }^{12}$ Since the factor's choice of location depends both on the policy of a given jurisdiction as well as the policy in competing jurisdictions, each government's policy is a function of its neighbors' policies. Note that this intergovernmental competition for the factor provides a theoretical explanation for the inverse relationship between tax base and rate shown in Equation (3.2). Once the optimal policy as a function of exogenous variables is derived for a given jurisdiction's neighbors, its best-response function may be obtained.

We follow Brueckner and Saavedra (2001) who derive an empirical version of jurisdictions' reaction functions for property taxation:

$$
\tau_{i}=\rho \sum_{j \neq i} \omega_{i j} \tau_{j}+X_{i} \beta+\varepsilon_{i}
$$

where $\tau_{i}$ is the effective property tax rate in jurisdiction $i, \varepsilon_{i}$ is a vector of error terms, and $\rho \sum_{j \neq i} \omega_{i j}$ is a weighting scheme that determines how neighboring jurisdictions' tax rates influence jurisdiction $i$ 's policy. The vector $X_{i}$ is made up of demographic and policy variables for jurisdiction $i$ which also affect the effective tax rate. The policy variables account for factors which directly impact the choice of $\tau_{i}$ while the demographic characteristics proxy for the preferences of consumer-voters. The weighting parameters $\omega_{i j}$ are chosen arbitrarily to quantify 'neighboring' jurisdictions. Traditionally, weight matrices have been based on contiguity or some function of distance [see LeSage and Pace (2009)]. Our initial analysis uses a contiguity

\footnotetext{
${ }^{12}$ Papke (1991) presents empirical evidence in support of this assumption by showing that new firm births in a given state are negatively related to effective business tax rates.
} 
weight matrix while additional specifications are explored as a test for robustness in a subsequent section of the paper. ${ }^{13}$

When Equation (3.8) is extended to account for multiple time periods, it can be expressed as the panel model:

$$
\tau_{i t}=\rho \sum_{j \neq i} \omega_{i j} \tau_{j t}+X_{i t} \beta+Z_{i}+Y_{t}+\varepsilon_{i t}
$$

with $\mathrm{Z}_{i}$ and $Y_{t}$ again representing cross-section and time-period fixed effects. Once all jurisdictions are considered, and represented as vectors, Equation (3.9) can be represented as

$$
\tau_{t}=\rho W \tau_{t}+X_{t} \beta+\mu+\varepsilon_{t}
$$

where $\tau_{t}$ is the vector of effective property tax rates such that $\tau_{t}=\left(\tau_{1 t}, \ldots, \tau_{N t}\right), X_{t}=\left(X_{1 t}, \ldots, X_{N t}\right)$, $\varepsilon_{t}=\left(\varepsilon_{1 t}, \ldots, \varepsilon_{N t}\right), W$ the spatial weight matrix, and $\mu$ a matrix of time and cross-section fixed effects. The weight matrix is made up of elements $\omega_{\mathrm{ij}}$ from Equation (3.7) and zeroes on the main diagonal. Since the geographic arrangement of jurisdictions does not change, the elements of $W$ are time invariant. As before, the inclusion of fixed effects accounts for omitted variables which are invariant either through time or across space. Further, as noted by Elhorst and Fréret (forthcoming) time-period fixed effects help correct for spatial interaction in the error term.

Equation (3.10) is the spatial autoregressive (SAR) model to be estimated using maximum likelihood techniques. ${ }^{14}$ The parameter of interest is $\rho$ which measures the degree of spatial dependence. If governments are in competition with one another, one would anticipate a positive dependence among their tax rates. When one jurisdiction lowers its rates, nearby

\footnotetext{
${ }^{13}$ Contiguity at the county level is first-order queen. School district and municipality contiguity is based on Delaunay triangles using latitude/longitude coordinates. Specifically, we use the 'xy2cont' function for MatLab from James P. LeSage's spatial econometrics toolbox.

${ }^{14}$ Specifically, we use the "sar_panel_FE" function for MatLab written by J. Paul Elhorst. A full treatment of the estimation technique can be found in Elhorst (2009). To calculate the total effect estimates (LeSage and Pace 2009) we use an updated version of the routine written by Donald Lacombe and available at http://www.rri.wvu.edu/lacombe/ lacombe.htm.
} 
governments must lower tax rates as well to remain competitive. The larger is the degree of spatial dependence $(\rho)$ the greater is the degree of competition. A value of zero would imply that governments act independently, either due to an absence of true competition or the presence of strict constitutional constraints that, for example, set tax rates at fixed levels.

In the estimation of Equation (3.10), we include additional socio-economic variables similar to Brueckner and Saavedra (2001), with some variation due to data availability. These extra control variables are real per-capita expenditure, real median household income, the proportion of the population that is African American, the student proportion of the population, real per-capita state and federal grants, population, and population density. Per-capita expenditure is collected from the Municipal Statistics data for counties and municipalities and the National Center for Education Statistics (NCES) for school districts. One problem with including expenditures as an independent variable in determining tax rates is the possibility that they are endogenous in that tax rates actually determine expenditures. To keep with the existing literature we include expenditures with a lag. However, in our robustness tests (detailed in Section 7), we estimate the model omitting this variable and find similar results. The expected sign for expenditure is positive as jurisdictions will set higher rates, ceteris paribus, as their expenditure needs grow. Data for state and federal grants is also obtained from Municipal Statistics for counties and municipalities, and from NCES for school districts. As grants increase we would expect to see a fall in effective tax rates. As before, these variables are adjusted for inflation using the Consumer Price Index (CPI). Finally, population data comes from the Municipal statistics for counties and municipalities and the NCES for school districts.

Data for median household income, the proportion African American, the proportion student-aged among the population, and population density are all obtained from Census 
estimates at the county level. For the municipality and school district models these county variables are considered reasonable proxies for jurisdictional characteristics. The expected sign for income is negative since higher incomes likely translate into higher property values which means the same level of public goods can be provided by the jurisdiction at lower rates, ceteris paribus. The proportion of the population that is African American captures any differences in demand for policy that results from larger minority populations. Similarly, population density captures differences in tax policy resulting from the urban/rural characteristics of the jurisdiction. Finally, as the student percentage of the population increases we would expect to see higher tax rates as the demand for services increases.

\subsection{Spatial Dependence Results}

Our spatial autoregressive (SAR) model estimates are summarized in the first three columns of Table 3.3 (the final column is a robustness check to be discussed in the next section). The models fit well, with R-squared measures of $0.71,0.89$, and 0.92 . We find positive, statistically significant spatial dependence at all three levels of local government. This indicates jurisdictions of all types base a portion of their tax policy on the policy of their neighbors - that is, there is spatial competition between jurisdictions, the extent of which differs across government levels. The estimates shown for the explanatory variables are the total effect estimates (which include direct and indirect effects), following LeSage and Pace (2009). 
Table 3.3: Spatial Autoregressive Models

\begin{tabular}{|c|c|c|c|c|}
\hline \multicolumn{5}{|c|}{ Dependent Variable: Effective Property Tax Rate, 1995-2004 } \\
\hline & Municipality & County & School District & School District (Alternate) \\
\hline \multirow[t]{2}{*}{ Rho (Spatial Dependence) } & $0.201 * * *$ & $0.155 * * *$ & $0.544 * * *$ & $0.528 * * *$ \\
\hline & $(77.162)$ & $(2.804)$ & $(33.461)$ & $(31.804)$ \\
\hline \multirow[t]{2}{*}{ Real Per Capita Expenditure (Lagged) } & -0.002 & $0.685 * *$ & $0.228 * * *$ & $1.297 * * *$ \\
\hline & $(-0.783)$ & $(2.546)$ & $(7.481)$ & $(7.082)$ \\
\hline \multirow[t]{2}{*}{ Real Median Household Income } & $-0.006 * *$ & $-0.011 * *$ & $-0.021 * *$ & $-0.021 * *$ \\
\hline & $(-2.084)$ & $(-2.309)$ & $(-2.327)$ & $(-2.414)$ \\
\hline \multirow[t]{2}{*}{ Proportion African American } & -0.440 & -3.656 & $18.141 * * *$ & $20.871 * * *$ \\
\hline & $(-0.180)$ & $(-0.958)$ & $(4.584)$ & $(5.542)$ \\
\hline \multirow[t]{2}{*}{ Proportion Student } & 0.280 & 2.422 & $12.539 * *$ & $13.170 * *$ \\
\hline & $(0.170)$ & $(0.729)$ & $(2.190)$ & $(2.423)$ \\
\hline \multirow[t]{2}{*}{ Real Per Capita State \& Federal Grants } & 0.053 & $-1.279 * * *$ & $-0.313 *$ & $-5.632 * * *$ \\
\hline & $(0.500)$ & $(-3.067)$ & $(-1.838)$ & $(-5.373)$ \\
\hline \multirow[t]{2}{*}{ Population } & -0.014 & $0.036 * * *$ & $1.802 * * *$ & $0.287 * * *$ \\
\hline & $(-0.680)$ & $(3.373)$ & $(8.259)$ & $(5.526)$ \\
\hline \multirow[t]{2}{*}{ Population Density } & 0.001 & -0.022 & $0.009 * * *$ & $0.010 * * *$ \\
\hline & $(1.400)$ & $(-3.484)$ & $(3.440)$ & $(4.059)$ \\
\hline Number of Observations $(\mathrm{N}, \mathrm{T})$ & $17300(1730,10)$ & $580(58,10)$ & $5000(500,10)$ & $5000(500,10)$ \\
\hline R-squared & 0.71 & 0.89 & 0.92 & 0.92 \\
\hline
\end{tabular}

Note: All models include cross-section and time period fixed effects; estimates for constant and fixed effect coefficients not shown. t-statistics in parentheses: * indicates statistical significance at the $10 \%$ level, ** at 5\%, *** at $1 \%$. Total effect estimates [direct plus indirect effects, see LeSage and Pace (2009)] shown for explanatory variables.

Our point estimates indicate that counties in our sample exhibit less spatial dependence (0.155) than do municipalities (0.201), implying they are facing weaker competitive forces.

Alternatively stated, municipalities appear less able to achieve Leviathan goals than counties.

This is the same result found using the Leviathan ratio estimates in the previous section. Thus, both estimation methods appear to indicate that with a much larger number of competing governments within the given geographic area, municipalities are less able to be Leviathans than are counties. However, it is worth noting that while the point estimate of spatial dependence for municipalities is higher, it is not significantly different from the value for counties using a $t$-test. The estimate of $\rho$ for school districts (0.544) is statistically much higher than the values for either municipalities or counties, implying school districts exhibit the highest degree of 
spatial interaction. If the degree of spatial dependence measures competitiveness, then this result would seem to suggest that school districts are the most competitive, and least able to achieve Leviathan goals. Not only is this inconsistent with the ordering predicted based on the number of governments (as school districts should have fallen in between municipalities and counties), but it is the exact opposite result obtained from the Leviathan ratio estimates. Our Leviathan tax rate estimates suggested that school districts were the least competitive, and most able to achieve Leviathan goals, with their tax rates being the closest of all levels to revenue-maximization. The spatial results, however, would imply exactly the opposite. This high degree of spatial dependence, coupled with more Leviathan-like tax rates appears to be a contradiction. Whether this is due to school districts being single-purpose and thus fundamentally different, as was found in previous Leviathan literature, or whether it is a sign of collusion (which would also result in a high degree of spatial dependence, but not be reflective of competition) is something we will return to after presenting our robustness checks.

Turning to our control variables and their performance, only income is statistically significant in the municipality specification, which may indicate tax policy is set mostly as a function of neighboring policy. This is consistent with a high level of competition at the municipality level. Lagged per capita expenditure is positive and statistically significant in the county and school district models, though the coefficient is economically small. Similarly, income is negative and statistically significant in the county and school district models, with a trivially small coefficient estimate. The proportion of the population that is African American is positive and significant in the school district specification. Unsurprisingly, the proportion student variable is positive and significant in the school district model. Per capita grants are negatively related to tax rates, also as predicted. For both the county and school district 
specifications, population is positive and significant, while density is negative in the county specification and positive in the school district model.

\subsection{Robustness Checks}

To estimate the revenue-maximizing property tax rates we used unbalanced panels for each level. However, our spatial autoregressive models required balanced panels of data due to the time invariant nature of the weight matrix. As such, in order to estimate the spatial models we were forced to drop a year of data for the municipality and school district models and a number of cross-section observations at each level. To ensure that the difference between our Leviathan revenue-maximizing rate results and the spatial dependence results is not caused by the slightly different samples used in the estimations, we re-estimate our Laffer curve models using the same sample used in our spatial model. The results are presented in the first three columns of Table 3.4. Despite losing observations, the point estimates for each revenue-maximizing tax rate remain largely unchanged. Moreover, the new estimates are within the computed confidence intervals presented earlier. We also recalculate the Leviathan ratio at each level using the new point estimates. Again, the results (also shown in Table 3.4) are largely unchanged, with only the county Leviathan ratio increasing slightly but remaining well below the school district ratio. Thus, the difference in the samples is not responsible for the different results, particularly for school districts, found in our earlier specification. 
Table 3.4: Laffer Curve Models: Balanced Panel Estimates

\begin{tabular}{|c|c|c|c|c|}
\hline \multicolumn{5}{|c|}{ Dependent Variable: Real Per Capita Property Tax Revenue } \\
\hline & Municipality & County & School District & School District (Alternate) \\
\hline Years & $1995-2004$ & $1995-2004$ & $1995-2004$ & $1995-2004$ \\
\hline Effective Property Tax Rate $(\alpha)$ & $\begin{array}{c}4.828 * * * \\
(6.475)\end{array}$ & $\begin{array}{c}31.953 * * * \\
(5.718)\end{array}$ & $\begin{array}{c}259.580 * * * \\
(28.433)\end{array}$ & $\begin{array}{c}37.291 * * * \\
(20.484)\end{array}$ \\
\hline Effective Property Tax Rate Squared ( $\beta$ ) & $\begin{array}{c}-0.073 * * * \\
(-5.383)\end{array}$ & $\begin{array}{c}-1.304 * * \\
(-1.990)\end{array}$ & $\begin{array}{c}-3.148 * * * \\
(-16.713)\end{array}$ & $\begin{array}{c}-0.345 * * * \\
(-9.175)\end{array}$ \\
\hline Calculated Revenue-Maximizing Rate $(\alpha /-2 \beta)$ & 33.40 & 12.25 & 41.23 & 54.11 \\
\hline Number of Observations $(\mathrm{N}, \mathrm{T})$ & $17300(1730,10)$ & $580(58,10)$ & $5000(500,10)$ & $5000(500,10)$ \\
\hline R-squared & 0.83 & 0.91 & 0.99 & 0.97 \\
\hline
\end{tabular}

Note: All models include cross-section and time period fixed effects. t-statistics in parentheses: * indicates statistical significance at the $10 \%$ level, $* *$ at $5 \%, * * *$ at $1 \%$.

Our second robustness check involves our inability to get annual data on school district population to use in the computation of per capita measures (population at the school district level is only available in the once-per decade census numbers). In our results presented earlier we use the number of students in the school district (which is available annually) in the computation of the per capita values for school districts. Here, as a check for robustness, we estimate annual school district population to compute property tax revenue per capita (rather than per student). By assuming the ratio of school district-to-county population remains unchanged, it becomes possible to use annual county level population changes to extrapolate annual changes in population within school districts starting from the true 2000 census school district population.

The fourth column of Table 3.4 includes a Laffer curve model using the alternative measure of population for school districts discussed above. The point estimate of the revenuemaximizing tax rate using this alternative measure is much higher than that we found earlier using per-student data. The estimate of 54.11 is also high enough to lie outside of our simulated confidence intervals. Since school districts were already setting tax rates much lower than our previous estimate of revenue-maximization, this result shows school districts are even further 
below their revenue-maximizing rates than we found previously. Using this new point estimate, the average school district is setting a tax rate of only $39.38 \%$ that which would maximize estimated per-capita revenue. Though this Leviathan ratio is much lower than the previously estimated ratio of $53.29 \%$, it still remains higher than either counties or municipalities. Thus, even with this alternative measure, school districts are setting tax rates nearer to revenue maximization than either counties or municipalities.

For completeness, we also estimate our spatial autoregressive model using the alternative school district population measure. These results are shown in the last column of Table 3.3. The measure of spatial dependence remained highly statistically significant and positive with a similar magnitude. The new value of $\rho, 0.528$, remains higher and statistically different from the county or municipality estimates. The sign and significance of the independent variables does not vary between the two specifications, and all total effects are of similar magnitude.

The tax competition literature, which motivates our SAR model, is based on the assumption that some mobile factor (labor, capital, etc.) considers all neighboring tax rates when making its location choice. While this clearly implies spatial dependence in tax-setting, it also suggests the possibility that a jurisdiction's tax revenue is not only a function of its own tax rate, but also a function of neighboring rates. Thus, as a check for robustness, we re-estimate our Laffer curve models including the geographically-weighted average of neighboring property tax rates as an additional explanatory variable. This variable is constructed using the effective property tax rate multiplied by the contiguity weight matrix developed for our SAR models. Including this measure of neighboring tax rates in equation (3.2) yields

$$
B_{i t}=\alpha+\beta \tau_{i t}+\gamma \tau_{i t}^{\text {neighbo }}
$$

while the equation to be estimated becomes 


$$
R_{i t}=\alpha \tau_{i t}+\beta \tau_{i t}^{2}+\gamma\left(\tau_{i t} \times \tau_{i t}^{n e i g h b o r}\right)+\mu_{1} Z_{i}+\mu_{2} Y_{t}+\varepsilon_{i t} .
$$

Table 3.5: Laffer Curve Models: Alternative Specification

\begin{tabular}{lccc}
\hline \multicolumn{4}{c}{ Dependent Variable: Real Per Capita Property Tax Revenue } \\
\hline Years & Municipality & County & School District \\
\hline & $1995-2004$ & $1995-2004$ & $1995-2004$ \\
Effective Property Tax Rate $(\alpha)$ & $5.281^{* * *}$ & $35.387 * * *$ & $271.994 * * *$ \\
& $(7.029)$ & $(5.863)$ & $(27.033)$ \\
Effective Property Tax Rate Squared $(\beta)$ & $-0.142^{* * *}$ & $-1.225^{*}$ & $-3.090^{* * *}$ \\
& $(-7.105)$ & $(-1.866)$ & $(-16.332)$ \\
Average Neighbor Effective Property Tax Rate & $0.387^{* * *}$ & -1.075 & $-0.500^{* * *}$ \\
& $(4.706)$ & $(-1.495)$ & $(-2.924)$ \\
Calculated Revenue-Maximizing Rate $(\alpha /-2 \beta)$ & 18.62 & 14.44 & 44.01 \\
& & & \\
\hline Number of Observations $(\mathrm{N}, \mathrm{T})$ & $17300(1730,10)$ & $580(58,10)$ & $5000(500,10)$ \\
R-squared & 0.83 & 0.91 & 0.99 \\
\hline
\end{tabular}

Note: All models include cross-section and time period fixed effects. t-statistics in parentheses: * indicates statistical significance at the $10 \%$ level, ** at $5 \%, * * *$ at $1 \%$.

Table 3.5 presents the results of these specifications. The sign, significance, and magnitude of the tax rate and tax rate squared variables remain largely unchanged from our previous estimates. While the revenue-maximizing rate for municipalities is lower than in previous specifications, it is still high enough such that the average municipality has a Leviathan Ratio of only .10. Thus, municipalities remain the most heavily constrained. The statistical significance and sign of the effect of the average neighboring tax rate variable varies across jurisdiction type. At the municipality level, increases in neighboring tax rates lead to increases in property tax revenue. This is consistent with our hypothesis of highly competitive municipal governments: ceteris paribus, increases in competitor taxes likely lead to increases in the amount of tax base choosing to locate in a given municipality. At the county level, an increase in neighboring tax rates has no statistically significant effect on property tax revenue. This result 
lends credence to county governments being less competitive. Finally, school district property tax revenues fall as neighboring school districts raise rates, ceteris paribus. This result is clearly not consistent with a model of competitive jurisdictions, providing further evidence of noncompetitive behavior at the school district level. In sum, while neighboring tax rates do seem to be significant drivers of property tax revenue at the municipality and school district levels, the Laffer curve relationship predicted by our original model is robust to the inclusion of this variable.

As mentioned previously, the inclusion of lagged expenditures in our spatial autoregressive models may introduce problems of simultaneity. Thus, we estimate these models without the expenditure control as a check for robustness. These results are presented in Table 3.6. The results are nearly identical, both in terms of magnitude and statistical significance. Most importantly, the estimated level of spatial dependence does not change significantly at any level. These results provide evidence that the inclusion of expenditures in the previous specification does not bias our results. 
Table 3.6: Spatial Autoregressive Models: Alternative Specification

\begin{tabular}{|c|c|c|c|c|}
\hline \multicolumn{5}{|c|}{ Dependent Variable: Effective Property Tax Rate, 1995-2004 } \\
\hline & Municipality & County & School District & School District (Alternate) \\
\hline \multirow[t]{2}{*}{ Rho (Spatial Dependence) } & $0.199 * * *$ & $0.149 * * *$ & $0.546 * * *$ & $0.528 * * *$ \\
\hline & $(17.220)$ & $(2.681)$ & $(33.522)$ & $(31.655)$ \\
\hline \multirow[t]{2}{*}{ Real Median Household Income } & $-0.006 * *$ & $-0.011 * *$ & $-0.021 * *$ & $-0.021 * * *$ \\
\hline & $(-2.067)$ & $(-2.524)$ & $(-2.359)$ & $(-2.451)$ \\
\hline \multirow{2}{*}{ Proportion African American } & -0.402 & -4.868 & $17.381 * * *$ & $20.240 * * *$ \\
\hline & $(-0.163)$ & $(-1.289)$ & $(4.321)$ & $(5.239)$ \\
\hline \multirow[t]{2}{*}{ Proportion Student } & 0.262 & 3.700 & $11.632 * *$ & $13.996 * * *$ \\
\hline & $(0.160)$ & $(1.101)$ & $(2.082)$ & $(2.566)$ \\
\hline \multirow[t]{2}{*}{ Real Per Capita State \& Federal Grants } & 0.046 & $-1.126 * * *$ & -0.148 & $-4.720 * * *$ \\
\hline & $(0.433)$ & $(-2.775)$ & $(-0.877)$ & $(-4.529)$ \\
\hline \multirow[t]{2}{*}{ Population } & -0.014 & $0.036 * * *$ & $1.721 * * *$ & $0.286 * * *$ \\
\hline & $(-0.696)$ & $(3.416)$ & $(7.849)$ & $(5.573)$ \\
\hline \multirow[t]{2}{*}{ Population Density } & 0.001 & $-0.022 * * *$ & $0.010 * * *$ & $0.011 * * *$ \\
\hline & $(1.355)$ & $(-3.499)$ & $(3.671)$ & $(4.162)$ \\
\hline Number of Observations $(\mathrm{N}, \mathrm{T})$ & $17300(1730,10)$ & $580(58,10)$ & $5000(500,10)$ & $5000(500,10)$ \\
\hline R-squared & 0.71 & 0.89 & 0.91 & 0.91 \\
\hline
\end{tabular}

Note: All models include cross-section and time period fixed effects; estimates for constant and fixed effect coefficients not shown. t-statistics in parentheses: * indicates statistical significance at the $10 \%$ level, ** at $5 \%$, *** at $1 \%$. Total effect estimates [direct plus indirect effects, see LeSage and Pace (2009)] shown for explanatory variables.

As a final check for robustness of our spatial autoregressive model, we explore the use of different weight matrices. The weight matrix is chosen arbitrarily, so the use of alternative weighting schemes ensures our previous findings are not an artifact of the definition of 'neighbor' imposed on the model. Our previous specification (shown in Table 3.3) employed the most frequently used weight matrix, based on first-order contiguity. A popular alternative is the use of distance-based 'nearest neighbor' weight matrices. These matrices assign to each jurisdiction a common number of neighbors (based on distance) regardless of whether the jurisdictions actually share a common border, while contiguity matrices are not so constrained and count any bordering jurisdiction as a neighbor.

Table 3.7 presents results from the estimation of our SAR model using two such weight matrices. $W_{5}$ denotes a specification using a weight matrix based on five nearest neighbors, 
while $W_{7}$ denotes a weight matrix based on seven nearest neighbors. ${ }^{15}$ Spatial dependence at each level remains statistically significant and largely unchanged in terms of magnitude. The county-level $\rho$ estimate is slightly higher in the $W_{5}$ specification $(0.171)$ but still remains lower than either the municipality or school district estimates. School district spatial dependence is higher in the $W_{7}$ specification. The parameter estimates for all control variables retain the same sign and statistical significance from the previous specification.

\footnotetext{
${ }^{15}$ The determination of nearest neighbors is based on distance calculated using latitude and longitude coordinates.
} 


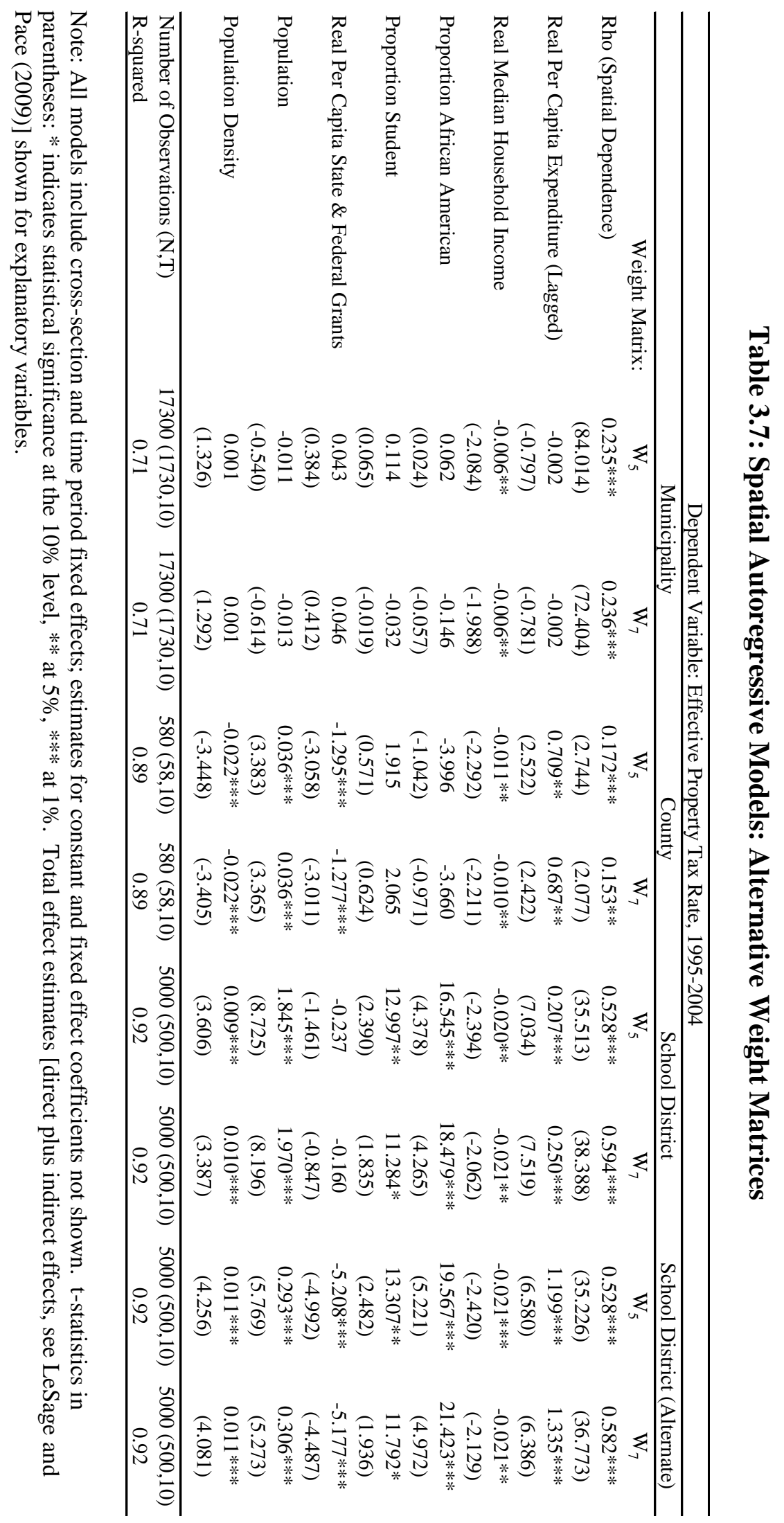




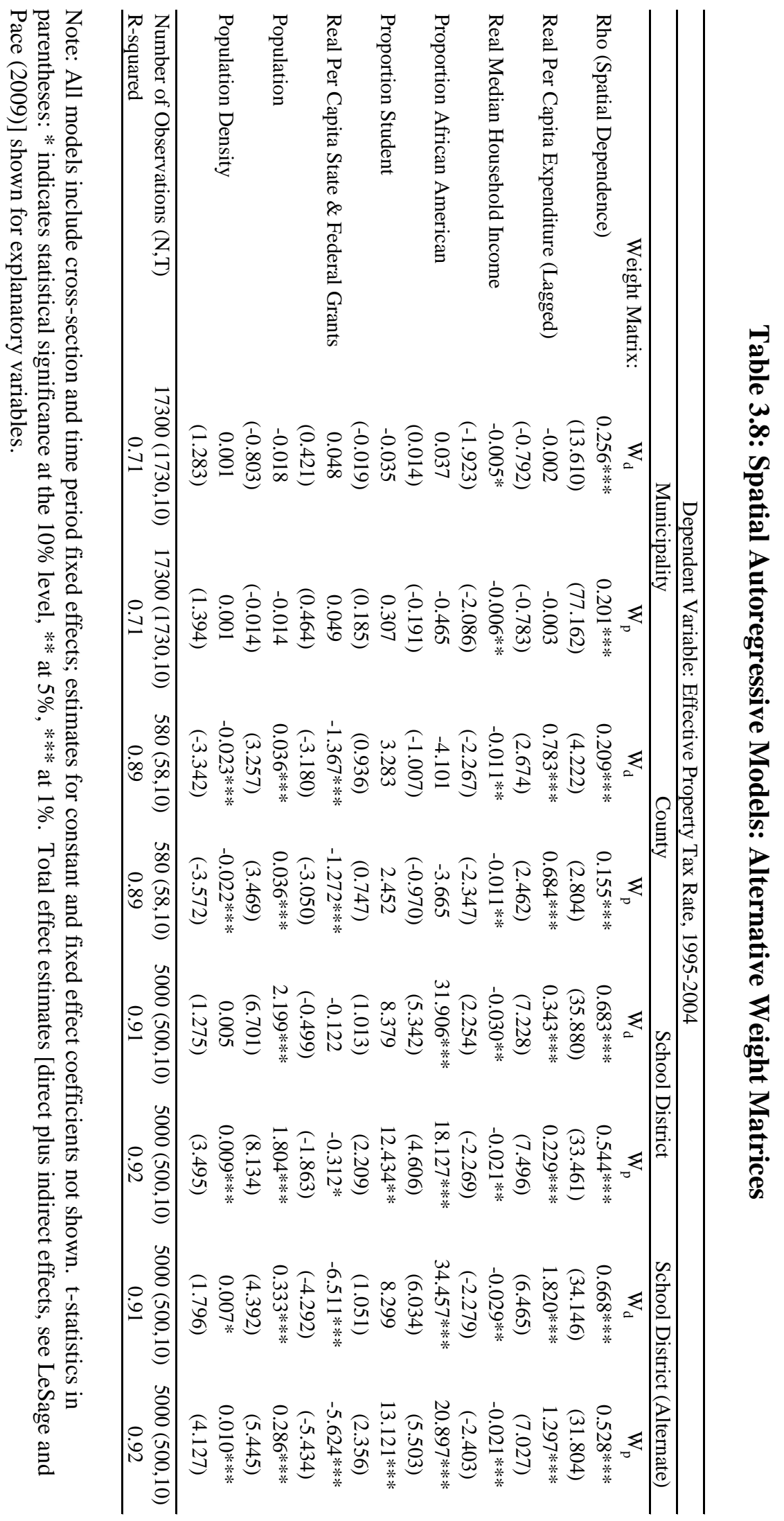


Table 3.8 presents SAR results using two more weight matrices. The $W_{d}$ specification employs a weight matrix based on distance (the nearer a jurisdiction is, the more heavily it is weighted) and allows for the possibility of jurisdictions to respond to all other jurisdictions of the same level. The $W_{p}$ weight matrix is the contiguity weight matrix used in our original specification, scaled by population. This technique, discussed in Baicker (2005), attributes more 'weight' to larger neighboring jurisdictions and is motivated by the traditional gravity model. As before, we observe few changes in our estimates of spatial dependence despite the use of these alternative weighting schemes. While the $W_{d}$ specification predicts higher dependence at the county level (0.209), it also predicts higher dependence at the municipality (0.256) and school district (0.683) levels, preserving the ordering found in our previous specifications. The population-scaled weight matrix results are largely identical to previous specifications as well. In sum, our spatial dependence results are robust to a variety of weighting specifications.

\subsection{Revisiting School Districts: Collusion vs. Single-purpose Jurisdictions}

Our results for counties and municipalities correspond to what one might have expected. There are a much larger number of municipalities $(2,522)$ than counties (66) in our data set for Pennsylvania, and based on the fiscal decentralization hypothesis, we should expect municipalities to be more competitive and thus less able to pursue Leviathan revenuemaximization goals. Our results from both our Laffer-curve, Leviathan models and the spatial dependence models showed the expected result: counties set tax rates closer to revenuemaximizing levels than do municipalities, and municipalities exhibit a higher degree of spatial dependence across jurisdictions. 
The results for school districts, however, did not fit this mold. While school districts number somewhere between the other two (501), they showed tax rates the closest to revenuemaximization (suggesting the least competitive or most Leviathan-like), but ironically they also exhibit the highest degree of spatial dependence (suggesting alternatively that they are the most competitive or least Leviathan-like). If these two measures of governmental competitiveness were measuring the same thing, one would have not expected school districts to have, simultaneously, the highest degree of spatial dependence and also tax rates closer to Leviathan levels than the other two levels of government. This leads us to one of two possible explanations for this seemingly odd result.

First, it is possible that the single-purpose nature of school districts simply causes them to be different. School districts provide a single good, while municipal and county governments provide a bundle of services. Recall that previous Leviathan literature finds that single-purpose governmental units (like school districts or special governmental units offering only fire or water service) seem to be fundamentally different than traditional (multi-purpose) jurisdictions such as city, county, or national governments. The previous literature argues that for single-purpose jurisdictions, fragmenting them into more units tends to have either no impact or a positive impact on size [see Nelson (1987), Boyne (1992), Eberts and Gronberg (1988), Baird and Landon (1972), Chicoine and Walzer (1985), Dowding, John, and Biggs (1994), and Zax (1988)].

The nature of the provision of education may have unique characteristics making school districts fundamentally different from other levels of government. While many of the services provided by municipal governments exhibit some public good characteristics, a number of these services are contracted to private providers (e.g. trash collection). This may indicate municipal 
governments are more inclined to act competitively. However, the sheer number of private schools suggests at least some quantity of education (the good provided by school districts) can be provided privately. Thus, this mix of private and public characteristics seems to exist at all levels of local government, and is not unique to school districts.

Further, even if the single-purpose jurisdiction argument were true, one would still expect our two measures to both show either high (or low) degrees of competition (which they did not), but with school districts simply not falling in between the results for counties and municipalities as predicted purely by the number of jurisdictions ordering. Thus, given school districts' divergent results on the two measures, the single-purpose jurisdiction argument can not explain our findings.

The second explanation is that the Leviathan ratio measures and the measures of spatial dependence simply do not both measure the degree of intergovernmental competition. Recall that other papers in this literature suggest that collusive behavior among governments, particularly through the use of intergovernmental grants, is important in explaining why some studies have found different results than others [see Grossman (1989), Marlow (1988), and Shadbegian (1999)]. In essence, one way governments can escape competitive pressures on tax levels is to get a higher level government to levy the taxes for them and redistribute the revenue back to the lower (colluding) level of government. This explanation is at least partially born out by the data in that state and federal grants as a share of revenue are $21 \%$ for municipalities, $30 \%$ for counties, and $45 \%$ for school districts in our sample, suggesting the highest degree of collusion among school districts.

There are several additional reasons to suspect school districts are uniquely able to engage in cooperation or collusion. First, school districts in Pennsylvania are organized under a 
single Department of Education. Further, school districts must negotiate with a single large teachers' union which has the ability to bargain for all teachers at the state level. In other words, by definition a number of costs (such as teacher salaries) are set collectively. Additionally, school districts tend to rely on the property tax as a primary source of revenue whereas other local governments have additional revenue sources available. As such, competition on property tax rates between school districts leading to a 'race to the bottom' would likely lead to serious revenue consequences as the districts do not have a ready substitute source of revenue. Finally, the state's Department of Education manages a subsidy program for "Basic Education Funding" which distributes funds to school districts based on the districts' spending relative to an 'adequacy target,' further collectivizing the fiscal decision-making of school districts (Pennsylvania Department of Education).

The problem collusion creates for the spatial dependence measure is that the intergovernmental correlations in tax rates are high not only when governments compete, but also when they collude. This fundamentally calls into question the current literature's blind use of the spatial dependence estimate as a measure of tax competition. Interestingly, while the spatial dependence measure is affected by collusion, the Leviathan ratio measure is not. Low rates relative to revenue maximization can only imply competition, not collusion. On the other hand high rates relative to the revenue-maximizing rate imply a lack of competition regardless of whether the competition is simply absent or whether it is collusive behavior that limits the competition.

As an analogy, if one were to try to measure the level of competitiveness of a private industry by examining measures of interdependence in pricing among firms, a high degree of interdependence could be a sign of either competition or collusion. To know the difference 
requires knowledge, for example, of how much prices are marked up over marginal cost (a similar measure to our Leviathan ratio).

To better understand our argument, Figure 3.2 shows a four quadrant diagram depicting the four possible pairings of measures from the spatial dependence measure and the Leviathan ratio tax rate measure. In the figure, the vertical axis shows the degree of spatial dependence while the horizontal axis shows the degree to which tax rates correspond to the Leviathan revenue-maximizing rates.

\section{Figure 3.2: Spatial Dependence vs. Leviathan Tax Rates}

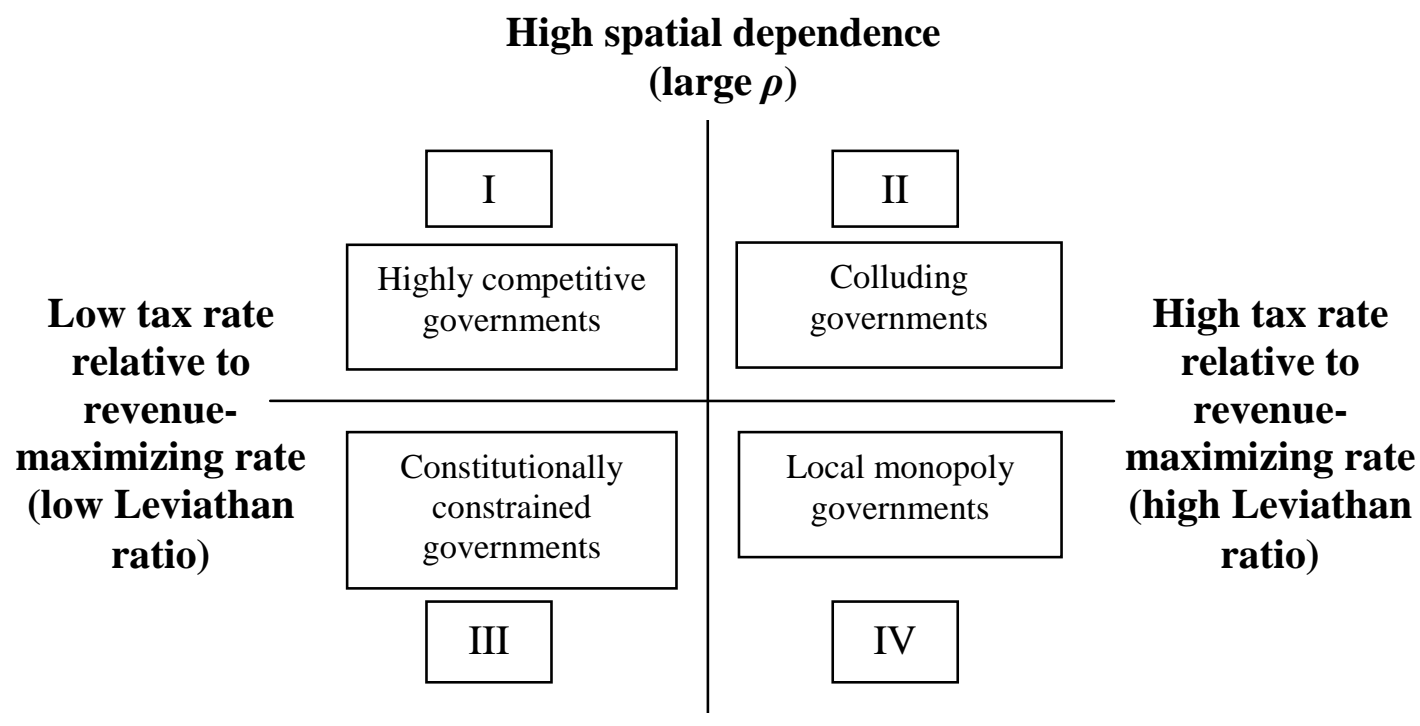

\section{Low spatial dependence}

(small $\rho$ )

Quadrant I, in the upper left, is the case of a government showing a high degree of spatial dependence (large $\rho$ ) while simultaneously showing a low tax rate relative to the revenuemaximizing rate (low Leviathan ratio). These are highly competitive governments by both measures, and this is the quadrant in which our estimates for both municipalities and counties in Pennsylvania fall. Quadrant II, in the upper right, is the case of a government showing a high 
degree of spatial dependence (large $\rho$ ) while simultaneously showing a high tax rate relative to the revenue-maximizing rate (high Leviathan ratio). This would be the sign of collusion among the governments, and this is the quadrant in which our estimates for Pennsylvania school districts fall. Quadrant III in the lower left is the case of a government showing a low degree of spatial dependence (small $\rho$ ) while simultaneously showing a low tax rate relative to the revenuemaximizing rate (low Leviathan ratio). These are governments that show no sign of interaction or competition with neighboring jurisdictions but yet maintain low tax rates despite the lack of competitive pressures. Because constitutional constraints are the alternative to competition in keeping Leviathan at bay, this quadrant best reflects these types of governments. Obviously a government whose tax rates are set constitutionally (and thus inflexibly) at low levels would fall in this quadrant.

Finally, quadrant IV, in the lower right, is the case of a government showing a low degree of spatial dependence (small $\rho$ ) while simultaneously showing a high tax rate relative to the revenue-maximizing rate (high Leviathan ratio). Like with quadrant III, the lack of spatial dependence suggests a lack of either competition or collusion, and is more suggestive of independent action. However, the high rate relative to the revenue-maximizing rate suggests that this independent action is not governed by strict constitutional constraints, but the lack of such constraints. This quadrant is more reflective of a true Leviathan government that sets high rates and seems immune to competitive pressures, similar to the case of a 'local monopoly' in a product market. Most importantly, however, the theory we outline in Figure 3.2 casts substantial doubt on the ability of spatial econometric estimates of interdependence to measure intergovernmental competition alone. 


\subsection{Conclusion}

There is no shortage of empirical studies attempting to uncover whether decentralization constrains the Leviathan behavior of governments. This literature, however, has found very mixed results and has been plagued by hard to measure issues related to collusion among governments, differing constitutional constraints on the governments in the sample, singlepurpose jurisdictions, and a necessitated use of aggregate revenue or government size data. Further, the widespread adoption of spatial econometric techniques in recent years has led to a proliferation of new research on intergovernmental competition using estimates of spatial dependence as measures of tax competition. While all of these previous studies are useful, they each provide an incomplete picture.

Studies that focus on decentralization's impact on government size are assuming strategic interaction without explicitly testing for it. Similarly, studies using spatial methods and finding high degrees of spatial dependence blindly assume it is due to intergovernmental competition and ignore the fact that high interdependence can be caused, alternatively, by collusion. Thus, models testing only for intergovernmental competition are ignoring its consequences by not explicitly examining whether the actual tax rates set by these governments are 'high' or 'low' relative to the Leviathan revenue-maximizing levels. Our paper joins these two approaches into one framework. No previous paper has explored both sides within the same study. These models, when looked at together, provide a coherent framework for studying how intergovernmental competition which follows from a fiscally decentralized federal system can lead to constraints on Leviathan behavior.

We investigate the role of fiscal federalism as a constraint on Leviathan through the use of two models and a unique panel of data for local jurisdictions in Pennsylvania. Importantly, 
we are able to directly examine the tax rates of these jurisdictions, and do not rely on aggregate measures of revenue or government size as has been done in prior Leviathan studies. We examine separately a measure of Leviathan rate-setting behavior, and a measure of the degree of intergovernmental interdependence, for municipal governments, school districts, and county governments. Previous literature has used some measure of the number of governments as a measure of decentralization or intergovernmental competition, and by this standard municipalities (of which there are 2,522 in our sample) should be more competitive than school districts (of which there are 501 in our sample), which in turn should be more competitive than counties (of which there are 66 in our sample).

First, we use a Laffer curve methodology to 'search' for Leviathan behavior at each level of local government. We obtain point estimates of the tax rates that would maximize tax revenue for these governments, and then calculate a ratio to measure how far each government is below these unconstrained Leviathan rates. Our Laffer curve-based Leviathan ratio estimates reveal that all local jurisdictions (municipalities, counties, and school districts) set tax rates well below revenue-maximization. As predicted based on the number of governments, these estimates show that counties are able to set rates closer to Leviathan levels than are municipalities. School districts, however, do not fit in this ordering; while they should have fallen in the middle, they are found to have rates the closest to Leviathan revenue maximization among all levels of government, suggesting that they are the least competitive.

We then turn to a model of spatial dependence to determine the level of strategic interaction at each level. The spatial model has traditionally been used in the literature as a measure of intergovernmental competition. We employ it here in this same context, and our results indicate the presence of significant spatial dependence within all three levels of 
government. As predicted based on the number of governments, these estimates also show that counties are less interdependent than are municipalities (i.e., suggesting municipalities are more competitive than counties). School districts, however, again do not fit in this ordering as while they should have fallen in the middle, they are found to have the highest degree of spatial interdependence - suggesting that they are the most competitive. This is an interesting finding as the Leviathan/Laffer curve estimates suggested that school districts were the least competitive.

Overall our findings are important for two reasons. First, based on our county and municipality results, we are able to confirm the positive role of intergovernmental competition and fiscal decentralization in constraining the Leviathan behavior of governments. The more decentralized municipal governments show both more spatial dependence (i.e., intergovernmental competition) and lower tax rates (compared to the revenue-maximizing tax rates) than do the less decentralized county governments. Second, based on our results for school districts we call into question the popular use of measures of spatial dependence as a measure of intergovernmental competition. High spatial dependence can be either a sign of high competition or of its opposite, collusion.

We outline a new theory using both of our measures that incorporates four possible categories of results. In our framework, high spatial dependence coupled with significantly lower than revenue-maximizing tax rates is reflective of intergovernmental competition, while high spatial dependence coupled with tax rates closer (or equal to) revenue-maximizing tax rates is reflective of intergovernmental collusion. Similarly, low spatial dependence (a sign of independent action) coupled with significantly lower than revenue-maximizing tax rates is reflective of strong constitutional constraints, while low spatial dependence coupled with tax rates closer (or equal to) revenue-maximizing tax rates is reflective of a 'local monopoly'-type 
government that is a true Leviathan insulated from competition. Taken together our results provide evidence that while federalism, and the competing governments inherent within it, can limit the ability of government to achieve Leviathan goals, a more complete model is required to ensure observed intergovernmental interaction is not in fact collusive in nature. 


\section{Chapter 4}

\section{Spatial Dependence in Constitutional Constraints: The Case of U.S. States}

\subsection{Introduction}

Since its inception, the field of constitutional political economy has been concerned with the selection of constitutional constraints on government. From a theoretical standpoint, Buchanan and Tullock (1962) and Buchanan (1975) have sought to explain the origin of constitutional constraints. For the most part, empirical studies in the area have been focused more exclusively on testing the effectiveness of various constitutional rules. To this point, however, little applied work has been undertaken to examine the origin of specific constitutional structures, chiefly because of the difficulty in empirically measuring constitutional constraints. Empirical studies of the origin of constitutional rules are in need of a model with testable implications.

Several theories including the political science concept of diffusion of innovations (which describes the spread of new rules, policy, etc. between governments) and Holcombe's (1994) contention that constitutions serve as a substitute for mobility suggest that constitutions are designed at least partially in response to the constitutions in use by neighboring governments. This idea provides a basis for a model of constitutional design which can be tested directly. In the present paper I contribute to the constitutional economics literature by performing the first spatial econometric analysis of constitutional constraints. Further, the primary analysis is focused on the presence of specific rules in state constitutions, rather than some aggregate measure, providing insight into the types of constitutional constraints which are most likely to be dependent on neighbors' constraints.

I outline a theory of constitutional design where a state's choice of constitutional constraints is a function of neighboring constitutions by extending Holcombe's (1994) argument. 
The theory follows closely previous work on strategic interaction among governments, and is based in part on a type of 'yardstick competition' traditionally used to explain tax policy. Unlike previous normative attempts to explain the choice of constraints, this model is directly testable using spatial econometric techniques. Further, the model is consistent with the theory of diffusion of constitutional rules. I employ a spatial probit model estimation of states' choice of nineteen specific constitutional provisions. This approach serves to effectively make constitutional constraints endogenous, adding to a comparatively underdeveloped strand in the current literature (Voigt 1997, 2010).

To this point, the majority of the empirical literature on constitutional rules is concerned with their effectiveness in constraining government. These studies typically focus on specific constraints or structures and model their success or failure at achieving some stated goal. In cross-country studies, Persson and Tabellini $(2002,2003,2004)$ show two specific types of constitutional rules, namely those defining electoral rules and the type of government, have significant impacts on economic outcomes. Blume, Müller, Voigt, and Wolf (2009) extend their work and confirm the electoral rule result, but contradict the regime-type result.

The empirical literature on the effectiveness of constraints at the state level in the United States is vast. Some of the specific types of constraints examined include term limits, fiscal constraints or tax and expenditure limits, the presence of popular initiative, and line-item veto. While Poterba $(1994,1996)$ finds that fiscal constraints lead to faster adjustment during crises, Sobel and Wagner (2006) provide evidence that states use 'rainy-day funds' to circumvent these constraints. Gubernatorial term limits have been shown to limit accountability (Besley and Case 1995a). The line-item veto literature provides little evidence supporting its effectiveness (Holtz- 
Eakin 1988; Carter and Schap 1990). Popular initiative, on the other hand, seems to constrain government (Bails and Tieslau 2000; Matsusaka 1995).

Meanwhile, comparably less applied work has focused on factors leading to adoption of certain constraints. Notable exceptions include Wibbels (2005) who models constitutional structure as a function of a variety of factors, specifically inequality at the "constitutional moment,' and Holcombe (1991) who provides evidence that a number of provisions in the U.S. Constitution were directly attributable to the self interest of the founding fathers. McGuire (1988) finds similar evidence that the founding fathers voted in support of their own interests as well as the interests of their constituents. Finally, Boix (1999) shows that electoral systems are designed in accordance with the interests of the ruling party.

These exceptions notwithstanding, the origin of constraints in the applied literature is an area ripe for further research. This has been identified by Voigt $(1997,2010)$ as the future of constitutional economics, and by Buchanan (1990) as squarely within the 'domain' of constitutional political economy. Buchanan differentiates constitutional economics from traditional economics by emphasizing this choice of constraints rather than traditional choice subject to constraints. As noted above, the majority of the analysis in the field thus far has been focused somewhere in between by analyzing the effectiveness of constraints.

This paper adds to the work on the origin of constitutional constraints by outlining and empirically testing an economic theory of constitutional design. Following Holcombe's (1994) contention that constitutional rules serve as a substitute for mobility, and drawing on the theory of diffusion of innovations in constitutional design, I employ spatial econometric techniques to analyze the presence in state constitutions of nineteen specific provisions. The results demonstrate states' constitutions depend significantly on the constitutions of neighboring states. 
This lends credence to the hypothesis that constitutional rules act as a substitute for mobility, and provides further evidence of diffusion amongst the 48 contiguous states.

The following section motivates the analysis by discussing diffusion of constitutional rules. Section 3 extends Holcombe's (1994) theory of constitutions serving as a substitute for mobility. Section 4 details the empirical methodology used to test the theory, while Section 5 summarizes the results. The final section provides a conclusion and briefly discusses implications for future research in constitutional political economy.

\subsection{Diffusion of Constitutional Rules}

While the majority of the empirical work described above focuses on testing the effectiveness of constitutional constraints, important work on the origin of such rules is based on the 'borrowing' of rules (known as diffusion) between governments. This work is primarily devoted to analysis of historical case studies, with a focus on how particular innovations in constitutional design spread to other governments or how newly adopted constitutions are similar to or different from constitutions in place in neighboring jurisdictions. Diffusion of policy or institutions refers to "the relative speed and the spatial patterns of adoption of new programs" (Walker 1969). Thus, the theory of diffusion provides a clear basis for spatial dependence in constitutional design.

Holcombe $(1991,1992,1998)$ has done extensive work on the constitutional history of the United States. While not explicitly studying diffusion, this work is clearly in the same vein. His work looks at the Confederate Constitution and compares it to its neighbor's, the U.S. Constitution. While the Confederate Constitution shares the majority of the features of the U.S. Constitution (indicating substantial diffusion of the constraints developed by the original framers) it differs in key ways as well. Specifically, Holcombe notes a significant weakening of 
the Confederacy's federal level of government relative to the U.S. federal government, and a specific prohibition against distributive favoritism to any particular industry $(1991,1992)$. Thus, while the majority of provisions in the U.S. Constitution 'diffused' into the Confederacy, key features viewed as problematic were rewritten and the Confederate Constitution is viewed as a stricter set of constraints on government.

Going even further back into American history, Holcombe (1998) provides evidence of diffusion of constitutional rules from the Iroquois nation to the neighboring thirteen American colonies. Specifically, key features of the Iroquois constitution were adopted as part of the Albany Plan (which was never ratified) and later the Articles of Confederation. Specifically, the Albany Plan borrowed the Iroquois's federal system of government. However, the Albany Plan weakened the unanimity present in the Iroquois system by removing direct accountability. Similarly, the Articles of Confederation were based on the Albany Plan (and thus the neighboring Iroquois constitution) with a further weakening of the legislature's voting rule.

While Holcombe's work focuses on national constitutions, the work of Tarr (1992, 1996, 1998) on state constitutions is of particular interest to the present paper. He notes significant diffusion of constitutional structure between the U.S. states. A specific example is the "Missouri Plan' for selecting supreme court justices, which was implemented in Missouri in 1940 and later spread (in one form or another) to more than 30 other states. Tarr also notes regional characteristics lead to similarities in state constitutions, most notably in the South. State constitutions also tend to be based in part on previous state constitutions.

Numerous other studies of diffusion across the U.S. states include Gray (1973), Benjamin (1985) (who explores the diffusion of executive tenure and term limits between the states), Caldeira (1985) (who looks at the diffusion of votes to adopt amendments to the U.S. 
Constitution), Puro, Bergerson, and Puro (1985) (who test the spread of the Missouri Plan empirically), Stonecash (1983) (who finds convergence across the states in terms of fiscal centralization), and Garrett, Wagner, and Wheelock (2005) (who examine spatial dependence in bank regulation). This borrowing of policies and provisions amongst the states is an issue which the model presented below directly addresses.

\subsection{Constitutions and Mobility}

Holcombe (1994) differentiates governments from clubs by defining government as having the ability to coercively tax all individuals in a given geographic area. This power over all residents in a location is a defining characteristic of government. While members of a club may quit the club without physically moving, a resident cannot 'quit' a government without moving. While the typical Tiebout (1956) model would predict sorting based on provision of public goods and services, in a world where movement is costly perfect intergovernmental competition is not expected.

For this reason, Holcombe describes constitutional rules as a substitute for mobility. Under a Brennan and Buchanan $(1977,1978,1980)$ Leviathan government, voters are only able to escape expropriation through intergovernmental competition or strict constitutional constraints. When voter-residents are unable to 'vote with their feet' due to high costs of moving, their only respite is a binding constitution. In the absence of such constraints, the Leviathan will seek to maximize its dominance over the citizenry. Knowing this ex ante, residents (who obviously wish to avoid excessive expropriation by the government) will choose a state which is either subject to a strict set of constitutional constraints or relatively easy to 
'escape' should Leviathan begin to rise. If given the choice, it is unlikely that any resident will choose a loosely constrained state where mobility into a neighboring state is high cost.

The logic in Holcombe's argument can be extended to the choice of constraints. If voterresidents consider constitutions as the substitute for mobility, the state, which wishes to attract residents, must also consider mobility when designing or amending its constitution. This is especially true over time, as mobility costs fall and the strictness of the constitution becomes the major motivating factor in residents' choice. If voters are able to move between states at increasingly lower costs (a fairly safe assumption, especially in the U.S. through time) then interstate differentials in constitutional strength become paramount, ceteris paribus.

Of course the assumption of perfect mobility is not realistic; voter-residents will always face a nonzero cost when moving from one state to another. As such, governments will still enjoy dominion over the geographic area and are not completely constrained by the possibility of a Tiebout-type exodus of citizens. With some limited mobility, however, the threat of exit into a neighboring state remains credible. ${ }^{16}$ Under this realistic assumption, states would be wise to attempt to preempt this threat by removing the incentive to exit.

When attempting to prevent exit by residents, a state will look to the residents' potential destinations, neighboring states. This follows from the contention that residents observe neighboring states' constitutions and draw comparisons. In the tax competition literature, this is known as 'yardstick competition' where states (realizing their choice of policy is measured by voters against that of other states) choose policy in response to neighboring states (see for example Besley and Case 1995b, Allers and Elhorst 2005). Specifically, since mobility serves as

\footnotetext{
${ }^{16}$ An interesting unit of analysis for the study of this phenomenon would be cities which form along a state's border. While such an undertaking is beyond the scope of the present paper, it would likely prove to be a worthwhile avenue for future research. I thank Donald Lacombe for this insight.
} 
a substitute for constitutional rules states will examine neighboring constitutional structures. Of course a state could completely remove the threat of exit by instituting an extremely strict constitution. However, since a Leviathan state wishes to maximize its size, this self-imposed 'chaining' is not a viable option. Alternatively, the state can remove the voters' incentive to exit by amending its own constitution to a form comparable to its neighbors'. In this scenario, voters no longer see 'greener pastures' across the border since all nearby states are subject to constitutions with similar constraints. While a more preferable constitution may exist elsewhere, the high cost of mobility makes those options nonviable.

In a survey of work on strategic interaction among governments, Brueckner (2003) outlines two models which explicitly deal with strategic interaction between governments, a type of which is described above. He refers to one of these models as the 'resource-flow model' in that government decisions are partly responsible for the location choice of a particular valuable resource. In the above discussion, the resource can be thought of as residents, capital investment, and other sources of tax revenue. The implication of this theory when adopted as a model of constitutional design is that states will choose constitutional constraints in response to the choices of neighboring jurisdictions. Since mobility remains costly, however, not all constitutions will take the same shape. Specifically, states will mimic only those states which present reasonably low cost alternatives to residents. Further, states will not choose constitutional rules solely based on neighboring institutions.

Following Brueckner (2003), the state's objective function can be summarized in Equation (4.1):

$$
V\left(y_{i}, r_{i} ; X_{i}\right)
$$


where $y_{i}$ is the choice of constitutional structure in state $i, r_{i}$ is the amount of the resource present in $i$, and $X_{i}$, represents other characteristics of state $i$. Since residents' choice of state is based in part on the constitutional structure in each state (as well as other factors), the resource level in $i$ can be expressed as

$$
r_{i}=f\left(y_{i}, y_{-i} ; X_{i}\right)
$$

with $y_{-i}$ representing the constitutions in all states other than $i .^{17}$ By substituting Equation (4.2) into (1), the state's objective function becomes

$$
V\left[y_{i}, f\left(y_{i}, y_{-i} ; X_{i}\right) ; X_{i}\right] \equiv V\left(y_{i}, y_{-i} ; X_{i}\right)
$$

States choose $y_{i}$ to maximize $V$. The solution (found by differentiating $V$ with respect to $y_{i}$ and setting equal to zero) is a function of a state's own characteristics and neighboring constitutional choices and can be expressed as

$$
y_{i}=R\left(y_{-i} ; X_{i}\right)
$$

which can be thought of as a constitution reaction function. Thus, states' choices of constitutional rules are dependent on state-specific characteristics as well as the rules chosen by other states.

If the theory outlined above is valid, states can be expected to design their constitutions at least in part as a function of neighbors' constraints. However, there is no ex ante expectation on the sign of the slope of the reaction function. Some specific provisions or rules are more likely to occur in a given state's constitution if they are also present in neighboring constitutions. This would explain the 'borrowing' of provisions observed by Tarr $(1992,1996,1998)$. At the same time, states may choose to avoid other provisions or rules in an effort to differentiate from

\footnotetext{
${ }^{17}$ If $X_{i}$ is expressed in relative terms, it is not necessary to include $X_{-_{i}}$ in equation (2). However, $X_{-}$can be included (with $X_{i}$ in absolute terms) to justify the Spatial Durbin Model presented later in the paper.
} 
neighboring states or in order to improve upon neighboring constitutions. Holcombe's (1991, 1992, 1998) extensive work on American constitutional history details several cases of governments adopting neighboring constitutions while still making fundamental changes to provisions which were deemed ineffective or problematic.

I examine the validity of this theory by analyzing state constitutions in the 48 contiguous states. State constitutions provide a natural unit of analysis in that they are formal documents which are only subservient to the U.S. Constitution. The state level is also a small enough unit that the assumption of limited mobility is reasonable. Clearly it remains costly to move between states, but the cost is doubtlessly far lower than mobility between nations, especially once one considers the U.S. states share a common language, a common currency, developed infrastructure, etc. Nevertheless, the costliness of mobility is addressed in two ways. First, the analysis is focused on the past several years, a period of time over which mobility between the states has become increasingly easy. Secondly, the cost of mobility is dealt with indirectly in the specification of the spatial weight matrix detailed in the following section.

As a first look, Figure 4.1 presents descriptive characteristics of state constitutions on a map of the 48 contiguous states. The maps display, in quintiles, the spatial distribution of basic constitutional structure including length, age, and number of amendments. These data are collected from the Council of State Government's Book of the States. While these descriptors are mute on the actual provisions contained in the constitutions, they provide insight into the complexity, longevity, and malleability of state institutions. 
Figure 4.1: Characteristics of State Constitutions, 2006
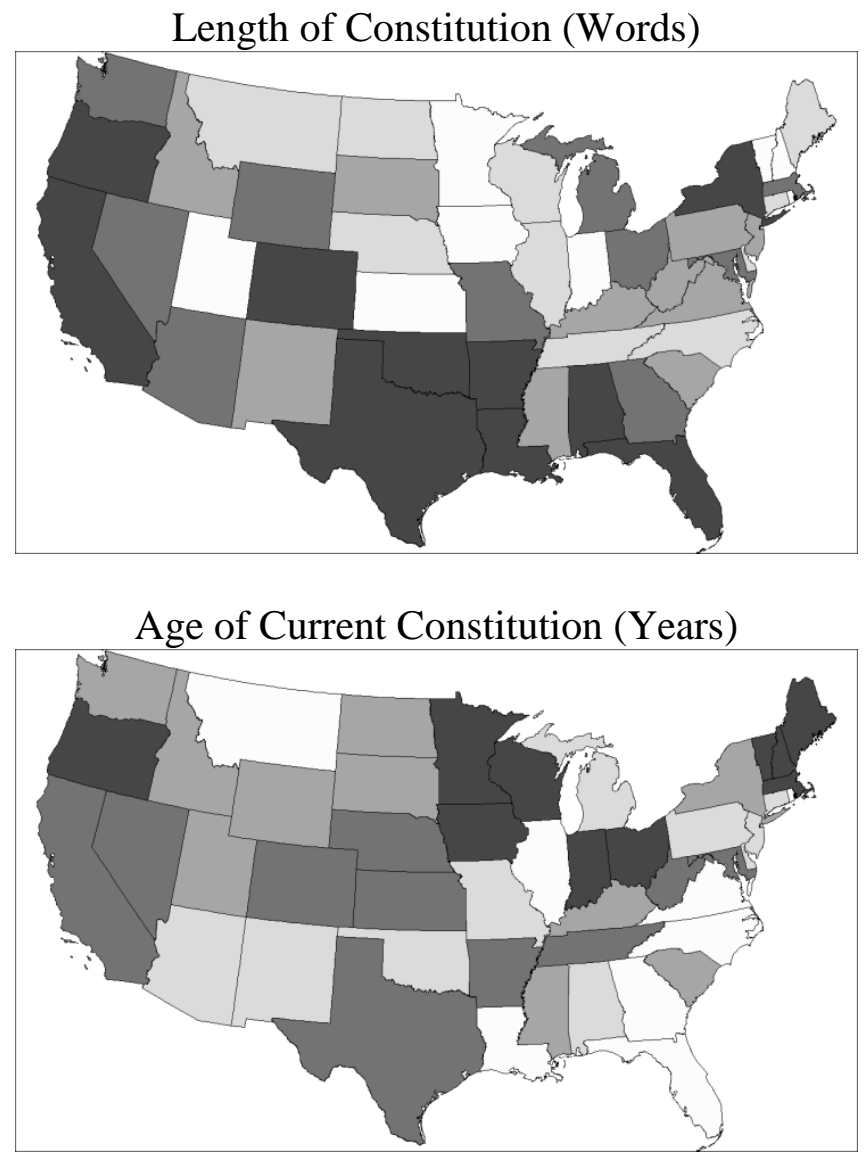

Number of Amendments to Current Constitution (Adopted)

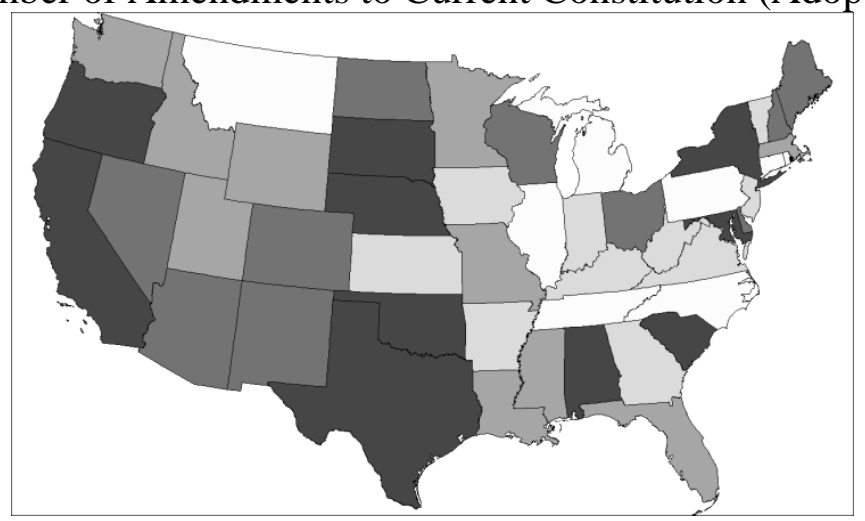

Quintiles

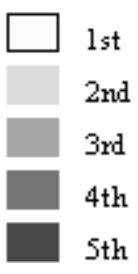


At first glance, it appears that longer constitutions (i.e. those with more words) are clustered in southern states and the west coast. States in the northeast tend to have shorter constitutions. Older constitutions are found in the northeast and mid-western states, while the southeast has more recently adopted constitutions. Finally, the number of amendments appears to be grouped in spatial clusters as well. Though these maps are hardly conclusive evidence of spatial dependence in state constitutions, they do provide suggestive support. If state constitutions are similar to neighbors in terms of basic structure, it likely follows that they are similar in terms of the constraints contained within them. Testing the spatial dependence of specific constitutional provisions is the task of the empirical analysis detailed in the next section.

\subsection{Empirical Model and Methodology}

Since the incidence of a specific rule or provision in a constitution is a binary variable, I employ a probit model. As the theory discussed above details a process whereby adoption of a rule depends partly on neighbor's adoption, I consider a spatial econometric approach. The theoretical constitution reaction function described by Equation (4.4) takes no specific functional form. Therefore, I employ two spatial models and use Bayesian model comparison techniques to produce posterior model probabilities. The highest of these probabilities indicates the most appropriate model. The first of these models is a spatial autoregressive (SAR) model. This models the presence of a rule in a state's constitution as a function of the presence (or lack thereof) of the same provision in neighboring constitutions. This same approach is employed by Fiva and Ratts $\varnothing$ (2007) who analyze spatial dependence in adoption of property taxation and Hall and Ross (forthcoming) who look at yardstick competition in income tax adoption. Specifically, 
the spatial autoregressive probit (which is fully developed in LeSage and Pace 2009) takes the form

$$
y_{i}^{*}=\alpha+\rho w y_{i}^{*}+x_{i} \beta+\varepsilon_{i}
$$

where the binary choice variable, $y_{i}$, is determined by the latent variable, $y_{i}{ }^{*}$, as follows

$$
y_{i}=\left\{\begin{array}{l}
1 \text { if } y_{i}^{*}>0 \\
0 \text { if } y_{i}^{*} \leq 0
\end{array} .\right.
$$

The choice variable $y_{i}$ takes a value of 1 if a state's constitution contains a given provision and a value of 0 if it does not. A description of the nineteen specific rules on which this equation is estimated is presented at the end of this section.

Variable $\alpha$ is an intercept term. The variable $x_{i}$ serves as a control for voter preferences and other economic conditions which may influence the presence constitutional rules. The matrix $w$ is an (n $\mathrm{x} n$ ) spatial weight matrix which weights the choices of neighboring states, and the parameter $\rho$ is a scalar which indicates the degree of spatial dependence. If the estimated value of $\rho$ is significant, spatial dependence is present. The weight matrix used in this analysis is based on contiguity: states are considered neighbors if they share a common border. ${ }^{18}$ As mentioned previously, mobility between states is costly. This analysis is focused only on contiguous neighbors under the assumption that it is easier to move to a neighboring state. Ex ante, the parameter $\rho$ may take either a positive or negative value. Positive spatial dependence indicates the presence of a constitutional provision in a neighboring state increases the likelihood of a given state's constitution containing the same provision. Negative spatial dependence would indicate differentiation. In either case, nonzero spatial dependence provides evidence that states are responding to one another in constitutional choice.

\footnotetext{
${ }^{18}$ Contiguity is determined using latitude and longitude coordinates and Delaunay triangles.
} 
Equation (4.5) above can be extended into a panel framework. This procedure follows Elhorst (2009) who develops the spatial autoregressive panel model and directly to Garrett, Wagner, and Wheelock (2005) who develop a spatial autoregressive probit model for panel data. The $N$ cross-sectional observations of Equation (4.5) are compiled into vectors comprising all $T$ time periods such that

$$
Y_{t}^{*}=\alpha+\rho W Y_{t}^{*}+X_{t} \beta+\varepsilon_{t}
$$

where $Y_{t}^{*}=\left(y_{1 t}^{*}, y_{2 t}^{*}, \ldots, y_{N t}^{*}\right), X_{t}^{*}=\left(x_{1 t}^{*}, x_{2 t}^{*}, \ldots, x_{N t}^{*}\right)$, and $\varepsilon_{t}^{*}=\left(\varepsilon_{1 t}^{*}, \varepsilon_{2 t}^{*}, \ldots, \varepsilon_{N t}^{*}\right)$. W is a $(T N x T N)$ block diagonal matrix with the $(N \mathrm{x} N)$ matrix $w$ on the main diagonal. This ensures only contemporaneous spatial autocorrelation. The implied data generating process is found by rewriting Equation (4.6) in reduced form

$$
Y_{t}^{*}=\left(I_{n}-\rho W\right)^{-1}\left(\alpha+X_{t} \beta+\varepsilon_{t}\right)
$$

The matrix $X_{t}$ contains variables which act as proxies for economic conditions and the preferences of voter-residents. Specifically, the explanatory variables included are the state's population, the proportion of the population 5-17 years old as well as the proportion over age 65, the proportion of the population living below the poverty line, the proportion of high school graduates, and the proportion that is white. These variables are fairly commonly used as controls for preferences. There is no ex ante prediction for the sign or significance of these control variables. Also included in the $X_{t}$ matrix is a variable representing the age of the state's constitution, in years. The inclusion of this variable will control for the potential of certain provisions being more or less common in older or more recently adopted constitutions. Finally, following Holcombe's $(1991,1992,1998)$ work on the constitutional history of the United States, the $X_{t}$ matrix includes an indicator variable which takes the value of 1 for states that were 
part of the Confederate States of America, since thee states share a common constitutional history. ${ }^{19}$

The second model considered is the spatial Durbin model (SDM). Hall and Ross (forthcoming) develop a SDM probit model. The SDM differs from the basic SAR model by including an additional term, $w x_{i}$, which geographically weights neighbors' characteristics. Theoretically, this can be justified by modifying Equation (4.2) to include neighboring characteristics in the resource's location decision

$$
r_{i}=f\left(y_{i}, y_{-i} ; X_{i}, X_{-i}\right)
$$

which subsequently changes the reaction function

$$
y_{i}=R\left(y_{-i} ; X_{i}, X_{-i}\right)
$$

When Equation (4.5) is augmented with the additional term, the model becomes

$$
y_{i}^{*}=\alpha+\rho w y_{i}^{*}+x_{i} \beta+\gamma w x_{i}+\varepsilon_{i}
$$

with $\gamma$ an additional set of parameters to be estimated. As before, in a panel setting, Equation (4.10) becomes

$$
Y_{t}^{*}=\alpha+\rho W Y_{t}^{*}+X_{t} \beta+\gamma W X_{t}+\varepsilon_{t}
$$

which in reduced form is

$$
Y_{t}^{*}=\left(I_{n}-\rho W\right)^{-1}\left(\alpha+X_{t} \beta+\gamma W X_{t}+\varepsilon_{t}\right) .
$$

Note that Equation (4.12) is identical to Equation (4.7) except for the inclusion of the additional matrix of explanatory variables, $\gamma W X_{t}$. This implies that the estimation strategy employed for the SAR model may also be used in the SDM.

\footnotetext{
${ }^{19}$ In general, former Confederate States have had a far greater number of constitutions than similarly-aged Northern states. Confederate States each adopted new constitutions following secession, asserting their place in the newly formed Confederate States of America. Following the end of the American Civil War, these states again adopted new constitutions rejoining the United States. Many adopted yet another constitution following Reconstruction.
} 
LeSage and Pace (2009) provide a compelling argument for the use of the SDM approach. Specifically, they show that if omitted variables exhibit spatial dependence the implied data generating process is identical to that of the SDM model. The SDM model, then, may be used to produce consistent estimates even in the presence of spatially dependent omitted variables which are correlated with included explanatory variables. Further, if the SDM approach is used in the unlikely event that no omitted variables exist, estimates are still consistent (though not efficient). Thus, the use of the SDM here may be viewed as a method of controlling for spatial dependence in any omitted variables, and if such dependence exists, the SDM estimates will be preferred to those of the SAR model described above. For example, 'culture' may play a role in constitutional design, and is most likely spatially dependent. Since this variable is likely correlated with the Confederate State variables included in the model, the SDM approach will be expected to produce consistent estimates.

Maximum likelihood estimation of limited dependent variable models in a spatial context is quite difficult. Fortunately, LeSage and Pace (2009) provide a Bayesian technique to estimate spatial probit models. The method is based on a Markov Chain Monte Carlo (MCMC) approach, and uses a Gibbs sampler algorithm. This is the same technique employed in Fiva and Ratts $\varnothing$ (2007). The key feature of the approach is the sampling of the conditional distribution of the latent variable, $y^{*}$. By treating the latent variable as another parameter to be estimated, this approach greatly simplifies estimation. In general, the Gibbs sampler algorithm is made up of the following steps: estimate the vector $\beta$ given assumed values for all other parameters, estimate $\rho$ given all other parameters, and finally estimate the latent variable $y^{*}$ given all other parameters. 
Parameter estimates come from the mean of the empirical distributions built by the MCMC

process. $^{20}$

Table 4.1: Summary Statistics

\begin{tabular}{lcr}
\hline Constitutional Rule Variables: 1998-2005 & Mean & Standard Deviation \\
\hline Age of Constitution & 104.667 & 52.171 \\
Government Structure & & \\
Governor Term Limit & 0.750 & 0.434 \\
Legislature Term Limit & 0.349 & 0.477 \\
Supreme Court Justices Elected & 0.458 & 0.499 \\
Supreme Court Justices Appointed & 0.521 & 0.500 \\
Supreme Court Justices Merit System & 0.438 & 0.497 \\
Recall Provision & 0.354 & 0.479 \\
Home Rule Provision & 0.776 & 0.417 \\
Constitution Amended by Convention & 0.813 & 0.391 \\
Direct Democracy Provision & 0.667 & 0.472 \\
Fiscal and Social Constraints & & \\
Balanced Budget Requirement & & \\
Tax/Expenditure Limit & 0.630 & 0.483 \\
Line Item Veto & 0.307 & 0.462 \\
Victims' Bill of Rights & 0.875 & 0.331 \\
Health and Welfare Provision & 0.643 & 0.480 \\
Official Language Specified & 0.208 & 0.407 \\
Right to Privacy Specified & 0.107 & 0.309 \\
Environment Provision & 0.164 & 0.371 \\
Sexual Discrimination Provision & 0.167 & 0.373 \\
Abortion Provision & 0.354 & 0.479 \\
\hline Demographic and Economic Variables: & 0.063 & 0.242 \\
1998-2005 & & \\
\hline Population (millions) & Mean & Standard Deviation \\
Proportion 5-17 & 5.914 & 6.320 \\
Proportion 65+ & 0.183 & 0.011 \\
Proportion Below Poverty Line & 0.126 & 0.016 \\
Proportion (18+) High School Graduates & 0.117 & 0.031 \\
Proportion White & 0.854 & 0.040 \\
Confederate State & 0.841 & 0.095 \\
\hline & 0.229 & 0.421 \\
\hline
\end{tabular}

Table 4.1 presents summary statistics for all data used in this study. All explanatory variables and constitutional data span the 8 year period of 1998-2005. The choice of

\footnotetext{
${ }^{20}$ A full description of the Gibbs sampler and Bayesian econometric technique employed is well beyond the scope of this paper. The interested reader is pointed to LeSage and Pace (2009) who provide a full treatment of the methodology. Fiva and Ratts $\emptyset$ (2007) also provide an excellent summary of the procedure.
} 
constitutional rules to be modeled is expansive, and includes the majority of the constraints mentioned in the previous literature (such as line-item veto, term limits, and balanced budget requirements) as well as additional constraints heretofore not extensively studied (such as the right to privacy). In total, nineteen specific constitutional provisions are considered, nine of which can be viewed broadly as rules concerning the structure of state government, and ten which serve as fiscal and social constraints. The most prevalent constitutional rule in the data is the line item veto, present in $87.5 \%$ of state-year observations. An explicit mention of abortion in the state constitution is the least prevalent provision, with only $6.3 \%$ of state-year observations.

All constitutional rule variables take a value of 1 if the state constitution explicitly contains a provision of the type in the given year. This methodology then tests for existence of the rule and not adoption. Statutory rules and other provisions not explicitly contained in the constitution are not considered. The balanced budget requirement examined is one which requires the legislature pass a balanced budget. All tax and expenditure limits, provided they are codified in the constitution, are considered. Direct democracy refers to the availability of popular initiatives of any type (statute or constitutional amendment). The methods of supreme court justice selection include all mechanisms available in the state. Since justices can still be appointed in states with a merit system (when a vacancy first appears, for example) several states have multiple selection rules specified in their constitutions.

Data on provisions in state constitutions comes from Maddex $(1998,2003)$ and is updated with reports from the National Conference of State Legislatures. Information on the selection rules for supreme court justices comes from the American Judicature Society’s “Judicial Selection in the States" material. State population and the proportions elderly, young, and white 
come from the Census Bureau's population estimates and volumes of the Statistical Abstract of the United States. Data on the proportion of the state population that lives below the poverty line and the proportion of high school graduates comes from the Census Bureau's Current Population Survey.

\subsection{Results}

Results from the estimation of the spatial autoregressive probit models for nineteen specific constitutional provisions are found in Tables 4.2 and 4.3. Table 4.2 shows results for the government structure provisions while Table 4.3 includes the fiscal and social constraints. Estimates are based on 384 observations of the 48 contiguous states over the period 1998-2005. I employ a Bayesian estimation technique following that described in LeSage and Pace (2009) and Fiva and Ratts $\varnothing$ (2007) featuring 3500 MCMC draws based on a Gibbs sampling algorithm. ${ }^{21}$ The first 500 draws are omitted as part of the 'burn-in' by the sampler. Experiments with up to 11000 draws (with the first 1000 omitted) yielded nearly identical results. ${ }^{22}$ I employ diffuse priors in the estimation. ${ }^{23}$ When interpreting coefficients in a Bayesian context, credible intervals are used. In the tables which follow, the $95 \%$ credible interval is presented. Functionally, the $95 \%$ credible interval is analogous to a $5 \%$ confidence

\footnotetext{
${ }^{21}$ A full treatment of the Bayesian estimation of the spatial autoregressive probit model can be found in LeSage and Pace (2009) Chapter 10. The models were estimated using the 'sarp_g' function found in LeSage's spatial econometrics toolbox, available at http://www.spatial-econometrics.com.

${ }^{22}$ While the results are nearly identical, the time needed for computation increases greatly. As such, I present the results based on fewer MCMC draws as my primary findings.

${ }^{23}$ Diffuse priors are also known as uninformative priors and indicate uncertainty about the expected values of the parameters. Specifically, the assumed prior mean for the $\beta$ coefficients is zero, the prior variance of $\beta$ is very large, and the parameter $\rho$ has a range of $[-1,1]$. For more information on the role of priors in Bayesian estimation, see LeSage and Pace (2009).
} 
interval in traditional econometric models; a parameter estimate can be said to be nonzero (with a $95 \%$ probability) if the credible interval does not contain zero.

Table 4.2: Spatial Autoregressive Probit Models: Government Structure

\begin{tabular}{|c|c|c|c|c|c|}
\hline Dependent Variable & $\begin{array}{c}\text { Governor Term } \\
\text { Limit } \\
\end{array}$ & $\begin{array}{c}\text { Legislature Term } \\
\text { Limit } \\
\end{array}$ & Justices Elected & $\begin{array}{c}\text { Justices } \\
\text { Appointed } \\
\end{array}$ & $\begin{array}{c}\text { Justices Merit } \\
\text { System } \\
\end{array}$ \\
\hline \multicolumn{6}{|l|}{ Spatial Dependence } \\
\hline$\rho$ & $\begin{array}{c}0.505^{*} \\
{[0.298,0.679]}\end{array}$ & $\begin{array}{c}0.234^{*} \\
{[0.007,0.440]}\end{array}$ & $\begin{array}{c}0.480^{*} \\
{[0.284,0.658]}\end{array}$ & $\begin{array}{c}0.629^{*} \\
{[0.482,0.762]}\end{array}$ & $\begin{array}{c}0.299^{*} \\
{[0.071,0.510]}\end{array}$ \\
\hline \multicolumn{6}{|l|}{ Explanatory Variables } \\
\hline Age of Constitution & $\begin{array}{c}-0.002 * \\
{[-0.004,-0.001]}\end{array}$ & $\begin{array}{c}-0.001 \\
{[-0.003,0.000]}\end{array}$ & $\begin{array}{c}-0.001^{*} \\
{[-0.002,-0.001]}\end{array}$ & $\begin{array}{c}0.005^{*} \\
{[0.002,0.009]}\end{array}$ & $\begin{array}{c}-0.004 * \\
{[-0.005,-0.002]}\end{array}$ \\
\hline Population (millions) & $\begin{array}{c}-0.039^{*} \\
{[-0.064,-0.022]}\end{array}$ & $\begin{array}{c}0.015^{*} \\
{[0.005,0.026]}\end{array}$ & $\begin{array}{c}-0.002 \\
{[-0.005,0.001]}\end{array}$ & $\begin{array}{c}0.007 \\
{[-0.012,0.027]}\end{array}$ & $\begin{array}{c}-0.039^{*} \\
{[-0.055,-0.024]}\end{array}$ \\
\hline Proportion 5-17 & $\begin{array}{c}-4.655 \\
{[-13.810,3.487]}\end{array}$ & $\begin{array}{c}11.096^{*} \\
{[4.974,17.452]}\end{array}$ & $\begin{array}{c}1.457 \\
{[-7.900,10.535]}\end{array}$ & $\begin{array}{c}7.741 \\
{[-4.525,20.549]}\end{array}$ & $\begin{array}{c}5.592 \\
{[-0.0989,12.612]}\end{array}$ \\
\hline Proportion $65+$ & $\begin{array}{c}-3.386 \\
{[-10.662,2.719]}\end{array}$ & $\begin{array}{c}5.075^{*} \\
{[0.485,10.116]}\end{array}$ & $\begin{array}{c}-4.907 \\
{[-11.538,1.417]}\end{array}$ & $\begin{array}{c}12.460 * \\
{[3.550,22.419]}\end{array}$ & $\begin{array}{c}4.961 * \\
{[0.373,10.198]}\end{array}$ \\
\hline Proportion Below Poverty Line & $\begin{array}{c}4.263 * \\
{[0.661,8.160]}\end{array}$ & $\begin{array}{c}6.067^{*} \\
{[3.519,8.883]}\end{array}$ & $\begin{array}{c}10.638^{*} \\
{[6.624,15.488]}\end{array}$ & $\begin{array}{c}-6.621^{*} \\
{[-11.876,-1.764]}\end{array}$ & $\begin{array}{c}0.761 \\
{[-1.890,3.456]}\end{array}$ \\
\hline Proportion (18+) High School Graduates & $\begin{array}{c}-1.105 \\
{[-4.330,1.758]}\end{array}$ & $\begin{array}{c}5.051^{*} \\
{[2.765,7.684]}\end{array}$ & $\begin{array}{c}0.023 \\
{[-3.132,3.219]}\end{array}$ & $\begin{array}{c}-2.400 \\
{[-6.858,1.584]}\end{array}$ & $\begin{array}{c}0.125 \\
{[-2.260,2.208]}\end{array}$ \\
\hline Proportion White & $\begin{array}{c}-2.807^{*} \\
{[-5.043,-1.120]}\end{array}$ & $\begin{array}{c}0.761 \\
{[-0.131,1.765]}\end{array}$ & $\begin{array}{c}1.222 \\
{[-0.154,2.615]}\end{array}$ & $\begin{array}{c}-1.582 \\
{[-3.514,0.170]}\end{array}$ & $\begin{array}{c}2.736^{*} \\
{[1.654,4.140]}\end{array}$ \\
\hline Confederate State & $\begin{array}{c}-0.251 \\
{[-0.601,0.044]} \\
\end{array}$ & $\begin{array}{c}0.014 \\
{[-0.191,0.215]} \\
\end{array}$ & $\begin{array}{c}-0.047 \\
{[-0.324,0.226]} \\
\end{array}$ & $\begin{array}{c}-0.599^{*} \\
{[-0.988,-0.249]} \\
\end{array}$ & $\begin{array}{c}0.027 \\
{[-0.194,0.234]} \\
\end{array}$ \\
\hline Dependent Variable & Recall & Home Rule & $\begin{array}{l}\text { Amend by } \\
\text { Convention }\end{array}$ & $\begin{array}{c}\text { Direct } \\
\text { Democracy }\end{array}$ & \\
\hline Spatial Dependence & & & & & \\
\hline$\rho$ & $\begin{array}{c}0.302^{*} \\
{[0.083,0.504]}\end{array}$ & $\begin{array}{c}-0.357^{*} \\
{[-0.563,-0.150]}\end{array}$ & $\begin{array}{c}-0.846^{*} \\
{[-0.997,-0.508]}\end{array}$ & $\begin{array}{c}0.526^{*} \\
{[0.342,0.698]}\end{array}$ & \\
\hline Explanatory Variables & & & & & \\
\hline Age of Constitution & $\begin{array}{c}-0.004^{*} \\
{[-0.006,-0.002]}\end{array}$ & $\begin{array}{c}-0.001 * \\
{[-0.002,-0.001]}\end{array}$ & $\begin{array}{c}-0.001 * \\
{[-0.002,-0.001]}\end{array}$ & $\begin{array}{c}-0.000 \\
{[-0.002,0.001]}\end{array}$ & \\
\hline Population (millions) & $\begin{array}{c}0.001 \\
{[-0.010,0.012]}\end{array}$ & $\begin{array}{c}0.038^{*} \\
{[0.026,0.050]}\end{array}$ & $\begin{array}{c}-0.002 \\
{[-0.005,0.001]}\end{array}$ & $\begin{array}{c}-0.022^{*} \\
{[-0.041,-0.008]}\end{array}$ & \\
\hline Proportion 5-17 & $\begin{array}{c}-2.677 \\
{[-9.546,3.642]}\end{array}$ & $\begin{array}{c}-0.445 \\
{[-3.016,2.285]}\end{array}$ & $\begin{array}{c}-2.679^{*} \\
{[-5.050,-0.443]}\end{array}$ & $\begin{array}{c}21.952 * \\
{[12.718,32.765]}\end{array}$ & \\
\hline Proportion $65+$ & $\begin{array}{c}-10.942 * \\
{[-16.393,-5.861]}\end{array}$ & $\begin{array}{c}2.908^{*} \\
{[0.453,5.429]}\end{array}$ & $\begin{array}{c}-3.132 * \\
{[-5.022,-1.560]}\end{array}$ & $\begin{array}{c}11.938^{*} \\
{[5.888,19.457]}\end{array}$ & \\
\hline Proportion Below Poverty Line & $\begin{array}{c}1.890 \\
{[-0.731,4.658]}\end{array}$ & $\begin{array}{c}2.481^{*} \\
{[1.294,3.594]}\end{array}$ & $\begin{array}{c}0.953^{*} \\
{[0.001,1.885]}\end{array}$ & $\begin{array}{c}7.951^{*} \\
{[4.485,12.360]}\end{array}$ & \\
\hline Proportion (18+) High School Graduates & $\begin{array}{c}2.136 \\
{[-0.238,4.585]}\end{array}$ & $\begin{array}{c}1.324^{*} \\
{[0.310,2.367]}\end{array}$ & $\begin{array}{c}0.847 * \\
{[0.042,1.665]}\end{array}$ & $\begin{array}{c}6.122 * \\
{[3.429,9.020]}\end{array}$ & \\
\hline Proportion White & $\begin{array}{c}0.110 \\
{[-0.937,1.044]}\end{array}$ & $\begin{array}{c}0.010 \\
{[-0.353,0.392]}\end{array}$ & $\begin{array}{c}0.070 \\
{[-0.210,0.362]}\end{array}$ & $\begin{array}{c}-3.074 * \\
{[-4.763,-1.763]}\end{array}$ & \\
\hline Confederate State & $\begin{array}{c}-0.396^{*} \\
{[-0.633,-0.179]} \\
\end{array}$ & $\begin{array}{c}-0.338^{*} \\
{[-0.422,-0.248]} \\
\end{array}$ & $\begin{array}{c}-0.096^{*} \\
{[-0.157,-0.034]}\end{array}$ & $\begin{array}{c}-0.744 * \\
{[-1.116,-0.475]} \\
\end{array}$ & \\
\hline & & & & & \\
\hline
\end{tabular}

The coefficient estimates reported in Tables 4.2 and 4.3 are the total effect estimates for each parameter. These total effect estimates include the direct and indirect effects a la LeSage 
and Pace (2009). Significant spatial dependence $(\rho)$ is found in all of the government structure specifications. Specifically, both gubernatorial and legislature term limits exhibit positive spatial dependence, as do provisions for election, appointment, and merit system selection of supreme court justices. In other words, a state's constitution is more likely to limit the number of terms a governor or legislator may serve, and is more likely to choose appointment, election, or merit system selection of justices if a neighboring state does. States are also more likely to allow for voter recall of government officials if neighboring states' constitutions contain similar provisions. Direct democracy provisions also exhibit positive spatial dependence. Taken together, these results suggest that states place restrictions on government officials similar to those in surrounding states.

Provisions for home rule and constitutional amendment by convention exhibit significant negative spatial dependence. These results suggest a differentiating of states from neighboring constitutions for these two provisions.

The first several columns of Table 4.3 present estimates for the fiscal constraints. While significant negative spatial dependence is found in the tax and expenditure limit specification, the $95 \%$ credible interval for $\rho$ in the balanced budget requirement specification contains zero. However, if the credible interval is reduced to $90 \%$, the negative spatial dependence becomes significant. Significant negative spatial dependence is found in the line item veto specification as well. This negative dependence can again be interpreted as states' attempting to differentiate from neighboring institutions. 


\section{Table 4.3: Spatial Autoregressive Probit Models: Fiscal and Social Constraints}

\begin{tabular}{|c|c|c|c|c|c|}
\hline Dependent Variable & Balanced Budget & TEL & Line Item Veto & $\begin{array}{l}\text { Victims' Bill of } \\
\text { Rights }\end{array}$ & $\begin{array}{l}\text { Health and } \\
\text { Welfare }\end{array}$ \\
\hline \multicolumn{6}{|l|}{ Spatial Dependence } \\
\hline$\rho$ & $\begin{array}{c}-0.290 \\
{[-0.598,0.006]}\end{array}$ & $\begin{array}{c}-0.370^{*} \\
{[[-0.743,-0.016]}\end{array}$ & $\begin{array}{c}-0.906^{*} \\
{[-0.997,-0.723]}\end{array}$ & $\begin{array}{c}0.251^{*} \\
{[0.026,0.451]}\end{array}$ & $\begin{array}{c}0.313 * \\
{[0.023,0.596]}\end{array}$ \\
\hline \multicolumn{6}{|l|}{ Explanatory Variables } \\
\hline Age of Constitution & $\begin{array}{c}-0.001^{*} \\
{[-0.002,-0.001]}\end{array}$ & $\begin{array}{c}-0.002 * \\
{[-0.002,-0.001]}\end{array}$ & $\begin{array}{c}-0.000 \\
{[-0.000,0.000]}\end{array}$ & $\begin{array}{c}-0.002^{*} \\
{[-0.003,-0.001]}\end{array}$ & $\begin{array}{c}-0.000 \\
{[-0.002,0.001]}\end{array}$ \\
\hline Population (millions) & $\begin{array}{c}-0.007 * \\
{[-0.014,-0.001]}\end{array}$ & $\begin{array}{c}0.008^{*} \\
{[0.004,0.014]}\end{array}$ & $\begin{array}{c}0.013 * \\
{[0.008,0.019]}\end{array}$ & $\begin{array}{c}0.014 * \\
{[0.002,0.029]}\end{array}$ & $\begin{array}{c}0.031 * \\
{[0.019,0.049]}\end{array}$ \\
\hline Proportion 5-17 & $\begin{array}{c}3.279 \\
{[-1.136,7.755]}\end{array}$ & $\begin{array}{c}-1.594 \\
{[-5.372,2.187]}\end{array}$ & $\begin{array}{c}1.653 * \\
{[0.129,3.184]}\end{array}$ & $\begin{array}{c}14.088^{*} \\
{[7.706,20.839]}\end{array}$ & $\begin{array}{c}-3.567 \\
{[-10.474,2.274]}\end{array}$ \\
\hline Proportion $65+$ & $\begin{array}{c}-1.942 \\
{[-5.178,1.024]}\end{array}$ & $\begin{array}{c}-0.387 \\
{[-2.888,2.077]}\end{array}$ & $\begin{array}{c}3.005^{*} \\
{[1.670,4.439]}\end{array}$ & $\begin{array}{c}-4.295 \\
{[-9.389,0.020]}\end{array}$ & $\begin{array}{c}-0.424 \\
{[-4.767,3.861]}\end{array}$ \\
\hline Proportion Below Poverty Line & $\begin{array}{c}0.380 \\
{[-1.309,2.013]}\end{array}$ & $\begin{array}{c}-0.808 \\
{[-2.174,0.642]}\end{array}$ & $\begin{array}{c}1.888^{*} \\
{[1.136,2.706]}\end{array}$ & $\begin{array}{c}-1.597 \\
{[-3.997,0.683]}\end{array}$ & $\begin{array}{c}1.798 \\
{[-0.325,4.321]}\end{array}$ \\
\hline Proportion (18+) High School Graduates & $\begin{array}{c}-1.061 \\
{[-2.565,0.332]}\end{array}$ & $\begin{array}{c}-2.186^{*} \\
{[-3.500,-1.016]}\end{array}$ & $\begin{array}{c}1.411 * \\
{[0.841,1.953]}\end{array}$ & $\begin{array}{c}-1.064 \\
{[-3.139,0.906]}\end{array}$ & $\begin{array}{c}-2.227^{*} \\
{[-4.529,-0.369]}\end{array}$ \\
\hline Proportion White & $\begin{array}{c}-0.323 \\
{[-0.891,0.247]}\end{array}$ & $\begin{array}{c}-0.180 \\
{[-0.646,0.313]}\end{array}$ & $\begin{array}{c}-0.452^{*} \\
{[-0.747,-0.201]}\end{array}$ & $\begin{array}{c}-1.048^{*} \\
{[-2.006,-0.107]}\end{array}$ & $\begin{array}{c}-0.325 \\
{[-1.245,0.509]}\end{array}$ \\
\hline Confederate State & $\begin{array}{c}-0.234 * \\
{[-0.345,-0.113]} \\
\end{array}$ & $\begin{array}{c}-0.031 \\
{[-0.136,0.068]} \\
\end{array}$ & $\begin{array}{c}-0.076^{*} \\
{[-0.135,-0.018]} \\
\end{array}$ & $\begin{array}{c}-0.057 \\
{[-0.256,0.136]} \\
\end{array}$ & $\begin{array}{c}-0.228^{*} \\
{[-0.452,-0.059]}\end{array}$ \\
\hline Dependent Variable & Official Language & Right to Privacy & Environment & $\begin{array}{c}\text { Sexual } \\
\text { Discrimination }\end{array}$ & Abortion \\
\hline \multicolumn{6}{|l|}{ Spatial Dependence } \\
\hline$\rho$ & $\begin{array}{c}0.230 \\
{[-0.170,0.632]}\end{array}$ & $\begin{array}{c}0.492^{*} \\
{[0.158,0.746]}\end{array}$ & $\begin{array}{c}-0.707^{*} \\
{[-0.965,-0.385]}\end{array}$ & $\begin{array}{c}0.282^{*} \\
{[0.045,0.488]}\end{array}$ & $\begin{array}{c}-0.934 * \\
{[-0.998,-0.791]}\end{array}$ \\
\hline \multicolumn{6}{|l|}{ Explanatory Variables } \\
\hline Age of Constitution & $\begin{array}{c}0.001 \\
{[-0.000,0.002]}\end{array}$ & $\begin{array}{c}-0.005^{*} \\
{[-0.010,-0.002]}\end{array}$ & $\begin{array}{c}-0.001^{*} \\
{[-0.001,-0.000]}\end{array}$ & $\begin{array}{c}-0.003 * \\
{[-0.005,-0.002]}\end{array}$ & $\begin{array}{c}-0.000 * \\
{[-0.001,-0.000]}\end{array}$ \\
\hline Population (millions) & $\begin{array}{c}0.018^{*} \\
{[0.009,0.036]}\end{array}$ & $\begin{array}{c}0.027^{*} \\
{[0.014,0.052]}\end{array}$ & $\begin{array}{c}0.008 * \\
{[0.005,0.011]}\end{array}$ & $\begin{array}{c}0.016^{*} \\
{[0.006,0.028]}\end{array}$ & $\begin{array}{c}-0.007 * \\
{[-0.014,-0.003]}\end{array}$ \\
\hline Proportion 5-17 & $\begin{array}{c}1.026 \\
{[-3.200,6.503]}\end{array}$ & $\begin{array}{c}6.550 \\
{[-0.435,15.121]}\end{array}$ & $\begin{array}{c}-4.720^{*} \\
{[-7.342,-2.244]}\end{array}$ & $\begin{array}{c}-0.576 \\
{[-7.134,5.820]}\end{array}$ & $\begin{array}{c}-2.480 * \\
{[-3.924,-1.191]}\end{array}$ \\
\hline Proportion 65+ & $\begin{array}{c}1.379 \\
{[-1.197,4.747]}\end{array}$ & $\begin{array}{c}3.487 \\
{[-1.179,10.069]}\end{array}$ & $\begin{array}{c}-1.357^{*} \\
{[-2.782,-0.065]}\end{array}$ & $\begin{array}{c}-13.863^{*} \\
{[-20.238,-8.740]}\end{array}$ & $\begin{array}{c}-3.052 * \\
{[-4.839,-1.662]}\end{array}$ \\
\hline Proportion Below Poverty Line & $\begin{array}{c}0.640 \\
{[-1.166,2.907]}\end{array}$ & $\begin{array}{c}6.488^{*} \\
{[3.156,11.431]}\end{array}$ & $\begin{array}{c}1.714^{*} \\
{[0.821,2.610]}\end{array}$ & $\begin{array}{c}-1.428 \\
{[-3.914,1.013]}\end{array}$ & $\begin{array}{c}0.234 \\
{[-0.267,0.725]}\end{array}$ \\
\hline Proportion (18+) High School Graduates & $\begin{array}{c}2.361^{*} \\
{[0.372,6.128]}\end{array}$ & $\begin{array}{c}5.374 * \\
{[2.433,9.991]}\end{array}$ & $\begin{array}{c}0.895^{*} \\
{[0.169,1.692]}\end{array}$ & $\begin{array}{c}-0.626 \\
{[-2.837,1.720]}\end{array}$ & $\begin{array}{c}-0.479 * \\
{[-0.821,-0.164]}\end{array}$ \\
\hline Proportion White & $\begin{array}{c}0.305 \\
{[-0.290,0.994]}\end{array}$ & $\begin{array}{c}-0.656 \\
{[-1.800,0.316]}\end{array}$ & $\begin{array}{c}-0.081 \\
{[-0.386,0.207]}\end{array}$ & $\begin{array}{c}0.162 \\
{[-0.710,1.019]}\end{array}$ & $\begin{array}{c}0.879^{*} \\
{[0.510,1.305]}\end{array}$ \\
\hline Confederate State & $\begin{array}{c}0.232 * \\
{[0.074,0.522]} \\
\end{array}$ & $\begin{array}{c}-0.028 \\
{[-0.281,0.172]} \\
\end{array}$ & $\begin{array}{c}0.035 \\
{[-0.019,0.087]}\end{array}$ & $\begin{array}{c}-0.464 * \\
{[-0.689,-0.254]}\end{array}$ & $\begin{array}{c}0.117 * \\
{[0.066,0.173]}\end{array}$ \\
\hline f Observa & & & & & \\
\hline
\end{tabular}

Turning to social constraints, constitutional protection of crime victims' rights exhibits

positive spatial dependence: a state's constitution is more likely to include a so-called 'victims'

bill of rights' if neighboring constitutions contain such provisions. Similarly, constitutional 
health and welfare provisions and an explicit mention of a right to privacy in a state's constitution exhibits positive spatial dependence as well, as does an explicit mention of sexual discrimination. Provisions concerning the environment and abortion both exhibit negative spatial dependence, again indicative of differentiation. No spatial relationship is found in provisions for an official language. Again, these results are largely consistent with the theory discussed above. States' choice of specific constraints, be them fiscal or social, are largely based on the contents of neighboring constitutions.

Tables 4.4 and 4.5 present results analogous to those discussed above estimated using the SDM framework. Again, these models follow the autoregressive process like the SAR model, but include spatially weighted explanatory variables as well. As before, the first set of results (Table 4.4) present the estimates for the government structure variables. The results differ somewhat from the SAR estimates. All three justice selection methods still exhibit positive spatial dependence, as does the provision for direct democracy. Amendment by convention exhibits negative spatial dependence, again as was the case in the SAR estimation. Governor and legislature term limits, however, no longer show signs of spatial dependence, though the $\rho$ parameter in the governor term limit specification remains significant if the credible interval is reduced from $95 \%$ to $90 \%$. Home rule no longer exhibits spatial dependence at the $95 \%$ level, but if the credible interval is reduced to $90 \%$ negative dependence is observed. Recall provisions no longer exhibit spatial dependence. While fewer provisions demonstrate a spatial relationship in the SDM model than did in the SAR model, there is still clear evidence of interaction between neighboring governments with six of the nine provisions tested exhibiting spatial dependence. 
Table 4.4: Spatial Durbin Probit Models: Government Structure

\begin{tabular}{|c|c|c|c|c|c|}
\hline Dependent Variable & $\begin{array}{l}\text { Governor Term } \\
\text { Limit }\end{array}$ & $\begin{array}{l}\text { Legislature Term } \\
\text { Limit }\end{array}$ & Justices Elected & Justices Appointed & $\begin{array}{l}\text { Justices Merit } \\
\text { System }\end{array}$ \\
\hline \multicolumn{6}{|l|}{ Spatial Dependence } \\
\hline$\rho$ & $\begin{array}{c}0.276 \\
{[-0.003,0.522]}\end{array}$ & $\begin{array}{c}-0.010 \\
{[-0.298,0.265]}\end{array}$ & $\begin{array}{c}0.557 * \\
{[0.367,0.720]}\end{array}$ & $\begin{array}{c}0.724 * \\
{[0.581,0.839]}\end{array}$ & $\begin{array}{c}0.387 * \\
{[0.142,0.588]}\end{array}$ \\
\hline \multicolumn{6}{|l|}{ Explanatory Variables } \\
\hline Age of Constitution & $\begin{array}{c}-0.001 \\
{[-0.002,0.000]}\end{array}$ & $\begin{array}{c}-0.001 \\
{[-0.002,0.000]}\end{array}$ & $\begin{array}{c}-0.005^{*} \\
{[-0.009,-0.002]}\end{array}$ & $\begin{array}{c}0.010 * \\
{[0.005,0.017]}\end{array}$ & $\begin{array}{c}-0.005^{*} \\
{[-0.007,-0.003]}\end{array}$ \\
\hline Population (millions) & $\begin{array}{c}-0.020^{*} \\
{[-0.034,-0.008]}\end{array}$ & $\begin{array}{c}0.021^{*} \\
{[0.012,0.033]}\end{array}$ & $\begin{array}{c}-0.013 \\
{[-0.035,0.007]}\end{array}$ & $\begin{array}{c}0.035^{*} \\
{[0.003,0.074]}\end{array}$ & $\begin{array}{c}-0.046^{*} \\
{[-0.075,-0.024]}\end{array}$ \\
\hline Proportion 5-17 & $\begin{array}{c}-7.332 * \\
{[-16.892,-0.449]}\end{array}$ & $\begin{array}{c}-1.365 \\
{[-6.391,3.173]}\end{array}$ & $\begin{array}{c}-2.244 \\
{[-16.904,12.005]}\end{array}$ & $\begin{array}{c}11.245 \\
{[-10.442,34.093]}\end{array}$ & $\begin{array}{c}-10.946^{*} \\
{[-20.989,-2.469]}\end{array}$ \\
\hline Proportion $65+$ & $\begin{array}{c}2.712 \\
{[-2.256,8.160]}\end{array}$ & $\begin{array}{c}4.614 * \\
{[1.317,8.726]}\end{array}$ & $\begin{array}{c}-9.835^{*} \\
{[-20.007,-1.197]}\end{array}$ & $\begin{array}{c}23.431^{*} \\
{[8.484,41.527]}\end{array}$ & $\begin{array}{c}6.257^{*} \\
{[0.590,12.964]}\end{array}$ \\
\hline Proportion Below Poverty Line & $\begin{array}{c}2.176 \\
{[-0.721,5.243]}\end{array}$ & $\begin{array}{c}1.002 \\
{[-1.068,2.981]}\end{array}$ & $\begin{array}{c}12.422 * \\
{[6.324,20.578]}\end{array}$ & $\begin{array}{c}-10.642 * \\
{[-21.313,-2.472]}\end{array}$ & $\begin{array}{c}-7.066^{*} \\
{[-11.775,-3.163]}\end{array}$ \\
\hline Proportion (18+) High School Graduates & $\begin{array}{c}3.119 * \\
{[0.390,6.476]}\end{array}$ & $\begin{array}{c}5.514 * \\
{[3.236,8.208]}\end{array}$ & $\begin{array}{c}-0.264 \\
{[-5.279,4.441]}\end{array}$ & $\begin{array}{c}-1.892 \\
{[-9.550,5.755]}\end{array}$ & $\begin{array}{c}-0.062 \\
{[-3.261,3.135]}\end{array}$ \\
\hline Proportion White & $\begin{array}{c}-2.148 * \\
{[-3.897,-0.879]}\end{array}$ & $\begin{array}{c}0.162 \\
{[-0.660,1.066]}\end{array}$ & $\begin{array}{c}1.999 * \\
{[0.021,4.312]}\end{array}$ & $\begin{array}{c}-2.152 \\
{[-5.568,0.922]}\end{array}$ & $\begin{array}{c}2.502 * \\
{[0.865,4.630]}\end{array}$ \\
\hline Confederate State & $\begin{array}{c}-0.571 * \\
{[-1.013,-0.255]}\end{array}$ & $\begin{array}{c}0.160 \\
{[-0.028,0.375]}\end{array}$ & $\begin{array}{c}0.126 \\
{[-0.322,0.590]}\end{array}$ & $\begin{array}{c}-1.693 * \\
{[-2.843,-0.846]}\end{array}$ & $\begin{array}{c}-0.331^{*} \\
{[-0.700,-0.012]}\end{array}$ \\
\hline Dependent Variable & Recall & Home Rule & $\begin{array}{l}\text { Amend by } \\
\text { Convention }\end{array}$ & Direct Democracy & \\
\hline$\overline{\text { Spatial Dependence }}$ & & & & & \\
\hline$\rho$ & $\begin{array}{c}0.151 \\
{[-0.265,0.500]}\end{array}$ & $\begin{array}{c}-0.380 \\
{[-0.772,0.002]}\end{array}$ & $\begin{array}{c}-0.974 * \\
{[-1.000,-0.905]}\end{array}$ & $\begin{array}{c}0.359 * \\
{[0.116,0.599]}\end{array}$ & \\
\hline Explanatory Variables & & & & & \\
\hline Age of Constitution & $\begin{array}{c}-0.003^{*} \\
{[-0.006,-0.002]}\end{array}$ & $\begin{array}{c}-0.001^{*} \\
{[-0.002,-0.001]}\end{array}$ & $\begin{array}{c}-0.002 * \\
{[-0.002,-0.002]}\end{array}$ & $\begin{array}{c}-0.001^{*} \\
{[-0.003,-0.000]}\end{array}$ & \\
\hline Population (millions) & $\begin{array}{c}-0.006 \\
{[-0.022,0.005]}\end{array}$ & $\begin{array}{c}0.043 * \\
{[0.028,0.061]}\end{array}$ & $\begin{array}{c}0.013 * \\
{[0.009,0.016]}\end{array}$ & $\begin{array}{c}-0.024 * \\
{[-0.041,-0.012]}\end{array}$ & \\
\hline Proportion 5-17 & $\begin{array}{c}-10.356^{*} \\
{[-22.334,-2.322]}\end{array}$ & $\begin{array}{c}-1.789 \\
{[-5.589,1.140]}\end{array}$ & $\begin{array}{c}-3.019^{*} \\
{[-5.561,-0.688]}\end{array}$ & $\begin{array}{c}3.544 \\
{[-8.409,15.964]}\end{array}$ & \\
\hline Proportion $65+$ & $\begin{array}{c}-12.463 * \\
{[-20.591,-6.850]}\end{array}$ & $\begin{array}{c}3.005^{*} \\
{[0.339,5.866]}\end{array}$ & $\begin{array}{c}-6.018^{*} \\
{[-7.670,-4.278]}\end{array}$ & $\begin{array}{c}13.375^{*} \\
{[7.300,21.951]}\end{array}$ & \\
\hline Proportion Below Poverty Line & $\begin{array}{c}-2.169 \\
{[-6.470,0.860]}\end{array}$ & $\begin{array}{c}1.444^{*} \\
{[0.058,2.828]}\end{array}$ & $\begin{array}{c}-0.278 \\
{[-1.042,0.440]}\end{array}$ & $\begin{array}{c}0.357 \\
{[-2.790,3.527]}\end{array}$ & \\
\hline Proportion (18+) High School Graduates & $\begin{array}{c}-2.668^{*} \\
{[-6.048,-0.098]}\end{array}$ & $\begin{array}{c}1.186^{*} \\
{[0.047,2.394]}\end{array}$ & $\begin{array}{c}1.440^{*} \\
{[0.700,2.134]}\end{array}$ & $\begin{array}{c}1.402 \\
{[-1.240,4.017]}\end{array}$ & \\
\hline Proportion White & $\begin{array}{c}-1.003 \\
{[-2.744,0.119]}\end{array}$ & $\begin{array}{c}-0.011 \\
{[-0.571,0.468]}\end{array}$ & $\begin{array}{c}-0.007 \\
{[-0.289,0.252]}\end{array}$ & $\begin{array}{c}-5.160 * \\
{[-7.557,-3.484]}\end{array}$ & \\
\hline Confederate State & $\begin{array}{c}0.0227 \\
{[-0.205,0.331]}\end{array}$ & $\begin{array}{c}-0.229 * \\
{[-0.371,-0.115]}\end{array}$ & $\begin{array}{c}0.108 * \\
{[0.038,0.178]}\end{array}$ & $\begin{array}{c}-0.809 * \\
{[-1.221,-0.516]}\end{array}$ & \\
\hline
\end{tabular}


Table 4.5: Spatial Durbin Models: Fiscal and Social Constraints

\begin{tabular}{|c|c|c|c|c|c|}
\hline Dependent Variable & Balanced Budget & TEL & Line Item Veto & $\begin{array}{l}\text { Victims' Bill of } \\
\text { Rights }\end{array}$ & $\begin{array}{l}\text { Health and } \\
\text { Welfare }\end{array}$ \\
\hline \multicolumn{6}{|l|}{ Spatial Dependence } \\
\hline$\rho$ & $\begin{array}{c}-0.575^{*} \\
{[-0.870,-0.265]}\end{array}$ & $\begin{array}{c}-0.861^{*} \\
{[-0.996,-0.585]}\end{array}$ & $\begin{array}{c}-0.754 * \\
{[-0.988,-0.351]}\end{array}$ & $\begin{array}{c}-0.027 \\
{[-0.384,0.302]}\end{array}$ & $\begin{array}{c}0.455^{*} \\
{[0.148,0.722]}\end{array}$ \\
\hline \multicolumn{6}{|l|}{ Explanatory Variables } \\
\hline Age of Constitution & $\begin{array}{c}-0.001 * \\
{[-0.002,-0.001]}\end{array}$ & $\begin{array}{c}-0.001 * \\
{[-0.002,-0.001]}\end{array}$ & $\begin{array}{c}-0.001 * \\
{[-0.001,-0.001]}\end{array}$ & $\begin{array}{c}-0.001 * \\
{[-0.002,-0.000]}\end{array}$ & $\begin{array}{c}-0.001 \\
{[-0.003,0.001]}\end{array}$ \\
\hline Population (millions) & $\begin{array}{c}-0.003 \\
{[-0.009,0.003]}\end{array}$ & $\begin{array}{c}0.012 * \\
{[0.009,0.016]}\end{array}$ & $\begin{array}{c}0.019^{*} \\
{[0.012,0.028]}\end{array}$ & $\begin{array}{c}-0.005 \\
{[-0.014,0.004]}\end{array}$ & $\begin{array}{c}0.046^{*} \\
{[0.025,0.082]}\end{array}$ \\
\hline Proportion 5-17 & $\begin{array}{c}2.387 \\
{[-1.593,6.742]}\end{array}$ & $\begin{array}{c}-3.078^{*} \\
{[-6.401,-0.457]}\end{array}$ & $\begin{array}{c}-0.396 \\
{[-2.613,1.277]}\end{array}$ & $\begin{array}{c}11.640^{*} \\
{[5.794,19.145]}\end{array}$ & $\begin{array}{c}3.530 \\
{[-6.775,15.493]}\end{array}$ \\
\hline Proportion $65+$ & $\begin{array}{c}-1.687 \\
{[-4.280,0.814]}\end{array}$ & $\begin{array}{c}-1.037 \\
{[-2.677,0.628]}\end{array}$ & $\begin{array}{c}4.457^{*} \\
{[2.397,8.056]}\end{array}$ & $\begin{array}{c}0.360 \\
{[-2.643,3.657]}\end{array}$ & $\begin{array}{c}1.619 \\
{[-3.833,7.827]}\end{array}$ \\
\hline Proportion Below Poverty Line & $\begin{array}{c}-1.266 \\
{[-3.001,0.449]}\end{array}$ & $\begin{array}{c}-1.830^{*} \\
{[-2.914,-0.757]}\end{array}$ & $\begin{array}{c}0.517 \\
{[-0.215,1.254]}\end{array}$ & $\begin{array}{c}-3.695^{*} \\
{[-6.985,-1.181]}\end{array}$ & $\begin{array}{c}1.231 \\
{[-2.478,5.358]}\end{array}$ \\
\hline Proportion (18+) High School Graduates & $\begin{array}{c}-1.580^{*} \\
{[-3.008,-0.161]}\end{array}$ & $\begin{array}{c}-1.119^{*} \\
{[-1.986,-0.237]}\end{array}$ & $\begin{array}{c}2.352^{*} \\
{[1.485,3.565]}\end{array}$ & $\begin{array}{c}-2.715^{*} \\
{[-5.104,-0.641]}\end{array}$ & $\begin{array}{c}-4.308^{*} \\
{[-9.435,-0.967]}\end{array}$ \\
\hline Proportion White & $\begin{array}{c}-0.513 \\
{[-1.116,0.092]}\end{array}$ & $\begin{array}{c}-0.036 \\
{[-0.432,0.345]}\end{array}$ & $\begin{array}{c}-0.128 \\
{[-0.503,0.175]}\end{array}$ & $\begin{array}{c}-1.858^{*} \\
{[-3.085,-0.864]}\end{array}$ & $\begin{array}{c}-0.286 \\
{[-1.606,0.893]}\end{array}$ \\
\hline Confederate State & $\begin{array}{c}-0.595 \\
{[-0.177,0.057]} \\
\end{array}$ & $\begin{array}{c}-0.071 \\
{[-0.144,0.002]} \\
\end{array}$ & $\begin{array}{c}-0.074 \\
{[-0.168,0.001]} \\
\end{array}$ & $\begin{array}{c}0.081 \\
{[-0.090,0.259]} \\
\end{array}$ & $\begin{array}{c}-0.610^{*} \\
{[-1.234,-0.271]} \\
\end{array}$ \\
\hline Dependent Variable & Official Language & Right to Privacy & Environment & $\begin{array}{c}\text { Sexual } \\
\text { Discrimination }\end{array}$ & Abortion \\
\hline Spatial Dependence & & & & & \\
\hline Frnlanatory Variables & $\begin{array}{c}-0.472 * \\
{[-0.904,-0.065]}\end{array}$ & $\begin{array}{c}0.472 \\
{[-0.371,0.770]}\end{array}$ & $\begin{array}{c}-0.402 \\
{[-0.857,0.379]}\end{array}$ & $\begin{array}{c}0.664 * \\
{[0.488,0.804]}\end{array}$ & $\begin{array}{c}-0.758^{*} \\
{[-0.406,-0.987]}\end{array}$ \\
\hline Explanatory Variables & & & & & \\
\hline Age of Constitution & $\begin{array}{c}0.001 * \\
{[0.000,0.002]}\end{array}$ & $\begin{array}{c}-0.007 * \\
{[-0.016,-0.001]}\end{array}$ & $\begin{array}{c}-0.001^{*} \\
{[-0.003,-0.000]}\end{array}$ & $\begin{array}{c}-0.010^{*} \\
{[-0.016,-0.005]}\end{array}$ & $\begin{array}{c}-0.003^{*} \\
{[-0.001,-0.000]}\end{array}$ \\
\hline Population (millions) & $\begin{array}{c}0.022 * \\
{[0.013,0.034]}\end{array}$ & $\begin{array}{c}0.047^{*} \\
{[0.018,0.097]}\end{array}$ & $\begin{array}{c}0.012^{*} \\
{[0.006,0.033]}\end{array}$ & $\begin{array}{c}0.050^{*} \\
{[0.017,0.101]}\end{array}$ & $\begin{array}{c}-0.012^{*} \\
{[-0.021,-0.007]}\end{array}$ \\
\hline Proportion 5-17 & $\begin{array}{c}-3.776^{*} \\
{[-7.383,-1.349]}\end{array}$ & $\begin{array}{c}-0.162 \\
{[-8.013,7.385]}\end{array}$ & $\begin{array}{c}-8.979 * \\
{[-18.629,-4.051]}\end{array}$ & $\begin{array}{c}18.973 \\
{[-1.214,44.208]}\end{array}$ & $\begin{array}{c}-1.956^{*} \\
{[-3.755,-0.757]}\end{array}$ \\
\hline Proportion $65+$ & $\begin{array}{c}-0.941 \\
{[-2.362,0.300]}\end{array}$ & $\begin{array}{c}14.820^{*} \\
{[1.227,35.772]}\end{array}$ & $\begin{array}{c}-0.561 \\
{[-4.241,1.607]}\end{array}$ & $\begin{array}{c}-30.762 * \\
{[-49.437,-16.568]}\end{array}$ & $\begin{array}{c}-1.335^{*} \\
{[-2.860,-0.393]}\end{array}$ \\
\hline Proportion Below Poverty Line & $\begin{array}{c}-0.848^{*} \\
{[-1.793,-0.111]}\end{array}$ & $\begin{array}{c}-1.098 \\
{[-4.014,1.086]}\end{array}$ & $\begin{array}{c}4.160^{*} \\
{[1.765,11.579]}\end{array}$ & $\begin{array}{c}1.681 \\
{[-4.934,8.768]}\end{array}$ & $\begin{array}{c}0.707^{*} \\
{[0.190,1.557]}\end{array}$ \\
\hline Proportion (18+) High School Graduates & $\begin{array}{c}1.442 * \\
{[0.509,2.465]}\end{array}$ & $\begin{array}{c}5.486^{*} \\
{[1.422,11.185]}\end{array}$ & $\begin{array}{c}1.985^{*} \\
{[0.508,5.802]}\end{array}$ & $\begin{array}{c}-4.452 \\
{[-10.986,1.684]}\end{array}$ & $\begin{array}{c}-0.222 \\
{[-0.695,0.265]}\end{array}$ \\
\hline Proportion White & $\begin{array}{c}0.285 \\
{[-0.001,0.775]}\end{array}$ & $\begin{array}{c}-4.333^{*} \\
{[-10.528,-0.433]}\end{array}$ & $\begin{array}{c}-0.105 \\
{[-0.670,0.428]}\end{array}$ & $\begin{array}{c}-0.611 \\
{[-2.864,1.718]}\end{array}$ & $\begin{array}{c}0.563 * \\
{[0.263,0.998]}\end{array}$ \\
\hline Confederate State & $\begin{array}{c}-0.001 \\
{[-0.107,0.089]}\end{array}$ & $\begin{array}{c}-0.046 \\
{[-0.461,0.245]}\end{array}$ & $\begin{array}{c}0.141 * \\
{[0.033,0.291]} \\
\end{array}$ & $\begin{array}{c}-2.253^{*} \\
{[-3.590,-1.327]}\end{array}$ & $\begin{array}{c}0.048^{*} \\
{[0.001,0.099]} \\
\end{array}$ \\
\hline
\end{tabular}

Table 4.5 presents SDM estimates for the ten fiscal and social constraints. The balanced

budget requirement, tax and expenditure limits, and line item veto provisions show negative spatial dependence, as was the case in the SAR models (with the balanced budget specification's $\rho$ estimate $95 \%$ credible interval no longer containing zero). Similarly, environmental and abortion provisions continue to exhibit negative spatial dependence, though the spatial 
relationship in environmental rules is only present with a $90 \%$ credible interval. Sexual discrimination provisions exhibit positive spatial dependence, consistent with the SAR estimation, as does the health and welfare provision.

The SDM estimation yields evidence of spatial dependence in the presence of an official language in state constitutions, which was not found in the SAR estimation. Notably absent in the SDM results is spatial dependence in the victims' bill or rights and the right to privacy, both of which showed a spatial relationship in the SAR model.

As before, the inclusion of the spatially weighted explanatory variables led to a reduction in the number of provisions exhibiting spatial dependence, though others, such as balanced budget and official language provisions, now show evidence of a spatial relationship. While fewer fiscal and social constraints exhibit spatial dependence than in the SAR model, clear evidence still exists that state constitutions are correlated in space. Seven of the ten rules considered exhibit spatial dependence at the $95 \%$ credible level, with an additional constraint providing weaker evidence at the $90 \%$ credible level.

Bayesian estimation allows for a unique type of model comparison. Specifically, the technique (which is described in detail in LeSage and Pace (2009)) involves comparing the posterior model probabilities of the SAR and SDM models presented above for each constitutional rule individually. The posterior model probability comes from an application of Bayes' rule, and can be thought of as the probability of a model's 'correctness' given the data. Since the SDM model is a special case of the SAR model, comparison of the SDM to the SAR essentially test for the validity of including the spatially weighted explanatory variables. For all nineteen rules considered, the SDM model far outperforms the SAR model. 
Taken together, these results strongly support the hypothesis that state constitutions are designed in response to neighboring institutions. Further, they provide additional evidence of diffusion of constitutional provisions between neighboring states. Both probit model estimations provide clear evidence that state constitutional provisions concerning supreme court justice selection, direct democracy, constitutional amendment by convention, tax and expenditure limits, line item veto, health and welfare, sexual discrimination, and abortion are related to the presence of the rule in neighboring states' constitutions. Further, provisions for both gubernatorial and legislative term limits, recall, home rule, balanced budget requirements, victims' rights, official language, privacy, and environmental protection all exhibit spatial dependence in at least one of the models estimated, lending additional credence to the theory.

\subsection{Conclusion}

Both Holcombe's (1994) argument that constitutions serve as a substitute for mobility and the phenomenon of policy and institutional diffusion suggest that state constitutions can be based, at least in part, on the constitutions of neighboring states. This paper presents a theory of constitutional design where states respond to neighboring states' choice of constraints in a manner similar to 'yardstick competition.' The theory proposed above is uniquely testable using spatial econometric methods, and effectively makes constitutional rules endogenous, adding to a relatively underdeveloped area in the constitutional political economy literature (Voigt 1997, 2010).

A state government's power over its residents is limited by both constitutional constraint and the geographic boundaries which determine its domain. Voter-residents, then, are able to escape a government's reach either by imposing stricter constraints or crossing the border into a 
neighboring state. Over time as mobility costs fall, especially between neighboring states, interstate constitutional differentials become an important factor in resident choice. As a result of this, states are likely to turn to neighbors when choosing constitutional structure.

The analysis is based on two spatial econometric models tested on nineteen specific constitutional provisions. The results provide clear evidence of spatial dependence in state constitutions, consistent with the proposed theory. Specifically, all nineteen rules analyzed exhibited spatial dependence in at least one of the probit models considered, with more than half of the rules showing dependence in both models.

This paper adds to the constitutional political economy literature in several ways. While a great deal of normative work has been done on constitutional design, less applied empirical research on the choice of constitutional constraints exists. This paper provides the first spatial econometric analysis of U.S. state constitutional structure. Further, the primary analysis focuses on specific provisions rather than aggregate measures of constitutional constraints. Hopefully, the findings discussed above help to spur on additional work in this area.

Additionally, these results speak to the importance of considering neighboring institutions when analyzing constitutional constraints. A straightforward implication of the present paper is that not only is the origin of constitutional rules a function of neighboring institutions, but so too is their effectiveness. As the majority of the constitutional constraint literature is concerned with the effectiveness of certain rules, consideration of these questions in a spatial framework would seem to be a fruitful area for future research.

Finally, the results of this empirical investigation have important implications for constitutional reform. Since states' constitutions are based in part on neighboring constitutions, reform efforts targeted in a given state may be expected to spill over into neighboring states. On 
the other hand, reforms in a state surrounded by 'bad' institutions could be of limited value as the neighbors' policies may diffuse into the state. In this case, a reform would need to target an entire region. This becomes even more important if the results presented above hold for international constitutions. A more thorough study of constitutional change in a setting of spatial dependence seems to be a clear extension of the empirical analysis presented here. 


\section{Chapter 5}

\section{Conclusion}

\subsection{Types of Strategic Interaction}

The analysis of strategic interaction amongst governments has been a longstanding research program in both public choice and public finance. Theoretical work in both the public choice tradition [such as Brennan and Buchanan (1977, 1978, 1980), who view intergovernmental competition as a constraint on Leviathan] as well as in public finance [such as Mintz and Tulkens (1986) who analyze competition between jurisdictions in the context of efficient public goods provision] has been followed by a voluminous empirical literature. The essays in this dissertation follow this tradition, and explore areas of strategic interaction between governments which were previously underdeveloped.

Chapter 2 presents a theoretical model combining the seminal paper by Weingast, Shepsle, and Johnsen (1981) [who posit the 'Law of 1/n' which states that as a legislature increases in size, the amount of inefficient projects it passes will similarly increase] with the Leviathan model of Brennan and Buchanan $(1977,1978,1980)$. While each model predicts an impact on government size following a change in the number of relevant jurisdictions (legislative vs. administrative), the Leviathan theory predicts decreases in spending while the $1 / \mathrm{n}$ model predicts the opposite. The key implication of the model presented in Chapter 2 is that the relationship between the two types of jurisdictions, which varies greatly across the U.S. states, is a key determinant of which effect will dominate.

Chapter 3 further explores the Leviathan hypothesis using two distinct approaches. First, a Laffer curve model is used to compare the tax-setting behavior of local Pennsylvania governments (municipalities, counties, and school districts) to the estimated revenue-maximizing 
rate. The further are the rates set by these governments from revenue-maximization, the less 'Leviathan-like' is their behavior. Second, a spatial autoregressive model is employed to estimate the level of dependence between governments. We then present a new taxonomy of government interaction using these two approaches.

Finally, Chapter 4 explores yet another type of strategic interaction between governments. Specifically, it models diffusion of constitutional provisions across the U.S. states. While policy diffusion has been studied in the political science and (to a lesser extent) public economics literatures, spatial econometric methods have not been employed. There are several theories which predict a spatial diffusion of constitutional rules, and Chapter 4 specifically extends the logic of Holcombe's (1994) argument of constitutions serving as a substitute for mobility, and tests it using spatial models.

\subsection{Primary Findings}

While the Brennan and Buchanan $(1977,1978,1980)$ Leviathan hypothesis has been tested repeatedly in the empirical literature, no clear consensus as to its validity has developed. While many studies do find a negative relationship between measures of decentralization and government size, nearly as many find either no relationship or even a positive effect. Chapter 2 argues that a possible explanation for these contradictory results is that previous studies have neglected to control for the Law of $1 / n$. If increases in fiscal decentralization lead to increases in the size of the legislature, the effect may appear ambiguous.

The theoretical model predicts, and the empirical analysis supports, this hypothesis. Specifically, I find that increases in fiscal decentralization do lead to decreases in government size, while increases in legislature size do lead to increases in spending. These results hold when 
tested separately and together. Further, and more interestingly, the effect of increased decentralization is partially offset by the ' $1 / \mathrm{n}$ effect' and the degree to which this occurs is a function of the 'link' between administrative jurisdictions (such as counties) and legislative districts. These results are robust to a variety of specifications, and to the exclusion of outliers or states without county governments.

To this point, the majority of the work on strategic interaction in the literature has focused on fiscal behavior and modeled tax and/or expenditure competition. These models typically examine a given government's response to changes in tax/expenditure policy undertaken by neighboring jurisdictions. Whether these empirical analyses are motivated by a public choice theory of competition as a constraint or a public finance analysis of the potential for a 'race to the bottom,' these studies typically find evidence of strategic interaction in fiscal behavior.

In Chapter 3, we employ two distinct models of tax competition and analyze the taxsetting behavior of three levels of local government in Pennsylvania. Our Laffer curve model shows that municipalities (which are the most numerous) set taxes the furthest from revenuemaximization. Counties (which are the least numerous) set taxes nearer revenue-maximization. Our spatial econometric models echo these results, with municipalities showing a higher degree of spatial dependence than counties. School districts, however, set rates nearest revenuemaximization while simultaneously exhibiting the highest degree of spatial dependence. These seemingly-contradictory results are only plausible if spatial dependence is not necessarily a measure of competition, but can instead reflect its opposite, collusive behavior. Thus, we present a taxonomy which uses the results of these two approaches to categorize the type of behavior undertaken at each level of government. 
While Chapters 2 and 3 follow the majority of the literature by focusing on fiscal implications of strategic interaction, in Chapter 4 I present the first spatial econometric analysis of diffusion of constitutional rules. Following previous studies of diffusion and the work of Holcombe (1994), I show that state constitutions are designed, at least in part, in response to neighboring institutions. Specifically, all nineteen of the constitutional provisions (ranging from the oft-studied, such as balanced budget rules, to the previously neglected, such as official language provisions) considered exhibit spatial dependence in at least one of the specifications. These empirical results are consistent with previous studies of diffusion, as well as the theoretical model presented in the chapter.

\subsection{Policy Implications and Future Research}

These results have numerous policy implications. First, fiscal decentralization may not necessarily lead to smaller government if it is accompanied by increases in the size of the legislature. Similarly, large legislatures that are characterized by similarly large amounts of intergovernmental competition may not necessarily be home to large governments. Chapter 2 shows that the link between administrative and legislative districts is a key factor in understanding the relationship between the number of jurisdictions and government size. Any attempts to reform government with the goal of limiting total expenditure need to be aware of this relationship.

Further complicating the relationship between the number of governments and government size is the issue of potentially collusive behavior. Chapter 3 provides a framework for differentiating intergovernmental competition from cooperative behavior. As noted by Brennan and Buchanan (1977, 1978, 1980), fiscal decentralization is not an effective constraint 
on Leviathan if it is subsequently circumvented by collusion. This seems to be the case with school districts, as they receive a relatively high level of grants, face the unique complication of negotiation with a single powerful teachers' union (essentially collectivizing a portion of their finances by definition) and are organized under a single Department of Education. As before, reforms targeting total expenditure need to take this type of cooperative behavior into account.

Finally, the diffusion of policy is important for attempts at constitutional reform. If a state finds itself surrounded by 'bad' institutions, any reform may not be as effective if these neighboring institutions diffuse back into the state. On the other hand, if the reform is able to diffuse into the neighboring states, an entire region's constitutional structure could be affected by a reform in a single state. This becomes even more crucial if the results found in Chapter 4 can be generalized to international constitutions. Clearly, a better understanding of this phenomenon is needed to fully exploit it for constitutional reform.

While each of these essays has extended the existing literature by exploring new questions in new ways, there is still quite a bit of work left for future research. The relationship between the Leviathan and $1 / \mathrm{n}$ models indicates previous studies of fiscal decentralization may have underestimated its effects by ignoring the legislature. Similarly, the $1 / \mathrm{n}$ effect may have been overestimated by studies which ignore the role of fiscal decentralization. Future work in these areas would do well to explicitly consider this relationship.

The current literature's reliance on spatial dependence as a measure of competition is called into question by the results in Chapter 3. Specifically, a high degree of spatial dependence may in fact suggest the exact opposite result: collusion. A second model, such as the Laffer curve approach, is needed to truly identify the nature of spatial dependence. Previous studies of the Leviathan hypothesis have assumed competition without testing for it, while the previous tax 
competition literature has not explicitly tested its consequences. A unified approach, such as the taxonomy presented at the end of the chapter, will provide a fruitful avenue for future research.

Finally, the finding of spatial dependence in constitutional design leads to several interesting research questions. First, a better understanding of the mechanism through which diffusion takes place is needed. Further, if the origin of constitutional rules is spatially dependent, then perhaps so is there effectiveness. Since the effectiveness of constitutional rules has been the focus of the majority of the empirical constitutional political economy literature, the exploration of these ideas in a spatial econometric framework would seem to be a logical next step. Finally, as constitutional provisions exhibit spatial dependence, it will be interesting to see what other types of institutions do as well. 


\section{REFERENCES}

Akai, Nobuo and Masay Sakata. 2002. "Fiscal Decentralization Contributes to Economic

Growth: Evidence from State-level Cross-section Data for the United States.” Journal of Urban Economics 52:93-108.

Allers, Maarten A. and J. Paul Elhorst. 2005. “Tax Mimicking and Yardstick Competition Among Local Governments in the Netherlands." International Tax and Public Finance 12: 493-513.

Anderson, John E. and Hendrik van den Berg. 1998. "Fiscal Decentralization and Government Size: An International Test for Leviathan Accounting for Unmeasured Economic Activity." International Tax and Public Finance 5:71-186.

Arikan, G. Gulsun. 2004. “Fiscal Decentralization: A Remedy for Corruption?” International Tax and Public Finance 11:175-195.

Baicker, Katherine. 2005. "The Spillover Effects of State Spending." Journal of Public Economics 89:529-544.

Bails, Dale and Margie A. Tieslau. 2000. “The Impact of Fiscal Constitutions on State and Local Expenditures." Cato Journal 20, 2: 255-277.

Baird, Robert N. and John H. Landon. 1972. "Political Fragmentation, Income Distribution, and the Demand for Government Services." Nebraska Journal of Economics and Business 11:171-184.

Baqir, Reza. 2002. "Districting and Government Overspending." Journal of Political Economy 110(6):1318-1354.

Beck, Nathaniel and Jonathan N. Katz. 1995. "What To Do (and Not To Do) With Time-Series Cross-Section Data." American Political Science Review 89(3):634-647. 
Benjamin, Gerald. 1985. "The Diffusion of Eexecutive Power in American State Constitutions: Tenure and Tenure Limitations." Publius 15, 4: 71-84.

Besley, Timothy J. and Anne Case. 1995a. "Does Electoral Accountability Affect Economic Policy Choices? Evidence from Gubernatorial Term Limits." Quarterly Journal of Economics 110: 769-798.

----. 1995b. "Incumbent Behavior: Vote-Seeking, Tax-Setting, and Yardstick Competition." American Economic Review 85, 1: 25-45.

Blume, Lorenz, Jens Müller, Stefan Voigt, and Carsten Wolf. 2009. "The Economic Effects of Constitutions: Replicating—and Extending—Persson and Tabellini.” Public Choice 139: $197-225$.

Boix, Carles. 1999. "Setting the Rules of the Game: The Choice of Electoral Systems in Advanced Democracies." American Political Science Review 93, 3: 609-624.

Boyne, George A. 1992. "Local Government Structure and Performance: Lessons from America?" Public Administration 70:333-357.

Bradbury, John Charles and W. Mark Crain. 2001. "Legislative Organization and Government Spending: Cross-Country Evidence.” Journal of Public Economics 82:309-325.

Bradbury, John Charles and E. Frank Stephenson. 2003. "Local Government Structure and Public Expenditures." Public Choice 115(1\&2):185-198.

Brennan, Geoffrey and James Buchanan. 1977. "Towards a Tax Constitution for Leviathan." Journal of Public Economics 8:255-274.

----. 1978. “Tax Instruments as Constraints on the Disposition of Public Revenues.” Journal of Public Economics 9:301-318. 
----. 1980. The Power to Tax: Analytical Foundations of a Fiscal Constitution, Cambridge University Press.

Brett, Craig and Joris Pinkse. 2000. "The Determinants of Municipal Tax Rates in British Columbia." Canadian Journal of Economics 33:695-714.

Brueckner, Jan K. 2000. “A Tiebout/Tax-competition Model.” Journal of Public Economics 77:285-306.

----. 2003. "Strategic Interaction Among Governments: An Overview of Empirical Studies." International Regional Science Review 26:175-188.

----. 2006. “Fiscal Federalism and Economic Growth.” Journal of Public Economics 90:21072120.

Brueckner, Jan and Luz Saavedra. 2001. "Do Local Governments Engage in Strategic PorpertyTax Competition?" National Tax Journal 54:203-229.

Buchanan, James M. 1975. The Limits of Liberty: Between Anarchy and Leviathan. Chicago: University of Chicago Press.

----. 1990. “The Domain of Constitutional Economics.” Constitutional Political Economy 1,1:1-18.

----. 1995. "Federalism as an Ideal Political Order and an Objective for Constitutional Reform.” Publius 25(2):19-27.

Buchanan, James M. and Gordon Tullock. 1962. The Calculus of Consent: Logical Foundations of Constitutional Democracy. Ann Arbor: University of Michigan Press.

Buettner, Thiess. 2001. "Local Business Taxation and Competition for Capital: The Choice of the Tax Rate." Regional Science and Urban Economics 31:215-245. 
Caldeira, Gregory A. 1985. "Cosntitutional Change in America: Dynamics of Ratification Under Article V.” Publius 15, 4: 29-49.

Carter, John R. and David Schap. 1990. "Line-Item Veto: Where is Thy Sing?” Journal of Economic Perspectives 4, 2: 103-118.

Cassette, Aurélie and Sonia Paty. Forthcoming. "Fiscal Decentralization and the Size of Government: A European Country Empirical Analysis." Public Choice.

Chen, Jowei and Neil Malhotra. 2007. "The Law of k/n: The Effect of Chamber Size on Government Spending in Bicameral Legislatures.” American Political Science Review 101(4): 657-676.

Chicoine, David L. and Norman Walzer. 1985. Governmental Structure and Local Public Finance. Boston: Oelgeschlanger, Funn \& Hain.

Crain, W. Michael. 1999. "Districts, Diversity, and Fiscal Biases: Evidence from the American States.” Journal of Law and Economics 42(2):675-698.

Crowley, George R. and Russell S. Sobel. 2010. “Does Fiscal Decentralization Constrain Leviathan? New Evidence from Local Property Tax Competition.” West Virginia University Department of Economics Working Paper, Number 10-16.

Dowding, Keith, Peter John, and Stephen Biggs. 1994. "Tiebout: A Survey of the Empirical Literature.” Urban Studies 31(4\&5):767-797.

Dye, Richard F. and Therese J. McGuire. 1997. “The Effect of Property Tax Limitation Measures on Local Government Fiscal Behavior.” Journal of Public Economics 66:469487. 
Eberts, Randall W. and Timothy J. Gronberg. 1988. “Can Competition Among Local Governments Constrain Government Spending?” Economic Review 24:2-9, Federal Reserve Bank of Cleveland.

Elhorst, J. Paul. 2009. “Spatial Panel Data Models.” In Fischer M. and A Getis (Eds.) Handbook of Applied Spatial Analysis. Springer: Berlin Heidelberg New York.

Elhorst, J.P. and S. Fréret. Forthcoming. "Evidence of Political Yardstick Competition in France using a Two-regime Spatial Durbin Model with Fixed Effects.” Journal of Regional Science.

Epple, Dennis and Allan Zelenitz. 1981. “The Implications of Competition among Jurisdictions: Does Tiebout Need Politics?” Journal of Political Economy 89:1197-1217.

Faguet, Jean-Paul. 2004. "Does Decentralization Increase Government Responsiveness to Local Needs? Evidence from Bolivia.” Journal of Public Economics 88:867-893.

Fiva, Jon H. and Jørn Rattsø. 2007. "Local Choice of Property Taxation: Evidence from Norway." Public Choice 132: 457-470.

Forbes, Kevin F. and Ernest M. Zampelli. 1989. "Is Leviathan a Mythical Beast?” The American Economic Review 79:568-577.

Garrett, Thomas A. 2001. "The Leviathan Lottery? Testing the Revenue Maximization Objective of State Lotteries as Evidence for Leviathan.” Public Choice 109:101-117.

Garrett, Thomas A., Gary A. Wagner, and David C. Wheelock. 2005. "A Spatial Analysis of State Banking Regulation.” Papers in Regional Science 84, 4: 575-595.

Gilligan, Thomas W. and John G. Matsusaka. 1995. "Deviations from Constituent Interests: The Role of Legislative Structure and Political Parties in the States.” Economic Inquiry 33(3):383-401. 
----. 2001. "Fiscal Policy, Legislature Size, and Political Parties: Evidence from State and Local Governments in the First Half of the $20^{\text {th }}$ Century." National Tax Journal 54(1):57-82.

Gray, Virginia. 1973. "Innovation in the States: A Diffusion Study.” American Political Science Review 67, 4: 1174-1185.

Grossman, Phillip J. 1989. "Fiscal Decentralization and Government Size: an Extension." Public Choice 62:63-70.

Hall, Joshua C. and Justin M. Ross. Forthcoming. "Tiebout Competition, Yardstick Competition, and Tax Instrument Choice: Evidence from Ohio School Districts.” Public Finance Review.

Hartman, William T. and Barbara J. Nelson. 2000. "Pennsylvania." In Sielke, Catherine C., John Dayton, C. Thomas Holmes, and Anne L. Jefferson (eds.) Public School Finance Programs in the United States and Canada: 1998-99. Washington, DC: National Center for Education Statistics.

Hall, Peter. 1992. The Bootstrap and Edgeworth Expansion. New York: Springer-Verlag. Hayashi, Masayoshi and Robin Boadway. 2001. "An Empirical Analysis of Intergovernmental Tax Interaction: The Case of Business Income Taxes in Canada." Canadian Journal of Economics 34:481-503.

Heil, James B. 1991. “The Search for Leviathan Revisited.” Public Finance Review 19:334346.

Holcombe, Randall G. 1991. "Constitutions as Constraints: A Case Study of Three American Constitutions." Constitutional Political Economy 2, 3: 303-328. 
----. 1992. "The Distributive Model of Government: Evidence from the Confederate Constitution.” Southern Economic Journal 58, 3: 762-769.

----. 1994. "The Distinction between Clubs and Governments." Chapter 5 in The Economic Foundations of Government. New York: NYU Press.

----. 1998. "Constitutional Theory and the Constitutional History of Colonial America." The Independent Review 3, 1:21-36.

Holtz-Eakin, Douglas. 1988. “The Line Item Veto and Public Sector Budgets: Evidence from the States.” Journal of Public Economics 36, 3: 269-292.

Jeong, J. and G. S. Maddala. 1993. "A Perspective on Application of Bootstrap Methods in Econometrics.” In Maddala, G.S., C. R. Rao, and H. D. Vinode (Eds.) Econometrics Handbook of Statistics, vol. 11. Amsterdam: North-Holland.

Joulfaian, David and Michael L. Marlow. 1990. “Government Size and Decentralization: Evidence from Disaggregated Data." Southern Economic Journal 56:1094-1102.

Kanbur, Ravi and Michael Keen. 1993. "Jeux Sans Frontieres: Tax Competition and Tax Coordination When Countries Differ in Size.” The American Economic Review 83:877892.

Laffer, Arthur B. 2004. “The Laffer Curve: Past, Present, and Future.” Backgrounder 1765, The Heritage Foundation.

LeSage, James P. and R. Kelley Pace. 2009. Introduction to Spatial Econometrics. CRC Press/Taylor \& Francis Group.

Maddex, Robert L. 1998. State Constitutions of the United States. Washington, D.C.: CQ Press.

----. 2003. State Constitutions of the United States: $2^{\text {nd }}$ Edition. Washington, D.C.: CQ Press. 
Marlow, Michael L. 1988. "Fiscal Decentralization and Government Size." Public Choice 56:259-269.

Matsusaka, John G. 1995. "Fiscal Effects of the Voter Initiative: Evidence from the Last 30 Years.” Journal of Political Economy 103, 3: 587-623.

McGuire, Robert A. 1988. “Constitution Making: A Rational Choice Model of the Federal Convention of 1787." American Journal of Political Science 32, 2: 438-522.

Mintz, Jack and Henry Tulkens. 1986. "Commodity Tax Competition Between Member States of a Federation: Equilibrium and Efficiency.” Journal of Public Economics 29:133-172.

Nelson, Michael A. 1986. “An Empirical Analysis of State and Local Tax Structure in the Context of the Leviathan Model of Government.” Public Choice 49:283-294.

-----. 1987. "Searching for Leviathan: Comment and Extension.” The American Economic Review 77:198-204.

Oates, Wallace E. 1972. Fiscal Federalism. New York: Harcourt Brace Jovanovich.

----. 1985. "Searching for Leviathan: An Empirical Study." The American Economic Review 75:748-757.

----. 1989. "Searching for Leviathan: A Reply and Some Further Reflections." The American Economic Review 79:578-583.

-----. 1999. “An Essay on Fiscal Federalism.” Journal of Economic Literature, 37:1120-1149.

Oates, Wallace E. and Robert M. Schwab. 1988. "Economic Competition Among Jurisdictions: Efficiency Enhancing or Distortion Inducing?” Journal of Public Economics 35:333354.

Papke, Leslie E. 1991. "Interstate Business Tax Differentials and New Firm Location: Evidence from Panel Data.” Journal of Public Economics 45:47-68. 
Pennsylvania Department of Education. "Basic Education Funding: 2010-2011 Fiscal Year." <http://www.portal.state.pa.us/portal/server.pt/community/education_budget/8699/propo sed_basic_education_funding/539259>. Accessed February 2011.

Persson, Torsten and Guido Tabellini. 2002. "Do Constitutions Cause Large Governments? Quasi-experimental Evidence.” European Economic Review 46: 908-918.

-----. 2003. The Economic Effects of Constitutions. Cambridge, MA: MIT Press.

-----. 2004. “Constitutional Rules and Fiscal Policy Outcomes.” American Economic Review $94,1: 25-45$.

Primo, David M. 2006. "Stop Us Before We Spend Again: Institutional Constraints on Government Spending.” Economics and Politics 18(3):269-311.

Primo, David M. and James M. Snyder Jr. 2008. "Distributive Politics and the Law of 1/n." The Journal of Politics 70(2):477-486.

Poterba, James M. 1994. "State Responses to Fiscal Crises: The Effects of Bugetary Institutions and Politics.” Journal of Political Economy 102, 4: 799-821.

-----. 1996. "Budget Institutions and Fiscal Policy in the U.S. States." American Economic Review 86, 2: 395-400.

Puro, Marsha, Peter J. Bergerson, and Steven Puro. 1985. “An Analysis of Judicial Diffusion: Adoption of the Missouri Plan in the American States.” Publius 15, 4: 85-97.

Rodden, Jonathan. 2003. "Reviving Leviathan: Fiscal Federalism and the Growth of Government.” International Organization 57:695-729.

Shadbegian, Ronald J. 1999. "Fiscal Federalism, Collusion, and Government Size: Evidence from the States." Public Finance Review 27:262-281. 
Sobel, Russell S. 1997. “Optimal Taxation in a Federal System of Governments.” Southern Economic Journal 64:468-485.

----. 1999. "Theory and Evidence on the Political Economy of the Minimum Wage." Journal of Political Economy 107:761-785.

Stansel, Dean. 2006. "Interjurisdictional Competition and Local Government Spending in U.S. Metropolitan Areas.” Public Finance Review 34(2):173-194.

Stonecash, Jeffrey M. 1983. "Fiscal Centralization in the American States: Increasing Similarity and Persisting Diversity." Publius 13: 123-137.

Tarr, G. Alan. 1992. “Understanding State Constitutions.” Temple Law Review 65: 1169-1195.

-----. 1996. Constitutional Politics in the States: Contemporary Controversies and Historical Patterns. Westport, CT: Greenwood Press.

-----. 1998. Understanding State Constitutions. Princeton: Princeton University Press.

Tiebout, Charles M. 1956. “A Pure Theory of Local Expenditures.” Journal of Political Economy 94:416-424.

Voigt, Stefan. 1997. "Positive Constitutional Economics: A Survey." Public Choice 90, 1-4: 11-53.

-----. 2010. “Positive Constitutional Economics II: A Survey of Recent Developments.” Public Choice, published online 4 May 2010.

Wagner, Gary A. and Russell S. Sobel. 2006. "State Budget Stabilization Fund Adoption: Preparing for the Next Recession or Circumventing Fiscal Constraints?" Public Choice 126: 177-199.

Walker, Jack L. 1969. “The Diffusion of Innovations Among the American States.” American Political Science Review 63, 3: 880-899. 
Wallis, John Joseph and Wallace E. Oates. 1988. "Does Economic Sclerosis Set in with Age? An Empirical Study of the Olson Hypothesis.” Kyklos 41(3): 397-417.

Weingast, Barry R., Kenneth A. Shepsle, and Christopher Johnsen. 1981. "The Political Economy of Benefits and Costs: A Neoclassical Approach to Distributive Politics.” Journal of Political Economy 89(4): 642-664.

Wibbels, Erik. 2005. "Decentralized Governance, Constitution Formation, and Redistribution." Constitutional Political Economy 16: 161-188.

Zax, Jeffrey S. 1988. "The Effects of Jurisdiction Types and Numbers on Local Public Finance.” In Rosen, Harvey S. (ed.) Fiscal Federalism: Quantitative Studies. National Bureau of Economic Research and the University of Chicago Press, 79-103.

-----. 1989. "Is There a Leviathan in Your Neighborhood?" The American Economic Review 79:560-567. 


\section{APPENDIX}

\section{Appendix 2.1: Excluding States with Outlying $\lambda$ Values (TX, RI, NH)}

\begin{tabular}{|c|c|c|c|c|c|c|}
\hline \multicolumn{7}{|c|}{ Dependent Variable: Real Per Capita State and Local Expenditure } \\
\hline Specification: & 1 & 2 & 3 & 4 & 5 & 6 \\
\hline Upper Chamber Seats & $\begin{array}{c}10.065^{\star \star *} \\
(0.970)\end{array}$ & $\begin{array}{c}-73.250^{\star * *} \\
(5.965)\end{array}$ & $\begin{array}{c}24.220^{\star * *} \\
(2.594)\end{array}$ & $\begin{array}{c}-8.365^{\star \star *} \\
(0.971)\end{array}$ & $\begin{array}{c}18.770^{\star \star \star} \\
(1.607)\end{array}$ & \\
\hline Lower Chamber Seats & $\begin{array}{c}-3.013^{* * *} \\
(0.287)\end{array}$ & $\begin{array}{l}3.023^{\star *} \\
(1.417)\end{array}$ & $\begin{array}{c}-7.282^{* * *} \\
(0.812)\end{array}$ & & $\begin{array}{c}2.588^{* * *} \\
(0.430)\end{array}$ & \\
\hline Counties & $\begin{array}{c}-2.425^{\star * *} \\
(0.318)\end{array}$ & $\begin{array}{c}-4.982^{* * *} \\
(1.335)\end{array}$ & & & $\begin{array}{c}-16.263^{* * *} \\
(1.286)\end{array}$ & \\
\hline Upper Chamber Seats Squared & & $\begin{array}{c}0.928^{* * *} \\
(0.601)\end{array}$ & & & & \\
\hline Lower Chamber Seats Squared & & $\begin{array}{c}-0.022^{\star * *} \\
(0.005)\end{array}$ & & & & \\
\hline Counties Squared & & $\begin{array}{c}0.022^{* * *} \\
(0.006)\end{array}$ & & & & \\
\hline Upper Chamber Seats x Counties & & & $\begin{array}{c}-0.196^{\star \star \star} \\
(0.026)\end{array}$ & $\begin{array}{c}0.128^{\star * *} \\
(0.009)\end{array}$ & & \\
\hline Lower Chamber Seats $x$ Counites & & & $\begin{array}{c}0.053^{* \star *} \\
(0.008)\end{array}$ & $\begin{array}{l}-0.002 \\
(0.003)\end{array}$ & & \\
\hline Upper Chamber Seats x Degree of Overlap & & & & & $\begin{array}{c}-3.634^{* * *} \\
(0.446)\end{array}$ & \\
\hline Lower Chamber Seats x Degree of Overlap & & & & & $\begin{array}{c}10.176^{\star \star \star} \\
(0.643)\end{array}$ & \\
\hline Upper Chamber $\lambda$ & & & & & & $\begin{array}{c}-147.051^{\star * *} \\
(17.223)\end{array}$ \\
\hline Lower Chamber $\lambda$ & & & & & & $\begin{array}{c}14.065 \\
(43.902)\end{array}$ \\
\hline Democrat Governor & $\begin{array}{c}47.497^{\star * *} \\
(16.415)\end{array}$ & $\begin{array}{c}52.036^{\star * *} \\
(15.092)\end{array}$ & $\begin{array}{c}28.040 \\
(17.120)\end{array}$ & $\begin{array}{l}40.753^{* *} \\
(16.381)\end{array}$ & $\begin{array}{l}33.148^{* *} \\
(15.807)\end{array}$ & $\begin{array}{c}40.955^{* * *} \\
(15.769)\end{array}$ \\
\hline Population Growth Rate & $\begin{array}{c}-45.233^{\star * *} \\
(12.760)\end{array}$ & $\begin{array}{c}-125.930^{* * *} \\
(18.161)\end{array}$ & $\begin{array}{c}-47.067^{\star \star \star} \\
(12.913)\end{array}$ & $\begin{array}{c}-62.267^{\star * *} \\
(13.157)\end{array}$ & $\begin{array}{c}-69.020^{* * *} \\
(12.296)\end{array}$ & $\begin{array}{c}-54.912^{* * *} \\
(12.820)\end{array}$ \\
\hline Population (millions) & $\begin{array}{c}12.887^{\star \star \star} \\
(1.759)\end{array}$ & $\begin{array}{c}13.719^{\star \star \star} \\
(2.485)\end{array}$ & $\begin{array}{c}11.707^{\star * \star} \\
(1.641)\end{array}$ & $\begin{array}{c}13.261^{\star \star \star} \\
(1.818)\end{array}$ & $\begin{array}{c}14.184^{\star \star \star} \\
(2.054)\end{array}$ & $\begin{array}{c}14.222^{\star \star *} \\
(1.672)\end{array}$ \\
\hline Real Per Capita Federal Aid & $\begin{array}{c}0.791^{\star * *} \\
(0.125)\end{array}$ & $\begin{array}{c}0.616^{* * *} \\
(0.096)\end{array}$ & $\begin{array}{c}0.763^{\star \star \star} \\
(0.122)\end{array}$ & $\begin{array}{c}0.785^{\star \star \star} \\
(0.122)\end{array}$ & $\begin{array}{c}0.646^{\star \star *} \\
(0.108)\end{array}$ & $\begin{array}{c}0.799^{\star \star \star} \\
(0.122)\end{array}$ \\
\hline Real Per Capita Personal Income & $\begin{array}{c}110.691^{* * *} \\
(9.064)\end{array}$ & $\begin{array}{c}80.631^{* * *} \\
(7.849)\end{array}$ & $\begin{array}{c}123.933^{* * *} \\
(10.536)\end{array}$ & $\begin{array}{c}103.466^{* * *} \\
(8.656)\end{array}$ & $\begin{array}{c}122.835^{* * *} \\
(10.050)\end{array}$ & $\begin{array}{c}110.653^{\star * *} \\
(9.284)\end{array}$ \\
\hline Percent Young (Age 5-17) & $\begin{array}{l}11.245 \\
(8.412)\end{array}$ & $\begin{array}{l}-6.122 \\
(7.916)\end{array}$ & $\begin{array}{c}16.622^{* *} \\
(8.453)\end{array}$ & $\begin{array}{c}4.512 \\
(8.496)\end{array}$ & $\begin{array}{l}13.950^{*} \\
(8.193)\end{array}$ & $\begin{array}{c}9.524 \\
(8.797)\end{array}$ \\
\hline Percent (Age 18+) High School Graduates & $\begin{array}{c}10.608^{\star \star \star} \\
(3.643)\end{array}$ & $\begin{array}{c}10.377^{\star \star \star} \\
(3.787)\end{array}$ & $\begin{array}{c}10.523^{\star \star \star} \\
(3.814)\end{array}$ & $\begin{array}{c}9.550^{\star \star \star} \\
(3.414)\end{array}$ & $\begin{array}{l}8.830^{\star \star} \\
(3.932)\end{array}$ & $\begin{array}{c}10.501^{\star * *} \\
(3.533)\end{array}$ \\
\hline Percent Below Poverty Line & $\begin{array}{c}0.040 \\
(4.169)\end{array}$ & $\begin{array}{c}2.241 \\
(4.276)\end{array}$ & $\begin{array}{l}-2.478 \\
(4.143)\end{array}$ & $\begin{array}{c}4.041 \\
(4.169)\end{array}$ & $\begin{array}{l}-4.134 \\
(4.087)\end{array}$ & $\begin{array}{l}5.097 \\
(4.096)\end{array}$ \\
\hline Population Density (pop/sq mi) & $\begin{array}{c}-0.532^{* * *} \\
(0.061)\end{array}$ & $\begin{array}{c}-0.287^{* * *} \\
(0.069)\end{array}$ & $\begin{array}{c}-0.709^{* * *} \\
(0.071)\end{array}$ & $\begin{array}{c}-0.341^{* * *} \\
(0.057)\end{array}$ & $\begin{array}{c}-0.826^{* * *} \\
(0.072)\end{array}$ & $\begin{array}{c}-0.425^{* * *} \\
(0.058)\end{array}$ \\
\hline Percent White & $\begin{array}{l}-1.343 \\
(1.057)\end{array}$ & $\begin{array}{c}-2.868^{* * *} \\
(1.049)\end{array}$ & $\begin{array}{c}0.246 \\
(1.354)\end{array}$ & $\begin{array}{c}0.244 \\
(1.082)\end{array}$ & $\begin{array}{c}0.930 \\
(1.050)\end{array}$ & $\begin{array}{l}-0.647 \\
(1.001)\end{array}$ \\
\hline $\begin{array}{l}\text { Number of Observations } \\
\text { R-Squared }\end{array}$ & $\begin{array}{c}528 \\
0.809\end{array}$ & $\begin{array}{c}528 \\
0.844\end{array}$ & $\begin{array}{c}528 \\
0.812\end{array}$ & $\begin{array}{c}528 \\
0.807\end{array}$ & $\begin{array}{c}528 \\
0.830\end{array}$ & $\begin{array}{c}528 \\
0.798\end{array}$ \\
\hline
\end{tabular}

Note: All models include year and census region fixed effects. Constant and fixed effect coefficient estimates not shown. Panel-corrected standard errors in parentheses: * indicates statistical significance at the $10 \%$ level, ** at the $5 \%$ level, and $* * *$ at the $1 \%$ level. 


\section{Appendix 2.2: Excluding States without County Governments (CT, RI, MA)}

\begin{tabular}{|c|c|c|c|c|c|c|}
\hline \multicolumn{7}{|c|}{ Dependent Variable: Real Per Capita State and Local Expenditure } \\
\hline Specification: & 1 & 2 & 3 & 4 & 5 & 6 \\
\hline Upper Chamber Seats & $\begin{array}{c}7.277^{\star * *} \\
(0.816)\end{array}$ & $\begin{array}{c}-67.870^{* * *} \\
(7.002)\end{array}$ & $\begin{array}{c}10.713^{\star * *} \\
(1.379)\end{array}$ & $\begin{array}{c}-4.636^{* * *} \\
(0.735)\end{array}$ & $\begin{array}{c}9.029^{* * *} \\
(0.872)\end{array}$ & \\
\hline Lower Chamber Seats & $\begin{array}{c}-2.147^{\star \star *} \\
(0.179)\end{array}$ & $\begin{array}{l}-0.996 \\
(0.632)\end{array}$ & $\begin{array}{c}-2.245^{\star \star \star} \\
(0.203)\end{array}$ & & $\begin{array}{c}1.535^{\star * *} \\
(0.483)\end{array}$ & \\
\hline Counties & $\begin{array}{c}-1.670^{* * *} \\
(0.199)\end{array}$ & $\begin{array}{c}-3.389^{* * *} \\
(0.734)\end{array}$ & & & $\begin{array}{c}-7.499^{* * *} \\
(0.643)\end{array}$ & \\
\hline Upper Chamber Seats Squared & & $\begin{array}{c}0.869^{\star \star *} \\
(0.074)\end{array}$ & & & & \\
\hline Lower Chamber Seats Squared & & $\begin{array}{c}-0.003^{* *} \\
(0.001)\end{array}$ & & & & \\
\hline Counties Squared & & $\begin{array}{c}0.009^{* * *} \\
(0.003)\end{array}$ & & & & \\
\hline Upper Chamber Seats x Counties & & & $\begin{array}{c}-0.052^{* * *} \\
(0.010)\end{array}$ & $\begin{array}{c}0.080^{* * *} \\
(0.006)\end{array}$ & & \\
\hline Lower Chamber Seats $\times$ Counites & & & $\begin{array}{l}0.005^{\star \star} \\
(0.002)\end{array}$ & $\begin{array}{c}0.000 \\
(0.004)\end{array}$ & & \\
\hline Upper Chamber Seats x Degree of Overlap & & & & & $\begin{array}{c}-0.808^{\star \star \star} \\
(0.077)\end{array}$ & \\
\hline Lower Chamber Seats x Degree of Overlap & & & & & $\begin{array}{c}4.012^{\star \star \star} \\
(0.569)\end{array}$ & \\
\hline Upper Chamber $\lambda$ & & & & & & $\begin{array}{c}-52.220^{* * *} \\
(6.800)\end{array}$ \\
\hline Lower Chamber $\lambda$ & & & & & & $\begin{array}{l}-72.528 \\
(51.385)\end{array}$ \\
\hline Democrat Governor & $\begin{array}{c}22.247 \\
(15.070)\end{array}$ & $\begin{array}{l}41.104^{\star \star *} \\
(14.612)\end{array}$ & $\begin{array}{c}20.470 \\
(15.761)\end{array}$ & $\begin{array}{c}3.541 \\
(16.805)\end{array}$ & $\begin{array}{c}25.246 \\
(15.679)\end{array}$ & $\begin{array}{c}6.552 \\
(16.018)\end{array}$ \\
\hline Population Growth Rate & $\begin{array}{c}-44.678^{\star \star \star} \\
(13.464)\end{array}$ & $\begin{array}{c}-125.515^{\star \star \star} \\
(17.230)\end{array}$ & $\begin{array}{c}-42.575^{\star \star \star} \\
(13.895)\end{array}$ & $\begin{array}{c}-48.172^{\star \star \star} \\
(14.906)\end{array}$ & $\begin{array}{c}-55.590^{\star \star \star} \\
(13.231)\end{array}$ & $\begin{array}{c}-49.908^{\star \star \star} \\
(14.471)\end{array}$ \\
\hline Population (millions) & $\begin{array}{c}10.930^{* * *} \\
(1.739)\end{array}$ & $\begin{array}{c}12.027^{* * *} \\
(1.999)\end{array}$ & $\begin{array}{c}8.242^{* * *} \\
(1.740)\end{array}$ & $\begin{array}{c}11.797^{* * *} \\
(1.880)\end{array}$ & $\begin{array}{c}9.472^{\star * *} \\
(1.814)\end{array}$ & $\begin{array}{c}12.450^{* * *} \\
(1.770)\end{array}$ \\
\hline Real Per Capita Federal Aid & $\begin{array}{c}0.816^{\star * *} \\
(0.123)\end{array}$ & $\begin{array}{c}0.611^{\star * *} \\
(0.093)\end{array}$ & $\begin{array}{c}0.823^{\star \star *} \\
(0.130)\end{array}$ & $\begin{array}{c}0.927^{\star * *} \\
(0.136)\end{array}$ & $\begin{array}{c}0.739^{* * *} \\
(0.118)\end{array}$ & $\begin{array}{c}0.912^{\star * *} \\
(0.132)\end{array}$ \\
\hline Real Per Capita Personal Income & $\begin{array}{c}130.000^{\star * *} \\
(12.823)\end{array}$ & $\begin{array}{c}88.075^{\star * *} \\
(10.726)\end{array}$ & $\begin{array}{c}130.879^{\star * *} \\
(12.784)\end{array}$ & $\begin{array}{c}108.182^{* * *} \\
(10.968)\end{array}$ & $\begin{array}{l}135.640 \\
(13.404)\end{array}$ & $\begin{array}{c}114.211^{* * *} \\
(11.546)\end{array}$ \\
\hline Percent Young (Age 5-17) & $\begin{array}{c}23.630^{* * *} \\
(8.630)\end{array}$ & $\begin{array}{l}-2.292 \\
(8.975)\end{array}$ & $\begin{array}{c}18.894^{\star *} \\
(8.325)\end{array}$ & $\begin{array}{c}6.419 \\
(7.728)\end{array}$ & $\begin{array}{c}19.989^{\star *} \\
(9.788)\end{array}$ & $\begin{array}{c}7.186 \\
(8.121)\end{array}$ \\
\hline Percent (Age 18+) High School Graduates & $\begin{array}{l}8.961^{* *} \\
(3.807)\end{array}$ & $\begin{array}{c}9.936^{* * *} \\
(3.862)\end{array}$ & $\begin{array}{l}8.326^{\star *} \\
(3.985)\end{array}$ & $\begin{array}{c}12.128^{* * *} \\
(3.726)\end{array}$ & $\begin{array}{l}6.361 \\
(4.032)\end{array}$ & $\begin{array}{c}12.824^{* * *} \\
(3.850)\end{array}$ \\
\hline Percent Below Poverty Line & $\begin{array}{c}3.915 \\
(4.375)\end{array}$ & $\begin{array}{c}4.343 \\
(4.271)\end{array}$ & $\begin{array}{c}1.760 \\
(4.361)\end{array}$ & $\begin{array}{l}9.288^{* *} \\
(9.288)\end{array}$ & $\begin{array}{l}2.317 \\
(4.164)\end{array}$ & $\begin{array}{c}10.938^{* *} \\
(4.512)\end{array}$ \\
\hline Population Density (pop/sq mi) & $\begin{array}{c}-0.495^{\star * *} \\
(0.068)\end{array}$ & $\begin{array}{c}-0.248^{\star * *} \\
(0.070)\end{array}$ & $\begin{array}{c}-0.496^{\star \star *} \\
(0.072)\end{array}$ & $\begin{array}{l}-0.082 \\
(0.054)\end{array}$ & $\begin{array}{c}-0.573^{\star \star *} \\
(0.072)\end{array}$ & $\begin{array}{c}-0.161^{* * *} \\
(0.057)\end{array}$ \\
\hline Percent White & $\begin{array}{c}0.324 \\
(1.144)\end{array}$ & $\begin{array}{l}-1.557 \\
(1.196)\end{array}$ & $\begin{array}{l}-0.272 \\
(1.294)\end{array}$ & $\begin{array}{c}0.807 \\
(0.054)\end{array}$ & $\begin{array}{c}1.366 \\
(1.366)\end{array}$ & $\begin{array}{l}-0.500 \\
(1.013)\end{array}$ \\
\hline Number of Observations & 528 & 528 & 528 & 528 & 528 & 528 \\
\hline R-Squared & 0.797 & 0.834 & 0.793 & 0.773 & 0.807 & 0.766 \\
\hline
\end{tabular}

Note: All models include year and census region fixed effects. Constant and fixed effect coefficient estimates not shown. Panel-corrected standard errors in parentheses: * indicates statistical significance at the $10 \%$ level, ** at the $5 \%$ level, and $* * *$ at the $1 \%$ level. 


\section{Appendix 3.1: Descriptive Statistics}

\begin{tabular}{|c|c|c|c|}
\hline Effective Tax Rate (Mills) & Municipality & County & School District \\
\hline Mean & 1.94 & 3.48 & 21.31 \\
\hline Mode & 1.14 & 3.15 & 18.90 \\
\hline Standard Deviation & 2.28 & 1.18 & 4.88 \\
\hline Minimum & 0.0001 & 1.30 & 1.00 \\
\hline Maximum & 81.31 & 7.17 & 49.8 \\
\hline \multicolumn{4}{|c|}{ Per Capita Property Tax Revenue } \\
\hline$\overline{\text { Mean }}$ & 71.87 & 132.08 & $3656.14(581.03)$ \\
\hline Standard Deviation & 272.69 & 48.38 & $2060.36(288.82)$ \\
\hline \multicolumn{4}{|c|}{ Real Per Capita Expenditures (Lagged, \$1000s) } \\
\hline Mean & 0.40 & 463.03 & $8.55(1.45)$ \\
\hline Standard Deviation & 4.31 & 199.51 & $2.07(0.35)$ \\
\hline \multicolumn{4}{|c|}{ Real Per Capita State/Federal Grants (\$1000s) } \\
\hline Mean & 0.07 & 160.54 & $4.05(0.70)$ \\
\hline Standard Deviation & 0.14 & 127.69 & $1.55(0.30)$ \\
\hline \multicolumn{4}{|l|}{ Population (1000s) } \\
\hline$\overline{\text { Mean }}$ & 4.38 & 165.70 & $3.60(24.41)$ \\
\hline Standard Deviation & 23.85 & 209.11 & $9.80(70.90)$ \\
\hline \multicolumn{4}{|c|}{$\overline{\text { Real Median Household Income }(\$ 1000 s)}$} \\
\hline Mean & -- & 37.49 & -- \\
\hline Standard Deviation & -- & 7.31 & -- \\
\hline \multicolumn{4}{|c|}{ Proportion African American } \\
\hline$\overline{\text { Mean }}$ & $\overline{--}$ & 0.03 & -- \\
\hline Standard Deviation & -- & 0.03 & -- \\
\hline \multicolumn{4}{|l|}{$\overline{\text { Proportion Student }}$} \\
\hline$\overline{\text { Mean }}$ & -- & 0.16 & -- \\
\hline Standard Deviation & -- & 0.02 & -- \\
\hline \multicolumn{4}{|l|}{$\overline{\text { Population Density }}$} \\
\hline Mean & -- & 278.79 & -- \\
\hline Standard Deviation & -- & 482.83 & -- \\
\hline
\end{tabular}

Note: Variables calculated using alternative school district population in parentheses. 